\begin{abstract}
UNIVERSIDADE DE SÃO PAULO
FACULDADE DE ECONOMIA, ADMINISTRAÇÃO E CONTABILIDADE DEPARTAMENTO DE ECONOMIA
\end{abstract}

\title{
DESEMPREGO DE JOVENS: UM ESTUDO SOBRE A DINÂMICA DO MERCADO DE TRABALHO JUVENIL BRASILEIRO
}

\author{
PRISCILLA MATIAS FLORI
}

Orientador: Prof. Dr. REYNALDO FERNANDES

São Paulo 
Reitor da Universidade de São Paulo

Prof. Dr. Adolpho José Melfi

Diretor da Faculdade de Economia, Administração e Contabilidade Prof. Dra. Maria Teresa Leme Fleury

\section{Chefe do Departamento de Economia}

Prof. Dra. Elisabeth Maria Mercier Querido Farina 


\title{
DESEMPREGO DE JOVENS: UM ESTUDO SOBRE A DINÂMICA DO MERCADO DE TRABALHO JUVENIL BRASILEIRO
}

\author{
ALUNA: PRISCILLA MATIAS FLORI \\ ORIENTADOR: PROF. DR. REYNALDO FERNANDES \\ Dissertação apresentada ao \\ Departamento de Economia da \\ Faculdade de Economia, Administração \\ e Contabilidade da Universidade de São \\ Paulo, para a obtenção do título de \\ Mestre em Economia
}

São Paulo

2003 
FICHA CATALOGRÁFICA

Elaborada pela Seção de Publicações e Divulgação do SBD/FEA/USP

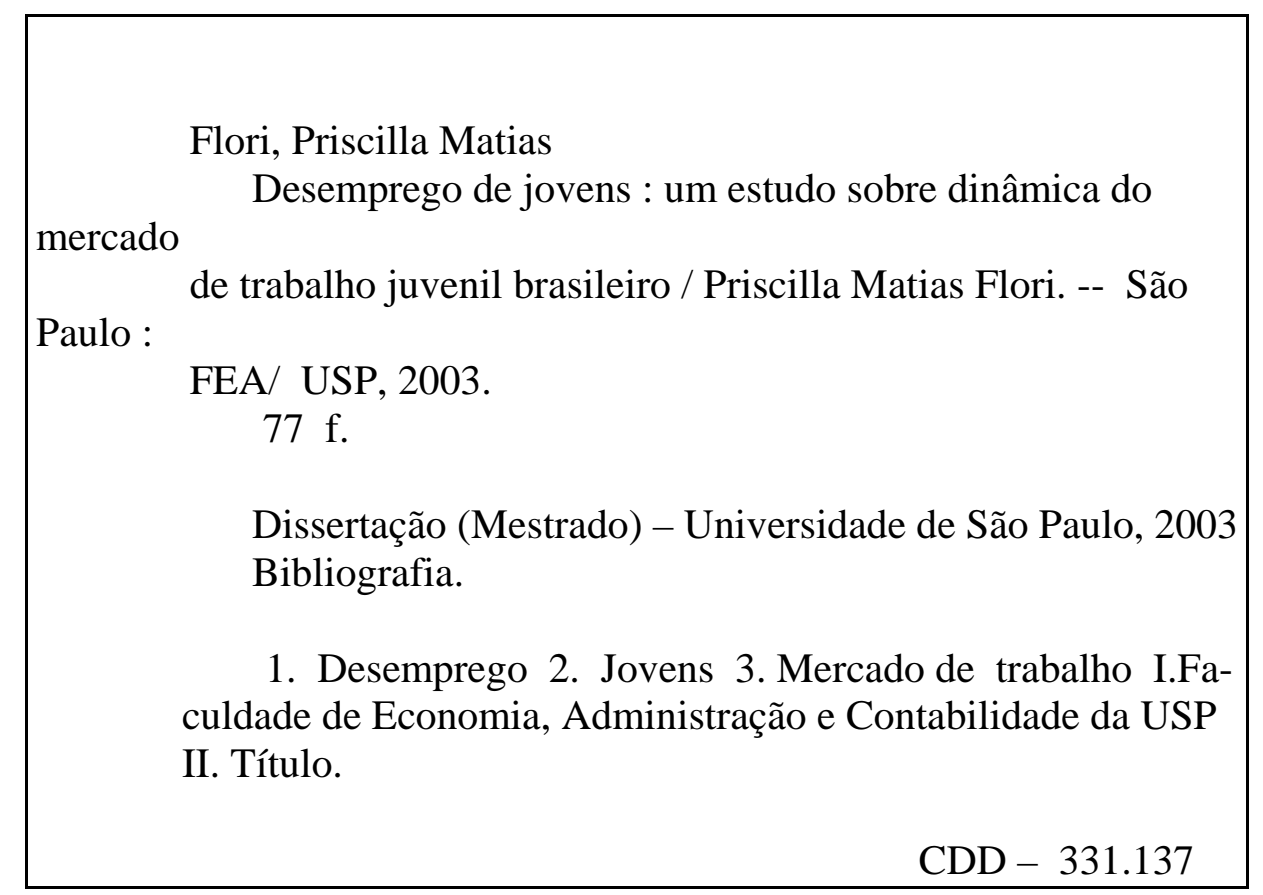


À minha mãe, Susete, com todo amor desse mundo 


\section{AGRADECIMENTOS}

Ao meu orientador Reynaldo Fernandes, pela importância fundamental desde o início deste trabalho com a sugestão do tema, execução e conclusão das idéias, e pela paciência e atenção comigo ao longo desses meses.

A todos os professores da FEA, especialmente a Paulo Picchetti e Naércio Aquino de Meneses Filho, pelas considerações feitas no exame de qualificação; a Francisco Anuatti, André Portela, Hélio Zylberstajn, por todo apoio, incentivo e oportunidade, assim como José Paulo Chahad, Simão Silber, Gledson e Elizabeth Farina.

À Felícia Madeira, pelo interesse e incentivo ao meu trabalho.

Ao CNPQ, pelo suporte financeiro durante o mestrado.

A todos os meus amigos da graduação e da pós, especialmente ao Edu, Alê, Rita, Léo, Guilherme Maia, Valente, Camila, Elisa, Guilherme, Matheus, Flávio, Carlos, Pitoli, Márcio; à Fabiana e Maria, pela ajuda com os dados, e ao Luís, pelas dicas quanto à dissertação.

A todos os funcionários da FEA (xerox, biblioteca, departamento, seção de graduação, segurança) e da FIPE (xerox, secretárias, serviços gerais, diretoria), pela amizade e por estarem presentes no meu cotidiano a tanto tempo, sempre me ajudando.

Ao pessoal do CIT, Telma, Jorge, Leo, Tiago, Ale, pela amizade e apoio técnico.

Aos meus grandes amigos de todos os dias, Moisés, Rogério, Dario, Marlei, Sílvia, Max, Carlos, por, cada um a seu modo, me ajudarem, estimularem, incentivarem e terem muita paciência comigo nos últimos meses.

Em São Lourenço, a todos os professores, funcionários e colegas do Colégio das Irmãs, do Colégio Laser e do CCAA, por estarem presentes nos meus primeiros passos.

A todos os meus amigos de São Lourenço.

A todas as pessoas que fizeram parte, direta ou indiretamente, da minha vida.

A todos que, talvez de uma forma meio conturbada, serviram-me de estímulo.

Aos meus avós, tios, tias, primos, primas e agregados.

Aos meus irmãos Eduardo e Leonardo, minha cunhada Luciana e meus sobrinhos.

Ao meu Pai, João Bosco Flori, que, lá de cima, guia meus passos e me protege.

À minha Mãe, Susete Maria Matias Flori, que sempre esteve ao meu lado, e é responsável por toda minha instrução, crescimento moral, intelectual e espiritual, a quem amo de paixão e devo tudo nessa vida, além de ser a pessoa que mais admiro no mundo.

A Deus por cada segundo da minha vida! 


\section{SUMÁRIO}

RESUMO

ABSTRACT

INTRODUÇÃO

CAPÍTULO 1 - REVISÃO DA LITERATURA 4

Introdução 4

I. Literatura Nacional 4

II. Literatura Internacional 6

CAPÍTULO 2 - EVIDÊNCIAS EMPÍRICAS: ROTATIVIDADE 10

Introdução 10

I. Fonte de Dados 10

II. Metodologia 11

III. Resultados 15

CAPÍTULO 3 - EVIDÊNCIAS EMPÍRICAS: FLUXOS DE ENTRADA E SAÍDA

DA FORÇA DE TRABALHO 23

Introdução 23

I. Fonte de Dados 24

II. Metodologia 25

III. Resultados 28

CAPÍTULO 4 - CONCLUSÃO 36

$\begin{array}{ll}\text { ANEXO A } & 38\end{array}$

$\begin{array}{ll}\text { ANEXO B } & 60\end{array}$

REFERÊNCIAS BIBLIOGRÁFICAS 


\section{LISTA DE TABELAS}

TABELA 1 - Média das taxas de desemprego e entrada, duração média completa e incompleta do desemprego, segundo faixa etária, São Paulo, 1983-2002.......................16

TABELA 2 - Probabilidades de transição de jovens e adultos, São Paulo, 2001...........29

TABELA 3 - Fração de tempo gasto em cada estado do mercado de trabalho e taxa de desemprego de jovens e adultos, São Paulo, 2001

TABELA 4 - Fração de tempo no mercado de trabalho e taxa de desemprego de jovens e adultos, substituindo a primeira linha das matrizes, São Paulo, 2001.

TABELA 5 - Fração de tempo no mercado de trabalho e taxa de desemprego de jovens e adultos, substituindo a segunda linha das matrizes, São Paulo, 2001

TABELA 6 - Fração de tempo no mercado de trabalho e taxa de desemprego de jovens e adultos, substituindo a terceira linha das matrizes, São Paulo, 2001.

TABELA 2.1 - Taxas de desemprego e entrada, duração média completa e incompleta do desemprego, segundo faixa etária, São Paulo, 1983-2002. 38

TABELA 2.2 - Taxas de desemprego e entrada, duração média completa e incompleta do desemprego, segundo faixa etária, Belo Horizonte, 1983-2002.

TABELA 2.3 - Taxas de desemprego e entrada, duração média completa e incompleta do desemprego, segundo faixa etária, Rio de Janeiro, 1983-2002.

TABELA 2.4 - Taxas de desemprego e entrada, duração média completa e incompleta do desemprego, segundo faixa etária, Porto Alegre, 1983-2002.

TABELA 2.5 - Taxas de desemprego e entrada, duração média completa e incompleta do desemprego, segundo faixa etária, Recife, 1983-2002.

TABELA 2.6 - Taxas de desemprego e entrada, duração média completa e incompleta do desemprego, segundo faixa etária, Salvador, 1983-2002. 
TABELA 2.7 - Taxa de entrada no desemprego de jovens que procuram pelo primeiro emprego e jovens que já trabalharam anteriormente, São Paulo, 1983-2002.

TABELA 2.8 - Taxa de entrada no desemprego de jovens que procuram pelo primeiro emprego e jovens que já trabalharam anteriormente, Belo Horizonte, 1983-2002. .45

TABELA 2.9 - Taxa de entrada no desemprego de jovens que procuram pelo primeiro emprego e jovens que já trabalharam anteriormente, Rio de Janeiro, 1983-2002............46

TABELA 2.10 - Taxa de entrada no desemprego de jovens que procuram pelo primeiro emprego e jovens que já trabalharam anteriormente, Porto Alegre, 1983-2002.

TABELA 2.11 - Taxa de entrada no desemprego de jovens que procuram pelo primeiro emprego e jovens que já trabalharam anteriormente, Recife, 1983-2002. .48

TABELA 2.12 - Taxa de entrada no desemprego de jovens que procuram pelo primeiro emprego e jovens que já trabalharam anteriormente, Salvador, 1983-2002. 49

TABELA 3.1 - Probabilidades de transição de jovens e adultos, nas cinco regiões metropolitanas brasileiras, 2001. .50

TABELA 3.2 - Fração de tempo gasto em cada estado do mercado de trabalho e taxa de desemprego, de jovens e adultos, nas cinco regiões metropolitanas, 2001. .51

TABELA 3.3 - Fração de tempo no mercado de trabalho e taxa de desemprego, de jovens e adultos, substituindo a primeira linha das matrizes, nas cinco regiões metropolitanas, 2001 .52

TABELA 3.4 - Fração de tempo no mercado de trabalho e taxa de desemprego, de jovens e adultos, substituindo a segunda linha das matrizes, nas cinco regiões metropolitanas, 2001 .53

TABELA 3.5 - Fração de tempo no mercado de trabalho e taxa de desemprego, de jovens e adultos, substituindo a terceira linha das matrizes, nas cinco regiões metropolitanas, 2001 .54

TABELA 3.6 - Probabilidades de transição de jovens e adultos, região metropolitana de São Paulo, 1986, 1991 e 1996. .55 
TABELA 3.7 - Fração de tempo gasto em cada estado do mercado de trabalho e taxa de desemprego, de jovens e adultos, São Paulo, 1986, 1991 e 1996.....................................56

TABELA 3.8 - Fração de tempo no mercado de trabalho e taxa de desemprego, de jovens e adultos, substituindo a primeira linha das matrizes, São Paulo, 1986, 1991 e 1996

TABELA 3.9 - Fração de tempo no mercado de trabalho e taxa de desemprego, de jovens e adultos, substituindo a segunda linha das matrizes, São Paulo, 1986, 1991 e 1996 58

TABELA 3.10 - Fração de tempo no mercado de trabalho e taxa de desemprego, de jovens e adultos, substituindo a terceira linha das matrizes, São Paulo, 1986, 1991 e 1996. 


\section{LISTA DE FIGURAS}

GRÁFICO 1 - Taxa de desemprego segundo faixa etária - São Paulo

GRÁFICO 2 - Taxa de entrada e duração média no desemprego - jovem/SP 18

GRÁFICO 3 - Taxa de entrada e duração média no desemprego - adulto/SP.

GRÁFICO 4 - Taxa de entrada e duração média no desemprego - idoso/SP.

GRÁFICO 5 - Taxa de entrada no desemprego de jovens segundo procura por emprego $-\mathrm{SP}$

GRÁFICO 2.1 - Taxa de desemprego segundo faixa etária - Belo Horizonte .60

GRÁFICO 2.2 - Taxa de desemprego segundo faixa etária - Rio de Janeiro...

GRÁFICO 2.3 - Taxa de desemprego segundo faixa etária - Porto Alegre.

61

GRÁFICO 2.4 - Taxa de desemprego segundo faixa etária - Recife.

GRÁFICO 2.5 - Taxa de desemprego segundo faixa etária - Salvador

GRÁFICO 2.6 - Taxa de entrada e duração média no desemprego - jovem/MG.

GRÁFICO 2.7 - Taxa de entrada e duração média no desemprego - adulto/MG

GRÁFICO 2.8 - Taxa de entrada e duração média no desemprego - idoso/MG.

GRÁFICO 2.9 - Taxa de entrada e duração média no desemprego - jovem/RJ.

GRÁFICO 2.10 - Taxa de entrada e duração média no desemprego - adulto/RJ.

GRÁFICO 2.11 - Taxa de entrada e duração média no desemprego - idoso/RJ............65

GRÁFICO 2.12 - Taxa de entrada e duração média no desemprego - jovem/RS .65 
GRÁFICO 2.13 - Taxa de entrada e duração média no desemprego - adulto/RS.........66

GRÁFICO 2.14 - Taxa de entrada e duração média no desemprego - idoso/RS...........66

GRÁFICO 2.15 - Taxa de entrada e duração média no desemprego - jovem/PE.........67

GRÁFICO 2.16 - Taxa de entrada e duração média no desemprego - adulto/PE..........67

GRÁFICO 2.17 - Taxa de entrada e duração média no desemprego - idoso/PE............68

GRÁFICO 2.18 - Taxa de entrada e duração média no desemprego - jovem/BA.........68

GRÁFICO 2.19 - Taxa de entrada e duração média no desemprego - adulto/BA.........69

GRÁFICO 2.20 - Taxa de entrada e duração média no desemprego - idoso/BA...........69

GRÁFICO 2.21 - Taxa de entrada no desemprego de jovens segundo procura por emprego - MG.

GRÁFICO 2.22 - Taxa de entrada no desemprego de jovens segundo procura por

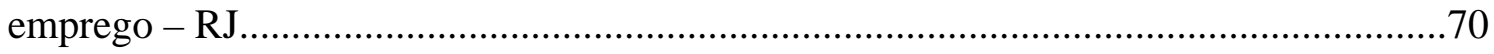

GRÁFICO 2.23 - Taxa de entrada no desemprego de jovens segundo procura por emprego - RS................................................................................................................71

GRÁFICO 2.24 - Taxa de entrada no desemprego de jovens segundo procura por

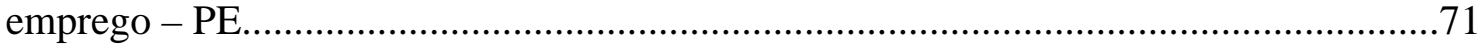

GRÁFICO 2.25 - Taxa de entrada no desemprego de jovens segundo procura por emprego - BA....................................................................................................................72 


\section{RESUMO}

Este trabalho tem como objetivo analisar a estrutura do desemprego dos jovens no Brasil, procurando identificar os motivos da taxa de desemprego dos jovens ser muito superior à dos adultos. Apesar de sua importância, este tema tem recebido pouca atenção na literatura sobre o mercado de trabalho brasileiro. Na primeira análise deste estudo, decompõe-se a taxa de desemprego em dois determinantes, duração média e taxa de entrada no desemprego de jovens, adultos e idosos; percebe-se que a duração do desemprego é praticamente a mesma para as três categorias, enquanto a taxa de entrada dos jovens é maior que a das outras duas, sendo, portanto, o determinante que faz com que o desemprego juvenil seja mais elevado que o de trabalhadores mais velhos; assim, com uma nova decomposição da taxa de entrada de jovens, verifica-se que cerca de 80\% dessa taxa é composta de jovens que já trabalharam. Outro método será o cálculo, para jovens e adultos, das matrizes de transição entre os estados do mercado de trabalho. Para avaliar a questão do desemprego dos jovens no Brasil, recalcula-se as taxas de desemprego de cada categoria, substituindo uma de cada vez nas matrizes, as probabilidades de transição da outra categoria; os resultados mostram a alta rotatividade dos jovens no mercado de trabalho. Com esses resultados, conclui-se que a causa do alto desemprego dos jovens não está na dificuldade em conseguir o primeiro emprego. 


\begin{abstract}
This work has the purpose to analyze the youth unemployment structure in Brazil, trying to identify the reasons for the youth unemployment rate being so superior relative to the unemployment of adults. Despite its importance, this subject has received less attention in the Brazilian labor market literature. In the first analysis of this work, the unemployment rate will be decomposed into two determinants, mean duration and inflow rate for young, adult and old people; it is noticed that the unemployment duration is practically the same for the three categories, but the youth inflow rate is relatively higher than the other two ones, being so, the determinant that makes youth unemployment be higher than unemployment of older workers; and, with a new decomposition of youth inflow rate, it is verified that about $80 \%$ of this rate is composed of young people that have already worked. Another method will be the calculus, for young and adult people, of the transition matrices between labor market states. To evaluate where is the problem of Brazilian youth unemployment, it is recalculated these rates for each one of the categories, substituting one at a time in the matrices, the transition probabilities of the other category; results show the high turnover of the category in labor market. With these results, it is concluded that the reason of the high youth unemployment is not the difficulty of finding the first job.
\end{abstract}




\section{INTRODUÇÃO}

A falta de emprego é vista por muitos como um grave problema social que vem afetando tanto economias desenvolvidas como em desenvolvimento. Pode-se afirmar que o desemprego representa a falta de capacidade da economia de um país em prover ocupação produtiva para todos aqueles que a desejam. Nas últimas décadas, houve uma deterioração do mercado de trabalho em todo o mundo, com o aumento da taxa de desemprego e diminuição da taxa de emprego (Korenman \& Neumark, 1997).

O emprego e o desemprego dos jovens são questões que vêm sendo objeto de preocupação crescente por parte dos governos e da sociedade. Este trabalho apresenta um estudo empírico que visa mostrar a concentração do desemprego dos jovens e analisar seus determinantes, cobrindo um tema muito pouco estudado no Brasil. Esta abordagem é relevante, pois constitui um subsídio às políticas de longo prazo e programas sociais de suporte. Ou seja, o conhecimento da estrutura do desemprego juvenil e de seus determinantes permite identificar o perfil dos trabalhadores desempregados e integrá-los ao mercado, focando de maneira mais adequada políticas de geração de emprego.

A taxa de desemprego juvenil tradicionalmente tem sido mais alta que a de adultos e idosos em todo o mundo. Mesmo em períodos que apresentam crescimento econômico e queda dos níveis de desemprego global, o desemprego juvenil não diminui, pelo menos na mesma proporção, sendo também comum a sua expansão exatamente nestes períodos. No Brasil, por exemplo, a melhoria do quadro econômico-social ocorrida com a implantação do Plano de Estabilização, em meados de 1994, não produziu a esperada ampliação das oportunidades ocupacionais, nem reduziu os elevados índices de desemprego dos jovens.

É nessa faixa etária que se concentra a maior parte das pessoas que procuram incorporar-se ao mercado de trabalho pela primeira vez. Um argumento recorrente é que a causa do alto desemprego juvenil está na dificuldade do jovem em conseguir o 
primeiro emprego (alguns estudos destacam características próprias da juventude, como a procura por ocupações incompatíveis com sua qualificação e/ou necessidades do mercado). Outro argumento associa o alto desemprego a um sistema de educação inadequado frente às exigências do mercado de trabalho e à incapacidade de muitos jovens permanecerem na escola. Quanto maior o nível de escolaridade, maior o tempo de procura de emprego porque as exigências dos jovens passam a ser maiores, e, desse modo, o elevado desemprego juvenil seria um resultado quase natural, uma vez que é longo o tempo de busca de uma inserção estável no mercado de trabalho (Centerfor/OIT, 1997, apud Madeira \& Rodrigues, 1998). Portanto, não parece adequado dizer que o aumento da escolaridade do jovem não está resolvendo o problema do desemprego juvenil. A importância da formação dos recursos humanos não teria relação alguma com a questão do desemprego em geral, e sim seu papel estaria em atuar sobre os níveis de produtividade e contribuir para o desenvolvimento da economia. Outros autores, como Silva (2001), destacam atitudes preconceituosas, como a opção, por parte dos empresários, por trabalhadores adultos, que somam experiência e hábitos de trabalho mais sedimentados, o que seria mais um obstáculo para a colocação do jovem no mercado de trabalho, principalmente para a obtenção do primeiro emprego.

Diante dessas considerações, temos as possíveis justificativas para o desemprego juvenil. Porém, não conseguimos identificar qual segmento dessa categoria ${ }^{1}$ faz com que esse desemprego seja tão elevado, e em qual situação ele se encontra ${ }^{2}$. Este trabalho tem como objetivo contribuir para a análise da estrutura do desemprego juvenil (de 14 a 24 anos de idade), e identificação dos determinantes da tão elevada taxa de desemprego dessa categoria. Para tal, discutiremos o que já é conhecido na literatura nacional e internacional, e verificaremos empiricamente o que acontece no caso brasileiro, com base nos dados da Pesquisa Mensal de Emprego (PME), do Instituto Brasileiro de

\footnotetext{
${ }^{1}$ Divide-se a categoria dos jovens em dois segmentos: os jovens que estão em busca do primeiro emprego, e os jovens que já trabalharam antes da pesquisa.

${ }^{2}$ Neste estudo, o jovem pode encontrar-se e transitar por três estados do mercado de trabalho: emprego, desemprego e inatividade.
} 
Geografia e Estatística (IBGE), nas seis principais regiões metropolitanas do $\mathrm{Brasil}^{3}$, de 1983 a 2002.

Além desta introdução, o trabalho está dividido em mais quatro capítulos. O primeiro traz uma revisão da literatura nacional e internacional. No segundo capítulo, faz-se uma decomposição da taxa de desemprego de jovens, adultos e idosos, baseada em um modelo de contratação, e, assim, observa-se qual componente (duração do desemprego, ou a taxa de entrada no desemprego - rotatividade) faz com que essas três categorias sejam diferentes entre si. Posteriormente, com base nesse resultado, será feita uma nova decomposição deste componente em jovens que já trabalharam antes da pesquisa e jovens que nunca trabalharam e estão em busca do primeiro emprego. No terceiro capítulo, serão apresentadas as probabilidades de transição entre as situações ocupacionais, e as taxas de desemprego associadas a elas, entre os três estados do mercado de trabalho, de jovens e adultos. Serão feitas simulações de como seria a reação da taxa de desemprego caso as probabilidades do jovem fossem iguais às do adulto, e vice-versa, fazendo substituições nas respectivas matrizes de transição. Então, pode-se responder a seguinte questão: será realmente a dificuldade em obter o primeiro emprego a causa dos jovens apresentarem uma taxa de desemprego tão alta, ou será a alta rotatividade no mercado de trabalho juvenil? Caso o motivo estiver associado ao primeiro emprego, isso pode ser considerado um problema passível de intervenção governamental. Entretanto, o principal motivo pode ser, simplesmente, a maior taxa de transição do emprego para o desemprego, ou seja, o jovem entra e sai de um emprego em um curto período de tempo. Finalmente, o quarto capítulo apresenta a conclusão deste trabalho.

\footnotetext{
${ }^{3}$ As seis principais regiões metropolitanas no Brasil são: São Paulo, Belo Horizonte, Rio de Janeiro, Porto Alegre, Recife e Salvador.
} 


\section{CAPÍTULO 1 - REVISÃO DA LITERATURA}

\section{Introdução}

Os jovens apresentam uma taxa de desemprego elevada e muito maior que a de trabalhadores mais velhos, e isso acontece em todo o mundo. Neste capítulo, apresentaremos alguns dos trabalhos realizados sobre desemprego juvenil em âmbito nacional e internacional. Apesar da maior atenção dada à questão do desemprego nos últimos anos, na literatura sobre o mercado de trabalho brasileiro, poucos são os estudos sobre a estrutura do desemprego dos jovens, embora essa categoria sempre tenha apresentado altas e persistentes taxas de desemprego. Na literatura internacional, a questão do desemprego dos jovens é um tema muito debatido.

\section{Literatura Nacional}

Recentemente, a estrutura do desemprego e seus determinantes começaram a ser mais estudados ${ }^{4}$. Alguns destes trabalhos são de Bivar (1993); Corseuil (1994); Corseuil et al. (1996); Rocha (1993); Barros et al. (1997); Fernandes \& Picchetti (1999); Menezes-Filho \& Picchetti (2000) e Avelino (2001). Especificamente sobre os jovens, mas não necessariamente sobre sua estrutura do desemprego, pode-se citar Sarriera et al. (2000); Corseuil et al. (2001) e Silva (2001), além de duas coletâneas publicadas pela Comissão Nacional de População e Desenvolvimento (CNPD) (1998).

Em seu trabalho sobre a estrutura do desemprego no Brasil, Barros et al. (1997) investigam como variam a incidência e a duração do desemprego ao longo de seis

\footnotetext{
${ }^{4}$ A Pesquisa Mensal de Emprego (PME), a Pesquisa Nacional por Amostra de Domicílios (PNAD) e a Pesquisa de Emprego e Desemprego (PED) são algumas das fontes de microdados disponíveis no Brasil.
} 
dimensões, sendo uma delas a idade. Seus resultados apresentam a categoria de jovens com altas taxas de desemprego, baixas durações médias do desemprego e elevada probabilidade de entrada no desemprego, sendo esta categoria caracterizada por exibir uma alta rotatividade (alta probabilidade de entrada e saída do desemprego). Ao medir a importância do desemprego como um dos determinantes da desigualdade e da pobreza, os autores concluem que o fato de a magnitude do desemprego ser elevada entre jovens certamente contribui para o aumento da desigualdade de renda pessoal, mas deve ter um menor impacto sobre a desigualdade de renda familiar e sobre a pobreza, uma vez que os jovens tendem a ter uma contribuição relativamente pequena para o orçamento familiar. Outro resultado é que a taxa de desemprego cai com a idade, fato associado a uma redução, com a idade, na probabilidade de entrada no desemprego ou a um crescimento, com a idade, na probabilidade de saída do desemprego, ou a ambos.

Resultados esses que são semelhantes, no que se refere à idade, aos de Fernandes \& Picchetti (1999), que analisam a estrutura do desemprego para o Brasil metropolitano, entre diferentes dimensões sócio-econômicas da população, usando um modelo de regressão da classe multinomial logit. Os autores também fizeram simulações apenas com participantes da força de trabalho: “...As simulações para a probabilidade de desemprego (...) mostraram um padrão monotonamente decrescente com a idade, corroborando as estatísticas descritivas de que a taxa de desemprego é mais elevada entre os jovens...” (Fernandes \& Picchetti, 1999, p. 100)

A alta rotatividade do jovem também foi encontrada nos trabalhos de MenezesFilho \& Picchetti (2000) e de Orellano \& Picchetti (2002). Menezes-Filho \& Picchetti (2000) fazem uma análise dos determinantes da duração do desemprego na região metropolitana de São Paulo, e usam, entre outras variáveis, a idade, se a pessoa já havia trabalhado alguma vez, e o tempo do último emprego. Os autores também apontam que aqueles que já trabalharam têm probabilidade inferior de continuarem desempregados em relação aos que estão procurando pela primeira vez ${ }^{5}$; e que, quanto maior a idade,

\footnotetext{
${ }^{5}$ Com o estimador de Kaplan-Meier, os autores compararam a taxa de sobrevivência no desemprego entre os indivíduos que já trabalharam e os que procuram emprego pela primeira vez na amostra.
} 
maior o tempo de duração esperado de desemprego ${ }^{6}$. Picchetti et al. (2002) chamam a atenção para a alta rotatividade da mão-de-obra no Brasil. Seu aspecto positivo seria permitir às firmas ajustar a sua demanda por trabalho, em resposta a variações na demanda pelo produto, não apenas ajustando o número de empregados, mas também variando o número de horas de trabalho contratadas e o tipo de função que os trabalhadores desempenham ao longo do tempo. O ponto negativo da alta rotatividade seria o reflexo da falta de comprometimento entre empregados e empregadores: de um lado, as firmas demitem parte de sua força de trabalho nos momentos de queda na produção; por outro lado, elas não induzem seus funcionários a permanecerem no mesmo emprego em momentos de aquecimento da economia.

\section{Literatura Internacional}

Há mais estudos sobre a questão do desemprego dos jovens em outros países, do que no Brasil. Parte desses trabalhos detém-se aos programas de combate ao desemprego em cada país, e seus respectivos resultados. Entre eles, o trabalho de Burgess et al. (1998) para a Austrália, que constata que, apesar de haver programas que dão prioridade à redução do desemprego (tais como reformas industriais, consolidação fiscal e do mercado de trabalho, e privatização de empresas estatais), especialmente ao desemprego dos jovens, o sucesso desses programas tem sido limitado e a criação de emprego permanece baixa. Para os países latino-americanos, segundo Sarriera et al. (2000), novas formas de contratação temporária e de redução da jornada de trabalho estão emergindo na tentativa de amenizar as dificuldades enfrentadas, principalmente pelos jovens, devido ao desemprego, ao trabalho informal e à exploração da mão-de-obra. No artigo de Fougère et al. (2000) é mostrado que a França introduziu políticas de mercado de trabalho (tais como programas de treinamento e subsídios do governo) desde os anos 70, quando o desemprego começou a subir e chegou a atingir $29 \%$ entre os jovens. Essas

\footnotetext{
${ }^{6}$ Os autores utilizaram um modelo semi-paramétrico de riscos proporcionais.
} 
políticas têm como alvo principalmente os trabalhadores com maior risco de desemprego, como os jovens, que são particularmente afetados por essas altas taxas de desemprego na França.

Por outro lado, há estudos que procuram medir a contribuição de mudanças na estrutura populacional para as mudanças no mercado de trabalho de jovens. Um desses trabalhos é o de Korenman \& Neumark (1997), que diante da crise no emprego de jovens enfrentada pelos países europeus nas últimas décadas, propuseram-se a medir essa contribuição nos anos 70, 80 e metade dos 90, e a usar isto para projetar os efeitos de futuras coortes no mercado de trabalho juvenil. O trabalho conclui que mudanças na população não têm muito efeito nos problemas de emprego nas economias desenvolvidas. Especificamente para os Estados Unidos, encontramos alguns estudos sobre o baby boom, e como ele alterou a estrutura demográfica do país. Shimer (1999) aponta que um aumento na parcela de jovens reduz tanto a taxa de desemprego juvenil quanto a de adultos, sendo uma possível explicação a migração de trabalhadores jovens para os estados com baixas taxas de desemprego (implicando em uma maior rotatividade por parte dos jovens). Já Blanchflower \& Freeman (2000) estudam a deterioração do mercado de trabalho dos jovens nos países da OECD nos anos 80 e 90. Nesse período, a participação dos jovens na população caiu na maioria dos países, enquanto a oferta de emprego se direcionou aos setores que empregavam relativamente muitos jovens. Apesar dessas tendências e do crescente número de jovens que se dedicam apenas a estudar, a situação do jovem no mercado de trabalho piorou em relação ao adulto: salários e taxas de emprego caíram, e as taxas de desemprego subiram em todos os países. Os autores estudaram os setores que mais empregam jovens, e, ao investigar se o emprego, nesses setores, estaria caindo (o que explicaria o mau desempenho do mercado de trabalho juvenil), encontraram evidências no sentido oposto: o emprego aumentou em relação ao emprego na economia como um todo. Muitos analistas esperavam que os problemas com relação ao emprego do jovem fossem amenizados quando a geração baby boom se tornasse mais velha e em seu lugar entrasse um menor número de jovens. Porém, esse último estudo mostrou que isso não ocorreu, o emprego e os ganhos dos jovens diminuíram em quase todos os países da OECD. 
A questão do primeiro emprego é tratada por outros autores. Lassibille et al. (2001), analisam a entrada dos jovens no mercado de trabalho espanhol focando, por um lado, a duração do desemprego depois de completo o período escolar, e, por outro, a transição entre o estudo e o trabalho durante este período inicial do primeiro emprego. Os autores fazem uma comparação entre os jovens que deixaram a escola antes de ingressar em uma faculdade e os que têm nível superior; concluem que estes últimos têm menor dificuldade em achar o primeiro emprego.

Outros estudos procuram explorar a abordagem que leva em consideração as causas da alta taxa de desemprego enfrentada pelos jovens. Nessa linha de estudo, para os Estados Unidos, pode-se citar o trabalho de Clark \& Summers (1982), em que se procura fazer uma análise da dinâmica do desemprego juvenil para o ano de 1977, e levantam-se duas explicações principais para a causa das altas taxas de desemprego: a visão da rotatividade enfatiza movimentos freqüentes de entrada e saída do emprego; uma segunda visão sugere que o problema real é a falta de vagas de emprego. Os autores mostram que ambas as visões descrevem uma parte da população jovem: por um lado, a grande maioria dos jovens entra e sai do mercado de trabalho com facilidade; e por outro, grande parte do desemprego juvenil deve-se a um grupo relativamente pequeno de jovens que apresenta dificuldade em achar trabalho e sofre longos períodos sem emprego (a maioria dos períodos de desemprego são curtos devido às altas taxas de desistência da força de trabalho, e não devido ao encontro de emprego). Enquanto instabilidade e alta rotatividade são os principais fatores na determinação geral do desemprego juvenil, a falta de oportunidades de empregos desejáveis é o problema crucial para aqueles jovens mais seriamente afetados pelo desemprego, como os que sofrem discriminação racial. Leighton \& Mincer (1979) mostram que, para os jovens, a rotatividade é maior que a duração (com adultos ocorre o contrário), o que sugere que o desemprego dos jovens é reflexo da sua mobilidade, concluindo que o desemprego cai com a idade não por causa da idade, mas devido ao tempo de experiência em um emprego (é por ter pouco tempo de emprego que o jovem tem uma incidência maior no desemprego). Conclusões similares são apontadas por Freeman (1979) e Fisher (2001). Freeman (1979) examina os problemas relacionados ao mercado de trabalho dos jovens 
dos anos setenta nos Estados Unidos, apresentando duas visões sobre as causas do alto desemprego dos jovens: falta de uma demanda adequada por trabalhadores jovens; falta de habilidades, incentivos e/ou aspirações por parte do jovem. O autor também atribui o declínio nos ganhos de trabalhadores jovens relativamente aos mais velhos à grande entrada da geração baby boom no mercado de trabalho. Segundo Fisher (2001), a alta taxa de desemprego entre os jovens nos Estados Unidos é um fenômeno persistente. Nesse artigo também considera-se que os trabalhadores jovens apresentam uma maior rotatividade, uma vez que eles tendem a entrar e sair do mercado de trabalho, devido ao fato de não terem que sustentar outras pessoas, podendo, então, esperar o emprego "certo".

Após essa breve resenha da literatura, este trabalho procura explorar as causas da alta taxa de desemprego enfrentada pelos jovens no Brasil. Como apresentado na revisão da literatura nacional, um resultado normalmente encontrado pelos autores é que a rotatividade é maior entre os trabalhadores jovens, mas isso não é estudado com mais atenção como nos trabalhos internacionais com a finalidade de descobrir se ela é responsável pelo alto desemprego desse grupo populacional ou não. No próximo capítulo, serão analisados os determinantes da taxa de desemprego de acordo com a metodologia aplicada por Layard et al. (1991), que será apresentada juntamente com seus resultados para Estados Unidos e Inglaterra. E, no terceiro capítulo, como em Clark \& Summers (1982), será apresentada uma análise da dinâmica do desemprego juvenil, porém, com uma investigação mais aprofundada das matrizes de transição. Enquanto sua análise estende-se até as probabilidades de transição, este presente trabalho estuda também o comportamento das frações de tempo que o indivíduo gasta em cada estado do mercado de trabalho e das taxas de desemprego geradas por elas. Desse modo, pode-se indicar os principais motivos para o elevado desemprego dos jovens no Brasil. 


\section{CAPÍTULO 2 - EVIDÊNCIAS EMPÍRICAS: ROTATIVIDADE}

\section{Introdução}

Neste capítulo, o objetivo será analisar a estrutura do desemprego dos jovens, nas seis principais regiões metropolitanas do Brasil, entre os anos de 1983 e 2002, com base nos dados da Pesquisa Mensal de Emprego (PME).

De acordo com um modelo de contratação, a taxa de desemprego será decomposta em dois determinantes, duração média e taxa de entrada no desemprego, das três categorias, jovens (de 14 a 24 anos de idade), adultos (de 25 a 59 anos de idade) e idosos (com mais de 60 anos de idade). Por uma questão de simplificação, serão considerados apenas dois estados do mercado de trabalho, emprego e desemprego. Com isso, pode-se indicar o determinante que diferencia as categorias e faz com que a taxa de desemprego juvenil seja mais elevada que a de adultos e idosos. Posteriormente, usando somente a categoria dos jovens, decompõe-se esse determinante em um componente que leva em consideração apenas jovens que já trabalharam e um que considera apenas jovens que estão à procura do primeiro emprego. Com esses resultados, torna-se possível definir o principal responsável pela alta taxa de desemprego juvenil brasileira.

\section{Fonte de dados}

A base de informações utilizada nesse estudo, como já mencionado anteriormente, será a Pesquisa Mensal de Emprego (PME), realizada nas seis principais regiões metropolitanas do Brasil $^{7}$, entre os anos de 1983 e $2002^{8}$. A PME adota um esquema de rotação de painéis. Um painel equivale a um conjunto de domicílios

\footnotetext{
${ }^{7}$ As seis principais regiões metropolitanas brasileiras são: São Paulo, Rio de Janeiro, Belo Horizonte, Porto Alegre, Recife e Salvador.

${ }^{8}$ Para o ano de 2002, os dados se restringem apenas aos seis primeiros meses do ano (janeiro a junho).
} 
selecionados e é dividido em quatro partes ou remessas correspondentes a cada semana do mês. A rotação de painéis é feita de forma que, a cada mês, seja substituída uma das remessas. Por esse esquema, se em um determinado mês for aplicado um dado painel, no mês seguinte será aplicado apenas $75 \%$ do seu todo, entrando $1 / 4$ do painel seguinte, e assim sucessivamente. Assim, há uma garantia de que 75\% dos domicílios são comuns a dois meses consecutivos. Por outro lado, um painel será investigado por quatro meses consecutivos, pára nos oito meses subseqüentes e retorna para outro período de quatro meses, sendo, então, definitivamente excluído. Desse modo, a cada par de anos, 100\% da amostra se repete.

Aqui, considera-se apenas uma das oito entrevistas de cada indivíduo (a primeira delas), desde que este fizesse parte da população economicamente ativa (ou seja, empregado ou desempregado), o que gerou uma amostra composta por 1.697.260 observações, no total das seis regiões e dos vinte anos considerados. Divide-se a população nas seguintes categorias: jovens (de 14 a 24 anos de idade), adultos (de 25 a 59 anos de idade) e idosos (com mais de 60 anos de idade). Nessa amostra, 60\% dos indivíduos são do sexo masculino, $27 \%$ são jovens, $70 \%$ são adultos e $3 \%$ são idosos. A idade média dos jovens é de 20 anos, a dos adultos é de 38, e a de idosos é de 66 anos.

Para este estudo, a população economicamente ativa será definida como a população com 14 anos de idade ou mais que trabalhava (empregado) ou procurava trabalho na semana de referência da pesquisa (desempregado). Como desempregados serão incluídos aqueles que estavam desempregados na semana de referência, mas que procuravam emprego. A duração do desemprego será entendida como o número de meses de desemprego decorrido até a data de referência da pesquisa.

\section{Metodologia}

Neste capítulo, o foco são os fluxos entre emprego e desemprego, ou seja, ainda não se leva em consideração a inatividade. No próximo capítulo, será apresentado um 
quadro mais completo do mercado de trabalho juvenil, onde serão examinados os movimentos de entrada e saída da força de trabalho, com os três estados do mercado de trabalho: emprego, desemprego e inatividade.

Para fazer a análise da duração média e da taxa de entrada no desemprego, a idéia, aqui, baseia-se na função contratação ${ }^{9}$. Esta função mostra que o número de contratações (inicialmente identificaremos como o número de pessoas que deixam o desemprego ${ }^{10}$ por período depende do número de vagas e do número de pessoas que estão efetivamente procurando emprego, admitindo que cada contratação envolve um “casamento" entre uma vaga e uma pessoa desempregada.

Serão utilizados, aqui, três indicadores básicos: a taxa de desemprego de estado estacionário para cada categoria; a taxa de entrada no desemprego da categoria (que será a taxa na qual as pessoas deixam o emprego para o desemprego); e a duração média do desemprego para os desempregados da categoria (que será, em estado estacionário, o tempo médio para aquele que entra no desemprego e lá permanece). Em estado estacionário, é conveniente pensar a taxa de desemprego ${ }^{11}$ como:

Taxa de desemprego = Taxa de entrada x Duração média.

Será utilizada uma identidade, na qual se considera a taxa de desemprego (U/N) de uma dada categoria como a razão entre o número de pessoas desempregadas $(U)$ e o número de pessoas empregadas $(N)$, seguindo a metodologia adotada por Layard et al.

\footnotetext{
${ }^{9}$ Para uma explicação mais detalhada da função contratação, ver Layard et al. (1991).

${ }^{10}$ Quando se considera a entrada no desemprego igual à saída no desemprego, tem-se o estado estacionário. A saída do desemprego, aqui, é identificada como uma contratação, e isso ignora dois problemas. O primeiro é que muitas pessoas são contratadas já estando empregadas, e não necessariamente desempregadas. Outras vêm direto de fora da força de trabalho. O segundo é que muitas das pessoas que deixam o desemprego saem da força de trabalho, principalmente jovens.

${ }^{11}$ As transições entre os estados do mercado de trabalho são tratadas como um processo de Markov, no qual o desenvolvimento futuro do processo, dado que está em um estado, depende apenas do estado e não de como o processo chegou a esse estado.
} 
$(1991)^{12}$. A taxa de entrada no desemprego $(S / N)$ será a razão entre o número de pessoas que estavam desempregadas por um mês ou menos (S) e o número de pessoas empregadas. E, a duração média do desemprego (U/S) será a razão entre o número de pessoas desempregadas e o número de pessoas que estavam desempregadas por um mês ou menos. Portanto,

$$
\frac{U}{N} \equiv \frac{S}{N} \cdot \frac{U}{S}
$$

Layard et al. (1991) apresentam a decomposição da taxa de desemprego e suas variações para os Estados Unidos e Inglaterra. Além da taxa de desemprego, taxa de entrada no desemprego e duração média, mais uma estimativa de duração média do desemprego é apresentada. A primeira segue o modelo acima descrito, onde a duração média (chamada de duração média completa do desemprego) é a razão entre o número de desempregados e o número de pessoas que entraram no desemprego em um período inferior a um mês $(U / S)$. A segunda (chamada de duração média incompleta do desemprego) é resultado da razão entre a soma da duração do desemprego de cada indivíduo desempregado e o número total de desempregados. Para os Estados Unidos, as variações no desemprego devem-se tanto à duração média quanto à taxa de entrada no desemprego. As duas medidas de duração média são muito próximas, apesar da segunda ser um pouco mais alta que a primeira. Já para a Inglaterra, as variações no desemprego para indivíduos do sexo masculino devem-se principalmente à duração média. As duas

${ }^{12}$ Os autores também decompõem o número de desempregados como número de pessoas que entram e saem do desemprego. A variação no desemprego seria o excesso de entrada no desemprego $(S)$ sobre a saída do desemprego $(H): \Delta U=S-H$

Quando $S=H$, o desemprego é constante e tem-se, então, o estado estacionário. Além disso, uma vez que em estado estacionário a entrada no desemprego $(S)$ se iguala à saída do desemprego $(H)$, ainda podese pensar na duração média $(U / S)$ como sendo o inverso da taxa de saída do desemprego $(1 /(H / U))$ : $\frac{U}{S}=\frac{1}{H / U}$ (duração média $=1 /$ taxa de saída $)$.

Portanto, TaxadeDesemprego $=\frac{\text { TaxadeEntrada }}{\text { TaxadeSaída }} \Rightarrow \frac{U}{N}=\frac{S / N}{H / U}$, se $(S=H)$. 
medidas de duração diferem-se bastante uma da outra, sendo a segunda praticamente três a quatro vezes maior que a primeira, possivelmente porque os indivíduos podem superestimar o tempo que eles estão desempregados. Layard et al. (1991) explicam o fato da segunda medida da duração média ser maior que a primeira demonstrando que a taxa de saída do desemprego é muito menor para longas durações de desemprego. Para uma explicação mais detalhada, ver Layard et al. (1991). Isso pode ser também ilustrado pelo exemplo de Barros et al. (1997). Suponha que a economia seja formada por dois grupos de trabalhadores de mesmo tamanho.

“...Em ambos os grupos, todos os trabalhadores ficam desempregados exatamente uma vez por ano. Num grupo, o período completo de desemprego dura um mês, ao passo que no outro, o episódio dura seis meses. Vamos assumir que num grupo 1/12 dos trabalhadores está desempregado a cada mês e que no outro, 1/2 dos trabalhadores fica desempregado no primeiro semestre e 1/2 no segundo. Neste caso, uma pesquisa feita no final de junho irá encontrar 1/2.(1/12+1/2) da força de trabalho desempregada, com 6/7 dos desempregados estando há seis meses desempregados e 1/7 estando desempregado há apenas um mês. Assim, a duração média do desemprego nesta amostra de desempregados será 37/7=5,3 [=6.(6/7)+1.(1/7)] meses, ao passo que na população total sabemos que a duração média dos episódios de desemprego que ocorrem no ano é de $(1+6) / 2=3,5$ meses. $O$ fato de o peso dos episódios de desemprego de longa duração ser maior na amostra (6/7) do que na população (1/2) leva a que a duração média fique superestimada. ...” (Barros, et al., 1997, p. 11)

Desta forma, duas razões seriam responsáveis para a duração média dos episódios completos ser diferente da duração média dos episódios em andamento até o momento da pesquisa. A primeira é que a duração média dos episódios em andamento 
subestima a duração dos episódios completos uma vez que parte da duração destes não é computada, ou seja, há uma interrupção dos episódios de desemprego. A segunda razão é que a amostra de desempregados em um determinado momento tende a superrepresentar os episódios de longa duração, por estarem em andamento no momento da pesquisa, o que leva a uma superestimação da duração média. Porém, quando a distribuição da duração dos episódios é exponencial, estes dois efeitos se cancelam.

Será feita, primeiramente, uma decomposição da taxa de desemprego em duração média e taxa de entrada no desemprego de jovens, adultos e idosos, com o objetivo de identificar qual desses componentes diferencia a taxa de desemprego dos jovens, fazendo com que ela seja mais alta, a duração ou a taxa de entrada no desemprego (rotatividade no mercado de trabalho juvenil). Em seguida, será feita a decomposição da taxa de entrada no desemprego juvenil entre dois grupos: jovens que buscam o primeiro emprego e jovens que já trabalharam antes (transição do emprego para o desemprego). Esta abordagem explicita, assim, o quão importante é a questão da “dificuldade” em se achar o primeiro emprego para explicar uma taxa de desemprego juvenil tão alta.

\section{Resultados}

As estimativas anuais para os indicadores utilizados (taxa de desemprego, taxa de entrada e duração média no desemprego - completa e incompleta ${ }^{13}$ ) para cada categoria investigada (jovem, adulto e idoso), em cada uma das seis regiões metropolitanas, encontram-se apresentadas nas Tabelas 2.1 a 2.6, no Anexo A. Como ilustração, na Tabela 1 a seguir, apresenta-se a média desse período de vinte anos de cada indicador para a região de São Paulo.

${ }^{13}$ A duração média incompleta do desemprego é também maior que a completa no Brasil, como Layard et al. (1991) e Barros et al. (1997) demonstraram com para longas durações de desemprego. E os dados utilizados neste trabalho mostraram que isso também acontece para o caso brasileiro, e por isso observouse que a duração média incompleta é maior que a duração média completa do desemprego. 
TABELA 1

Média das taxas de desemprego e entrada, duração média completa e incompleta do desemprego, segundo faixa etária, São Paulo, 1983-2002

\begin{tabular}{ccccc}
\hline \hline CATEGORIA & $\begin{array}{c}\text { TD } \\
(\mathrm{U} / \mathrm{N})^{1}\end{array}$ & $\begin{array}{c}\text { TE } \\
(\mathrm{S} / \mathrm{N})^{2}\end{array}$ & $\begin{array}{c}\text { DMC } \\
(\mathrm{U} / \mathrm{S})^{3}\end{array}$ & $\mathrm{DMI}^{4}$ \\
\hline JOVEM & 13,39 & 3,73 & 3,59 & 4,31 \\
ADULTO & 4,48 & 1,09 & 4,11 & 4,61 \\
IDOSO & 1,15 & 0,26 & 4,42 & 6,64
\end{tabular}

Fonte: Construído pela autora com base na PME

${ }^{1} \mathrm{TD}(\mathrm{U} / \mathrm{N})$ : taxa de desemprego, em porcentagem (indivíduos desempregados/indivíduos empregados)

${ }^{2} \mathrm{TE}(\mathrm{S} / \mathrm{N}$ ): taxa de entrada no desemprego por mês, em porcentagem, (indivíduos que entraram no desemprego em um mês ou menos/indivíduos empregados)

${ }^{3}$ DMC (U/S): duração média completa do desemprego de estado estacionário, em meses (indivíduos desempregados/indivíduos que entraram no desemprego em um mês ou menos)

${ }^{4}$ DMI: duração média incompleta do desemprego corrente, em meses, (razão entre a soma da duração do desemprego de cada indivíduo desempregado e o número total de desempregados)

Pode-se notar, de acordo com as tabelas em anexo, que a taxa de desemprego dos jovens, nesse período, foi sempre maior e menos estável que a de adultos e a de idosos para as seis regiões metropolitanas. Esse fato fica claro no Gráfico 1 a seguir, referente à região metropolitana de São Paulo e nos Gráficos 2.1 a 2.5, no Anexo B, que fazem essa comparação entre as taxas de desemprego de cada categoria, segundo região metropolitana. Percebe-se a magnitude do problema do desemprego dos jovens no Brasil quando se observa que nas regiões metropolitanas de São Paulo, Belo Horizonte, Rio de Janeiro e Porto Alegre, a taxa de desemprego juvenil é o triplo da taxa de desemprego dos adultos, por todo esse período, chegando a ser quatro vezes maior em alguns anos; e nas regiões metropolitanas de Recife e Salvador, ela varia de duas a três vezes a de adultos (a não ser nos anos de 1999 e 2000 em Salvador, quando a taxa de desemprego dos jovens cai muito e fica abaixo da taxa de adultos). 
Gráfico 1 - Taxa de desemprego segundo faixa etária - São Paulo

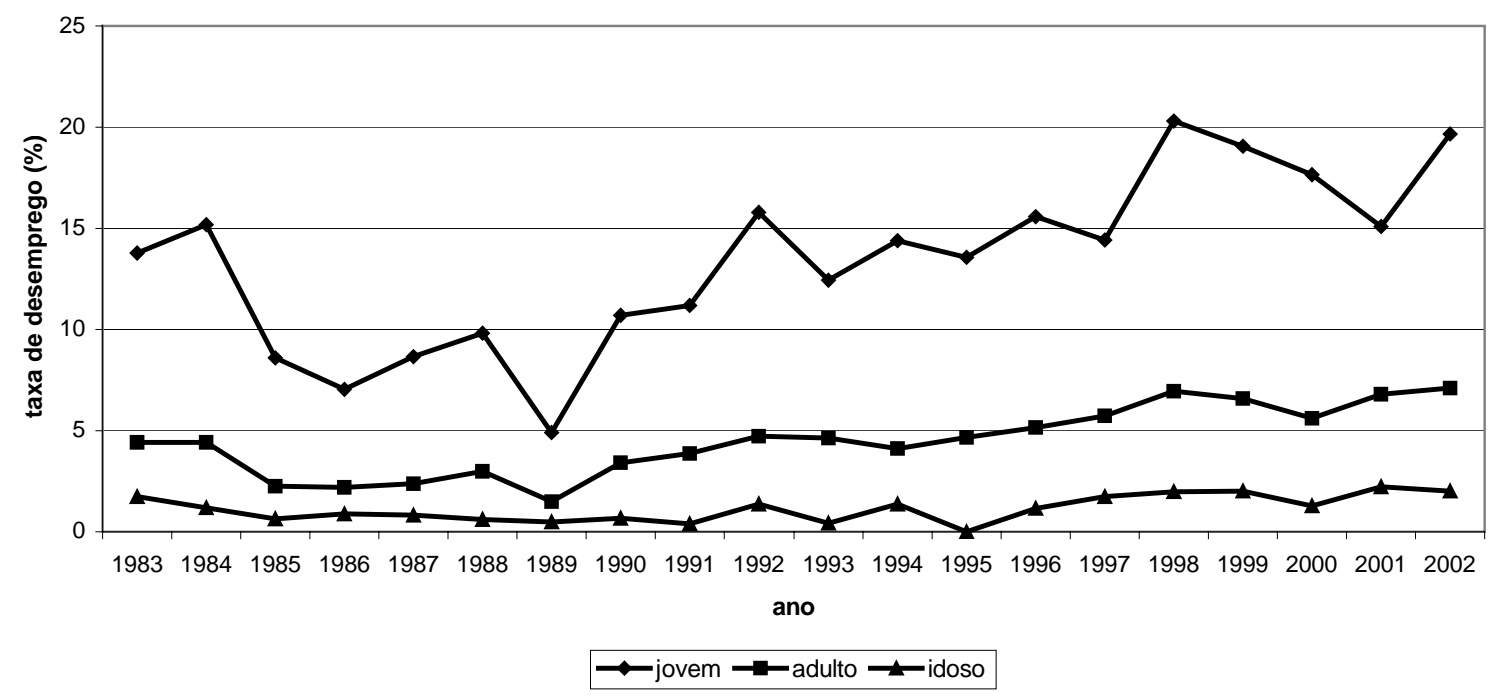

Fonte: Construído pela autora com base na PME

A decomposição da taxa de desemprego em taxa de entrada e duração média do desemprego, apresentada nas tabelas mencionadas acima, será melhor analisada com o auxílio dos Gráficos 2, 3 e 4 a seguir, que apresentam os resultados para as três categorias na região metropolitana de São Paulo, e os Gráficos 2.6 a 2.20, no Anexo B, para as outras cinco regiões, segundo categoria. Verifica-se que, independente da região, a taxa de entrada no desemprego de adultos e idosos é baixa e a duração média, alta ${ }^{14}$. Portanto, o principal responsável pela magnitude da taxa de desemprego, dessas duas categorias, é a duração média do desemprego. Para os jovens, essa diferença não se verifica, ambas as medidas contribuem praticamente de forma igual para a alta taxa de desemprego juvenil. Porém, a duração média dos jovens é tão alta quanto a dos adultos e idosos, enquanto a taxa de entrada no desemprego é maior.

\footnotetext{
${ }^{14}$ Para os idosos, os picos apresentados nos gráficos para a duração média mostram a super-representação dos episódios de longa duração no desemprego.
} 
Gráfico 2 - Taxa de entrada e duração média no desemprego - jovem/SP

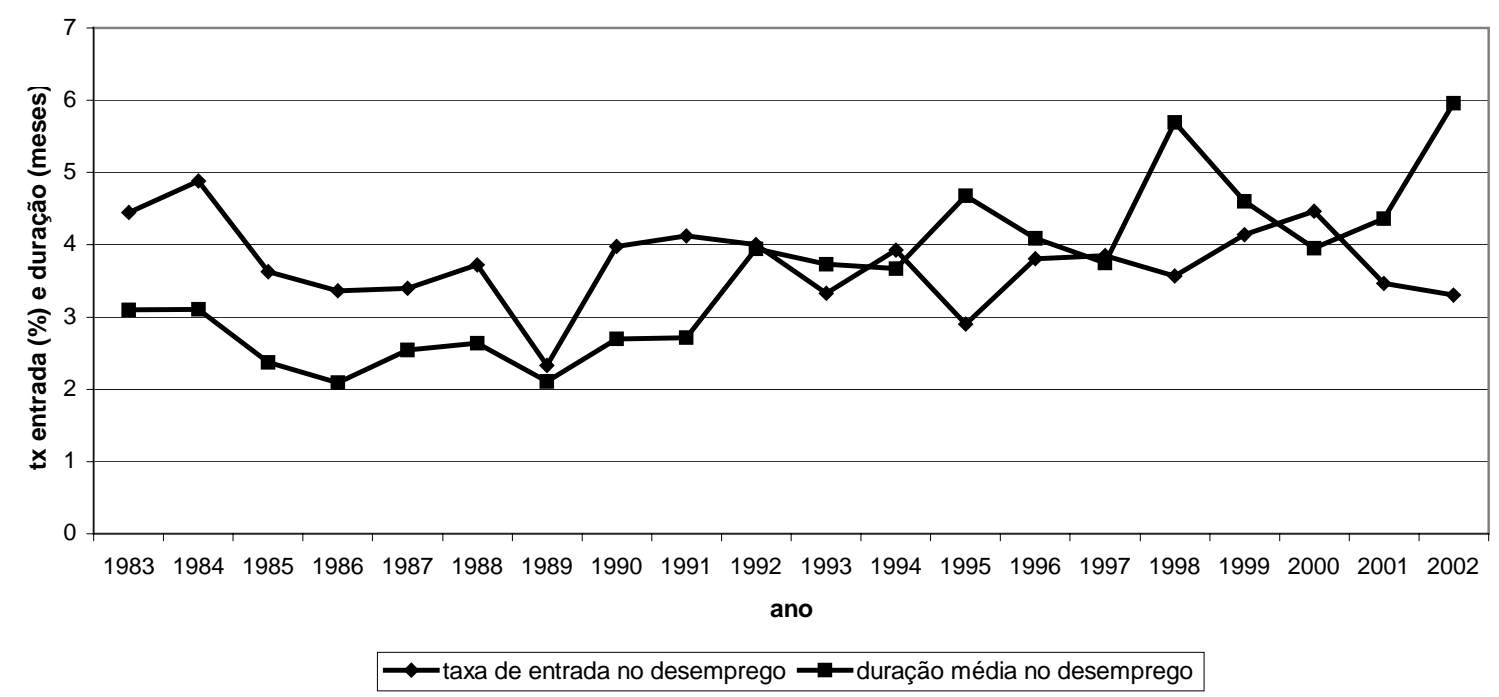

Fonte: Construído pela autora com base na PME

Gráfico 3 - Taxa de entrada e duração média no desemprego - adulto/SP

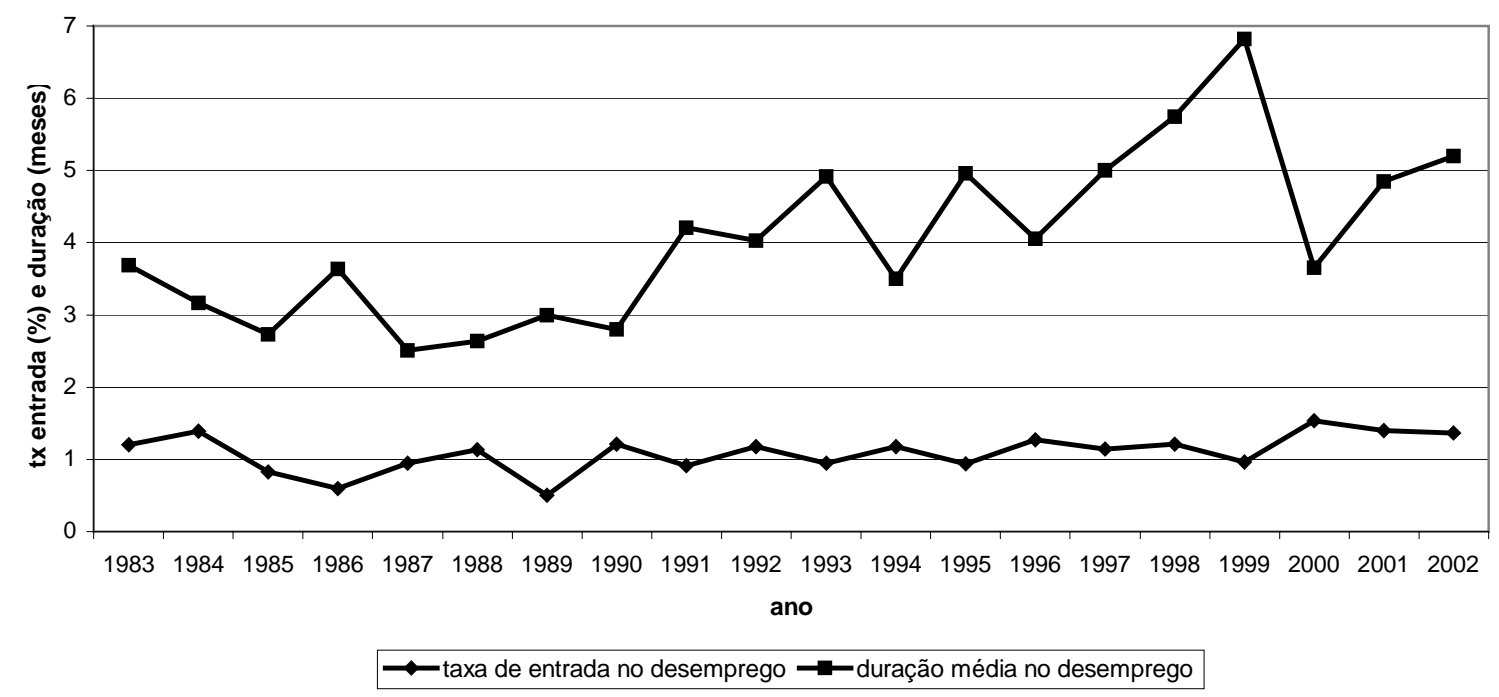

Fonte: Construído pela autora com base na PME 
Gráfico 4 - Taxa de entrada e duração média no desemprego - idoso/SP

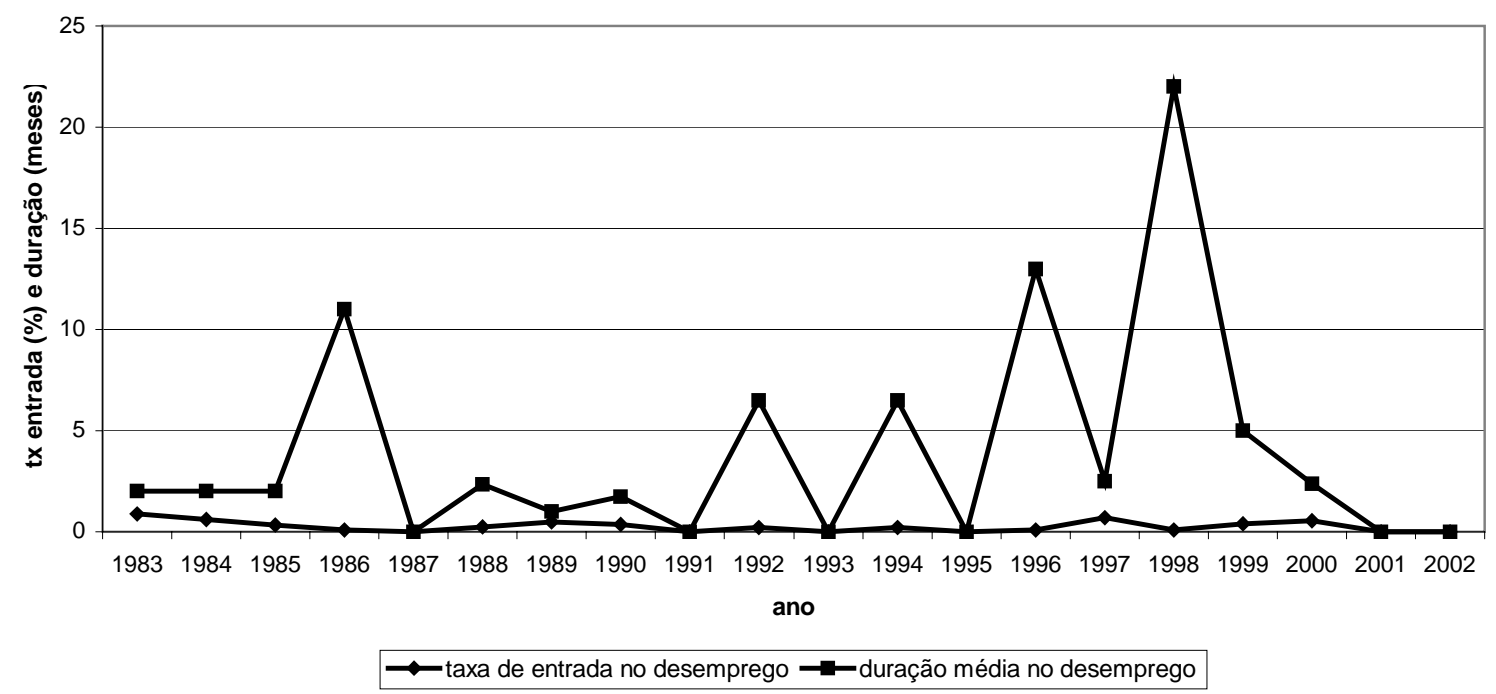

Fonte: Construído pela autora com base na PME

Desse modo, conclui-se que o que diferencia a taxa de desemprego de jovens da taxa de adultos e de idosos é a taxa de entrada no desemprego, uma vez que a duração média do desemprego para as três categorias é muito parecida, e a taxa de entrada de jovens no desemprego é bem maior que a das outras duas categorias. Assim, as Tabelas 2.7 a 2.12 (Anexo A), o Gráfico 5 a seguir, referente à região metropolitana de São Paulo, e os Gráficos 2.21 a 2.25 (Anexo B) mostram a decomposição da taxa de entrada no desemprego ${ }^{15}$, de modo a evidenciar quanto desta taxa $(S / N)$ refere-se aos jovens que estão procurando o primeiro emprego $\left(S_{p} / N\right)$, e aos jovens que tiveram empregos anteriores $\left(S_{n p} / N\right)$, ou seja:

$$
\frac{S}{N}=\frac{S_{p}}{N}+\frac{S_{n p}}{N}
$$

\footnotetext{
15 Novamente, como ilustração, tem-se a taxa média de entrada no desemprego dos jovens ( $S / N)$, no período na região metropolitana de São Paulo, sendo de 3,73\%. E, quando decomposta, a taxa média de entrada do jovem que procura o primeiro emprego $(S p / N)$ é de $0,50 \%$, enquanto a taxa média de entrada do jovem que já trabalhou anteriormente $(S n p / N)$ é de $3,23 \%$.
} 
Gráfico 5 - Taxa de entrada no desemprego de jovens segundo procura por emprego SP

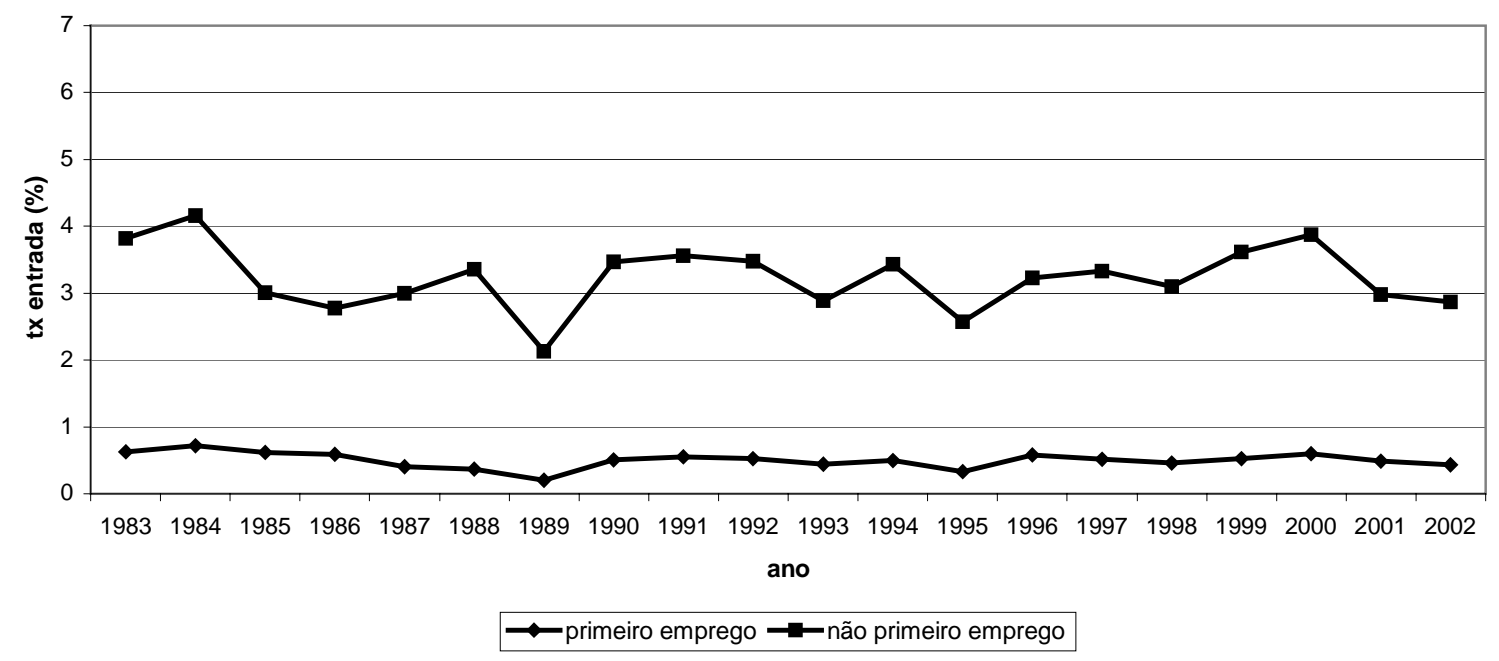

Fonte: Construído pela autora com base na PME

As tabelas e gráficos deixam claro que a taxa de entrada no desemprego dos jovens que já trabalharam antes é bem maior que a dos que estão em busca do primeiro emprego. Os resultados mostram que na região metropolitana de São Paulo, pouco mais de $10 \%$ dos jovens que entram no desemprego, nesse período estudado, estão à procura do primeiro emprego, enquanto mais de $80 \%$ deles já tiveram empregos anteriormente; em Belo Horizonte e Porto Alegre, apenas 10 a 20\% dos jovens que entram no desemprego nunca trabalharam; na região metropolitana de Recife esse número fica entre 15\% a 30\%; e, nas regiões do Rio de Janeiro e Salvador, 10 a 30\% desses jovens que entram no desemprego, no período, procuram pelo primeiro emprego.

Com esses resultados, sendo a taxa de entrada no desemprego o principal determinante pela elevada taxa de desemprego juvenil brasileiro, pode-se concluir que os jovens que já trabalharam anteriormente são os principais responsáveis, entre os jovens, pela alta taxa de entrada no desemprego da categoria. Logo, os que nunca trabalharam e procuram o primeiro emprego não têm muita influência nessa alta taxa de desemprego juvenil. 
Como mencionado no capítulo anterior, grande parte dos trabalhos apresentam evidências de que a taxa de rotatividade é maior entre os jovens, e o que foi encontrado aqui é que, ela não só é maior, como também é o principal determinante para a taxa de desemprego juvenil ser tão elevada. Tem-se, então, que a alta taxa de entrada no desemprego juvenil indica uma alta taxa de rotatividade (freqüente entrada e saída do desemprego) entre os jovens no mercado de trabalho brasileiro, o que pode estar indicando o longo tempo de busca por uma inserção estável no mercado de trabalho por parte do jovem. E, apesar de não ser o objetivo deste trabalho avaliar a importância dos principais determinantes da taxa de rotatividade, é interessante lembrar as considerações de Picchetti et al. (2002) a respeito dos aspectos positivos e negativos de uma elevada taxa de rotatividade, e ressaltar que a questão da rotatividade da mão-de-obra, segundo Barros, et al. (1997), responde a fatores econômicos e institucionais:

“... quanto maior a instabilidade da demanda pelo produto de um dado setor e quanto menor o custo de treinamento de um certo tipo de trabalhador (...) quanto menos informação tiverem os trabalhadores sobre as firmas e vice-versa, (...) maior será a taxa de rotatividade.(...) as demissões são freadas por elevados custos de demissão $e$ incentivadas por dispositivos institucionais (...) que por vezes requerem que os salários cresçam a taxas maiores que a produtividade. (...) os desligamentos voluntários ou induzidos são estimulados por dispositivos institucionais (como o FGTS e o seguro-desemprego) que fazem com que o custo do desligamento para o trabalhador decline com a duração da relação de trabalho. ...” (Barros, et al., 1997, p. 28)

É importante lembrar que, neste capítulo, considera-se apenas os indivíduos empregados e desempregados, sem levar em consideração os inativos, e que Clark \& Summers (1982) criticam essa visão do desemprego juvenil como resultado de altas 
taxas de rotatividade, por não considerar os movimentos de entrada e saída da força de trabalho:

“... Sob essa visão, o desemprego juvenil não é devido a poucos empregos para os jovens. Ao invés disso, ocorreria porque os jovens, especialmente adolescentes, não podem ou não são capazes de segurar seus empregos por muito tempo. Essa visão de rotatividade do desemprego juvenil tipicamente foca nos fluxos entre desemprego $e$ emprego. Menos atenção é dada aos movimentos de entrada e saída da força de trabalho. ..." ${ }^{\prime 16}$ (Clark \& Summers, 1982, p. 3)

Desse modo, no próximo capítulo, será analisada, de forma mais completa, a dinâmica do mercado de trabalho juvenil brasileiro, utilizando os movimentos de transição entre os três estados do mercado de trabalho: emprego, desemprego e inatividade.

${ }^{16}$ Tradução do original pela autora. 


\section{CAPÍTULO 3 - EVIDÊNCIAS EMPÍRICAS: FLUXOS DE ENTRADA E SAÍDA DA FORÇA DE TRABALHO}

\section{Introdução}

Neste capítulo, apresenta-se um retrato mais detalhado do mercado de trabalho, examinando os movimentos dos indivíduos da amostra entre os três estados do mercado de trabalho (emprego, desemprego e inatividade). A divisão desses fluxos brutos pelo tamanho do grupo leva a estimativas das probabilidades de transição mensais médias (a proporção de pessoas em cada estado do mercado de trabalho que deixa esse estado e ruma para outro até o mês seguinte).

Adota-se uma metodologia baseada em dois trabalhos de Clark \& Summers. No primeiro (1982), os autores estudam especificamente a dinâmica do desemprego juvenil, utilizando matrizes de transição. Entretanto, os autores analisam somente até as probabilidades de transição. No segundo trabalho (1990), aborda-se o segurodesemprego, mas novamente utilizam matrizes de transição, desta vez fazendo uma análise mais completa, calculando, também, as frações de tempo que seriam esperadas que o indivíduo ficasse em cada estado do mercado de trabalho e as taxas de desemprego geradas por elas. Neste presente trabalho, serão calculadas, para jovens e adultos, as probabilidades de transição entre os $\operatorname{estados}^{17}$, as frações de tempo e as taxas de desemprego de cada categoria. Para avaliar onde se encontra a causa da elevada taxa de desemprego dos jovens no Brasil, serão recalculadas as taxas de desemprego de estado estacionário de cada uma das duas categorias, substituindo uma de cada vez, nas matrizes de transição, as probabilidades de transição da outra categoria. Por exemplo, usando a matriz dos jovens, substitui-se a primeira linha, ou seja, as probabilidades de transição do emprego para os três estados, pela primeira linha da matriz dos adultos;

\footnotetext{
${ }^{17}$ Como estão sendo usados três estados do mercado de trabalho, nove fluxos mensais são calculados para cada categoria.
} 
assim, observa-se como seria o comportamento da taxa de desemprego dos jovens, caso eles tivessem as mesmas probabilidades dos adultos.

No que se refere ao mercado de trabalho, torna-se indispensável conhecer os fluxos dos trabalhadores entre as categorias, movimentos estes que se dão de forma dinâmica e simultânea, mesmo que não na mesma intensidade, esteja a economia em crescimento ou não. A taxa de desemprego de uma categoria poderia ser mantida elevada se seus membros têm dificuldades em encontrar emprego uma vez que estejam desempregados, porque têm dificuldades (por motivos voluntários ou involuntários) em permanecer empregados uma vez que um emprego seja encontrado ou porque entram e saem freqüentemente da força de trabalho.

A política apropriada a ser adotada dependerá do tamanho relativo desses fluxos mensais de um estado para outro no mercado de trabalho e de quais fluxos são mais responsáveis pela taxa elevada. Os resultados informam sobre a extensão pela qual a alta taxa de desemprego dos jovens é causada pelos valores de cada uma de suas probabilidades de transição. Uma vez que diferentes políticas governamentais provavelmente afetarão diferentes probabilidades de transição, chegar a essas conclusões pode sugerir os tipos de medidas a serem intensificadas ao se buscar a estrutura das taxas de desemprego da população.

\section{Fonte de dados}

A base de informações utilizada, nesse capítulo, mais uma vez, será a Pesquisa Mensal de Emprego (PME), para o ano de $2001^{18}$ nas seis regiões metropolitanas, e para os anos de 1986, 1991 e 1996 apenas para a região metropolitana de São Paulo. A intenção, com isso, é descartar a possibilidade de que os resultados sejam válidos apenas para uma das regiões ou que sejam um fato isolado no tempo. Consideram-se os dados

${ }^{18}$ Optou-se pelo ano de 2001 e não por 2002, pois a amostra de 2002 seria reduzida, a partir do fato que os dados correspondem apenas aos seis primeiros meses do ano. E 2001 seria o ano mais recente do qual se tem dados para o ano inteiro. 
de duas entrevistas mensais seguidas dos indivíduos, com a intenção de captar suas transições de um estado do mercado de trabalho de um mês para outro. Para o cálculo da taxa de desemprego observada da PME foi usada a segunda entrevista de cada indivíduo, do respectivo ano.

Aqui, utiliza-se apenas as duas primeiras entrevistas ${ }^{19}$ do ano de cada indivíduo, gerando uma amostra composta por 235.769 observações, no total das seis regiões no ano de 2001 mais a região metropolitana de São Paulo nos anos de 1986, 1991 e 1996, onde 48\% são do sexo masculino, 31\% são jovens e 69\% adultos. A idade média dos jovens na amostra é de 19 anos, e a dos adultos é de 40 anos.

A população será dividida em duas categorias, jovens (de 14 a 24 anos de idade) e adultos (de 25 a 59 anos de idade), e em três estados que mais diretamente dizem respeito ao mercado de trabalho e à própria dinâmica de formação de salários e emprego na economia: empregados $-e$ (indivíduos ocupados), desempregados $-u$ (indivíduos desocupados) e inativos - $n$ (indivíduos em idade ativa, mas fora da força de trabalho).

\section{Metodologia:}

Como mencionado anteriormente, a metodologia adotada será baseada em matrizes de transição, com as quais serão apresentados os fluxos de entrada e saída do mercado de trabalho. Assumindo que o comportamento individual pode ser caracterizado por uma matriz de probabilidade de transição $p^{i}$, onde $p_{j k}^{i}$ é a

\footnotetext{
${ }^{19}$ Ou seja, consideramos a transição do indivíduo, da ocupação que encontrava-se no mês da primeira entrevista concedida no respectivo ano, para a que declarou estar quando da segunda entrevista concedida no mês seguinte. Para anos ímpares (1991 e 2001), a primeira entrevista que o indivíduo concede no ano, na realidade já é a sua quinta entrevista, uma vez que estamos levando em consideração somente indivíduos que começaram a responder os questionários da PME em anos pares, pois estes correspondem a mais de $80 \%$ da amostra (suas quatro primeiras entrevistas foram realizadas no ano par, neste caso, 1990 e 2000). Como nosso objetivo é somente captar a transição de ocupação de um mês para outro, é indiferente pegar a primeira ou quinta entrevista do indivíduo, optamos pelo que gerava uma amostra maior. Então, para esses anos, a segunda entrevista corresponde, na realidade, à sexta entrevista.
} 
probabilidade do indivíduo $i$ estar no estado $k$ em $t+1$, dado que ele estava no estado $j$ no período $t$, e que $\pi_{j}^{i}$ seja a fração de tempo que o indivíduo i gasta no estado $j$ :

$$
p^{i}=\left[\begin{array}{lll}
p_{e e}^{i} & p_{e u}^{i} & p_{e n}^{i} \\
p_{u e}^{i} & p_{u u}^{i} & p_{u n}^{i} \\
p_{n e}^{i} & p_{n u}^{i} & p_{n n}^{i}
\end{array}\right], \quad \pi^{i}=\left[\begin{array}{c}
\pi_{e}^{i} \\
\pi_{u}^{i} \\
\pi_{n}^{i}
\end{array}\right]
$$

Da matriz de probabilidade de transição $p^{i}$, é possível calcular a parcela de tempo que seria esperada que o indivíduo $i$ ficasse em cada um dos três estados do mercado de trabalho, $\pi_{j}^{i}$. O problema é que os $\pi_{j}^{i}$ não são variáveis observáveis. Entretanto, admitindo que as probabilidades de transição entre os estados sejam independentes do tempo que os indivíduos estão em um determinado estado ${ }^{20}$, pode-se escrever a relação entre $\pi_{t}$ e $\pi_{t-1}$ na forma matricial como:

$$
\pi_{t}=p^{\prime} \pi_{t-1}
$$

Em estado estacionário, $\pi_{t}=\pi_{t-1}$. Logo, pode-se mostrar que:

$$
p^{i} \pi^{i}=\pi^{i} \Rightarrow\left[\begin{array}{ccc}
p_{e e}^{i} & p_{u e}^{i} & p_{n e}^{i} \\
p_{e u}^{i} & p_{u u}^{i} & p_{n u}^{i} \\
p_{e n}^{i} & p_{u n}^{i} & p_{n n}^{i}
\end{array}\right]\left[\begin{array}{c}
\pi_{e}^{i} \\
\pi_{u}^{i} \\
\pi_{n}^{i}
\end{array}\right]=\left[\begin{array}{c}
\pi_{e}^{i} \\
\pi_{u}^{i} \\
\pi_{n}^{i}
\end{array}\right]
$$

\footnotetext{
${ }^{20}$ As transições entre os estados do mercado de trabalho são tratadas como um processo de Markov. Esta hipótese pode ser considerada muito forte, e se tal hipótese não for válida, $\pi_{j}^{i}$ será viesado. A crítica à essa hipótese seria que as probabilidades de transição são dependentes da duração, uma vez que quanto mais tempo o indivíduo está desempregado, maior seria a dificuldade para achar um emprego e menor a probabilidade de sair do desemprego, com a probabilidade de saída declinando com a duração. Em relação a essa crítica, é possível medir o viés das nossas taxas estimadas comparando-as com as taxas observadas na PME. Desse modo, verifica-se que o modelo usado neste trabalho ajusta-se bem aos dados.
} 


$$
\begin{aligned}
& \Rightarrow p_{e e}^{i} \pi_{e}^{i}+p_{u e}^{i} \pi_{u}^{i}+p_{n e}^{i} \pi_{n}^{i}=\pi_{e}^{i} \\
& \Rightarrow p_{e u}^{i} \pi_{e}^{i}+p_{u u}^{i} \pi_{u}^{i}+p_{n u}^{i} \pi_{n}^{i}=\pi_{u}^{i} \\
& \Rightarrow p_{e n}^{i} \pi_{e}^{i}+p_{u n}^{i} \pi_{u}^{i}+p_{n n}^{i} \pi_{n}^{i}=\pi_{n}^{i}
\end{aligned}
$$

onde uma equação do sistema linear descrito é uma combinação linear das outras equações. Porém, pode-se usar a relação $\pi_{e}^{i}+\pi_{u}^{i}+\pi_{n}^{i}=1$, substituindo em qualquer das equações, e, então, resolver o sistema.

A taxa de desemprego, a fração da força de trabalho que está desempregada, é dada por $\frac{\pi_{u}}{\pi_{u}+\pi_{e}}$, em estado estacionário, onde as probabilidades da população são iguais às médias das probabilidades individuais. Faz-se uma comparação desta com a taxa de desemprego observada na PME, calculada segundo a fórmula $\frac{U}{U+E}$, que representa a razão entre o número de pessoas desempregadas e o número de pessoas na força de trabalho no mês (aqui, utiliza-se a ocupação que o indivíduo declarou quando da segunda entrevista).

Após o cálculo das taxas de desemprego de estado estacionário, para avaliar as diferenças entre as duas categorias, recalcula-se essas taxas de uma das categorias substituindo, uma de cada vez, as probabilidades de transição da outra categoria. Por exemplo, se o objetivo for verificar o que aconteceria com a taxa de desemprego do jovem caso suas probabilidades de transição do emprego se comportassem como as do adulto, substitui-se a primeira linha da matriz $p$ do jovem pela primeira linha da matriz $p$ do adulto, uma vez que cada linha soma 1, além de ser independente das outras duas linhas da matriz. Ou seja, as transições do desemprego e da inatividade, continuariam as mesmas do jovem, mas as transições do emprego seriam como as do adulto. Faz-se, assim, com que o jovem que está empregado tenha a mesma probabilidade que o adulto, de continuar empregado, ficar desempregado ou inativo. O mesmo procedimento será 
realizado para as outras duas linhas da matriz do jovem e também para as três linhas da do adulto.

\section{Resultados}

Serão apresentados, a seguir, os resultados referentes à região metropolitana de São Paulo, para o ano de $2001^{21}$, e no Anexo A, na Tabela 3.1, encontram-se os resultados para as outras regiões, e na Tabela 3.6, para os outros anos na região de São Paulo. As probabilidades mensais de transição entre os três estados do mercado de trabalho (emprego, desemprego e inatividade) para as duas categorias demográficas (jovens e adultos) estão apresentadas, na Tabela 2.

Percebe-se, de acordo com a tabela, que, quando o jovem encontra-se empregado em $t$, ele tem uma grande probabilidade de continuar empregado em $t+1$; quando desempregado, maiores são as probabilidades de continuar no desemprego, sendo alta também a probabilidade de desistir de procurar emprego e sair do mercado de trabalho ${ }^{22}$ (em Belo Horizonte, Recife e Salvador, a probabilidade de sair do mercado de trabalho é um pouco maior que a de continuar desempregado); e estando inativo, o jovem tem uma alta probabilidade de continuar inativo.

\footnotetext{
${ }^{21}$ Lembrando que esses resultados de São Paulo, 2001, refletem bem o que acontece nos outros anos para São Paulo e nas outras regiões metropolitanas para 2001.

22 Segundo Clark \& Summers (1982), a alta taxa de saída da força de trabalho entre jovens desempregados sustenta a conclusão de que a procura por emprego, para o jovem, é um processo passivo, no qual o principal elemento é a espera por uma oportunidade de emprego ser apresentada. Os autores argumentam que muitos jovens que deixaram a força de trabalho não teriam feito isso se uma oportunidade de emprego tivesse disponível no mês anterior à desistência.
} 
TABELA 2

Probabilidades de transição de jovens e adultos, São Paulo, 2001

TRANSIÇÕES

CATEGORIAS

\begin{tabular}{ccc} 
& JOVENS & ADULTOS \\
$\mathrm{P}_{\mathrm{ee}}{ }^{1}$ & 0,899 & 0,946 \\
$\mathrm{P}_{\mathrm{eu}}{ }^{2}$ & 0,030 & 0,016 \\
$\mathrm{P}_{\mathrm{en}}{ }^{3}$ & 0,071 & 0,038 \\
$\mathrm{P}_{\mathrm{ue}}{ }^{4}$ & 0,186 & 0,261 \\
$\mathrm{P}_{\mathrm{uu}}{ }^{5}$ & 0,493 & 0,450 \\
$\mathrm{P}_{\mathrm{un}}{ }^{6}$ & 0,321 & 0,289 \\
$\mathrm{P}_{\mathrm{ne}}{ }^{7}$ & 0,071 & 0,096 \\
$\mathrm{P}_{\mathrm{nu}}{ }^{8}$ & 0,049 & 0,034 \\
$\mathrm{P}_{\mathrm{nn}}^{9}$ & 0,880 & 0,870 \\
\hline
\end{tabular}

Fonte: Construído pela autora com base na PME

${ }^{1} \mathrm{P}_{\mathrm{ee}}$ : probabilidade de um indivíduo empregado no período $t$, continuar empregado em $t+1$

${ }^{2} \mathrm{P}_{\mathrm{eu}}$ : probabilidade de um indivíduo empregado em $t$, ficar desempregado em $t+1$

${ }^{3} \mathrm{P}_{\mathrm{en}}$ : probabilidade de um indivíduo empregado em $t$, sair da força de trabalho em $t+1$

${ }^{4} \mathrm{P}_{\mathrm{ue}}$ : probabilidade de um indivíduo desempregado em $t$, conseguir um emprego em $t+1$

${ }^{5} \mathrm{P}_{\text {uu }}$ : probabilidade de um indivíduo desempregado em $t$, continuar desempregado em $t+1$

${ }^{6} \mathrm{P}_{\mathrm{un}}$ : probabilidade de um indivíduo desempregado em $t$, sair da força de trabalho em $t+1$

${ }^{7} \mathrm{P}_{\text {ne: }}$ : probabilidade de um indivíduo inativo em $t$, entrar na força de trabalho como empregado em $t+1$

${ }^{8} \mathrm{P}_{\mathrm{nu}}$ : probabilidade de um indivíduo inativo em $t$, entrar na força de trabalho desempregado em $t+1$

${ }^{9} \mathrm{P}_{\mathrm{nn}}$ : probabilidade de um indivíduo inativo em $t$, continuar inativo em $t+1$

Como ilustração, para São Paulo, comparando essas probabilidades de jovens e adultos, observa-se que, se o indivíduo encontra-se empregado, a probabilidade de continuar no emprego é maior quando ele é adulto $(94,6 \%)$ do que quando é jovem (89,9\%); caso o indivíduo esteja desempregado em um determinado mês, ocorre o contrário (com exceção de Belo Horizonte, Porto Alegre e Salvador, embora a diferença seja muito pequena), a probabilidade dele continuar desempregado no próximo mês é 
maior se for jovem (49,3\% contra 45\% do adulto); no caso da inatividade, a probabilidade de continuar inativo é bem próxima para as duas categorias. Estando empregado, a probabilidade do jovem perder o emprego é quase o dobro (3\%) da do adulto (1,6\%); e a probabilidade do jovem ir do emprego para fora da força de trabalho de um mês para o outro é de $7,1 \%$ contra $3,8 \%$ do adulto. Encontrando-se desempregado, a probabilidade do jovem estar empregado no próximo mês é bem menor que a do adulto, 18,6\% contra 26,1\%; e a probabilidade do jovem desistir e sair do mercado de trabalho $32,1 \%$ contra 28,9\% do adulto. Finalmente, ao se encontrar fora da força de trabalho, o adulto tem maior probabilidade de entrar diretamente empregado (9,6\%) que o jovem (7,1\%), com exceção do ano de 1986 para São Paulo; e a probabilidade do jovem entrar para o mercado via desemprego é maior do que a do adulto, 4,9\% contra 3,4\%, exceto em Recife e Salvador.

Com esses resultados, conclui-se que na maioria dos cenários analisados, independentemente da idade, em $t+1$, maiores são as probabilidades do indivíduo continuar no mesmo estado em que se encontrava em $t$. Estando em qualquer dos três estados em $t$, o adulto sempre tem maior probabilidade de estar empregado em $t+1$ que o jovem, com exceção de 1986 para São Paulo. Do mesmo modo, em qualquer dos três estados, o jovem tem maior chance que o adulto de encontrar-se desempregado ou inativo no próximo mês.

A seguir, encontram-se as estimativas para as frações de tempo gasto em cada estado do mercado de trabalho $\left(\pi_{\mathrm{e}}, \pi_{\mathrm{u}}, \pi_{\mathrm{n}}\right)$ para jovens e adultos, e suas respectivas taxas de desemprego de estado estacionário e as observadas na PME, na Tabela 3 para a região metropolitana de São Paulo em 2001, e, no Anexo A na Tabela 3.2 para as outras cinco regiões e na Tabela 3.7 para os outros anos na região de São Paulo. 
TABELA 3

Fração de tempo gasto em cada estado do mercado de trabalho e taxa de desemprego de jovens e adultos, São Paulo, 2001

\begin{tabular}{cccccc}
\hline \hline & \multicolumn{3}{c}{ FRAÇÃO DE TEMPO } & \multicolumn{2}{c}{ TAXA DE } \\
DESEMPREGO
\end{tabular}

Fonte: Construído pela autora com base na PME

Para os jovens da amostra, a maior parte do tempo é gasta na inatividade. Quase a mesma porcentagem é gasta no emprego, e em apenas 7,2\% do tempo os jovens estão desempregados. Resultados esses que geraram uma taxa de desemprego de estado estacionário de 13,5\%, enquanto a taxa calculada, levando em consideração o número de pessoas $(U /(U+E))$, ou seja, a taxa de desemprego observada na PME, foi de 13,8\%. Já os adultos encontram-se empregados grande parte do tempo, em pouco mais de $25 \%$ do tempo estão inativos, e apenas 3,7\% é gasto no desemprego, gerando uma taxa de desemprego de estado estacionário de 5,2\%, enquanto a taxa observada é de $5,1 \%{ }^{23}$. Pode-se concluir que os adultos passam mais tempo empregados, e os jovens passam mais tempo desempregados e na inatividade, resultando em uma taxa de desemprego juvenil que é mais que o dobro da do adulto.

O próximo passo é realizar o mesmo exercício para achar a fração do tempo que cada categoria gasta em cada estado do mercado de trabalho, porém, ao invés de usar a matriz completa da categoria, substitui-se, uma de cada vez, as linhas da matriz de uma categoria pela da outra. Primeiramente, usando a matriz de probabilidade de transição dos jovens e substituindo a primeira linha, ou seja, as probabilidades de transição do

\footnotetext{
${ }^{23}$ Taxas de desemprego efetiva e calculada pela matriz tão próximas, tanto para jovens como para adultos, indicariam que a hipótese forte de Markov não está viesando os resultados.
} 
emprego para os três estados, pela primeira linha da matriz dos adultos, observa-se como seria o tempo gasto em cada estado e o comportamento da taxa de desemprego caso o jovem tivesse as mesmas probabilidades de transição do emprego dos adultos; e, do mesmo modo, usando a matriz dos adultos e substituindo a primeira linha pela dos jovens, tem-se como seria o comportamento da taxa do adulto caso tivesse as probabilidades de transição do emprego dos jovens. Os resultados encontram-se na Tabela 4, abaixo para a região metropolitana de São Paulo em 2001, e, no Anexo A na Tabela 3.3 para as outras cinco regiões e na Tabela 3.8 para os outros anos na região de São Paulo:

\section{TABELA 4}

Fração de tempo no mercado de trabalho e taxa de desemprego de jovens e adultos, substituindo a primeira linha das matrizes, São Paulo, 2001

\begin{tabular}{ccccc}
\hline \hline & & & FRAÇÃO DE TEMPO & TAXA DE \\
CATEGORIAS & $\begin{array}{c}\pi_{\mathrm{e}}(\text { no } \\
\text { emprego })\end{array}$ & $\begin{array}{c}\pi_{\mathrm{u}} \text { (no } \\
\text { desemprego })\end{array}$ & $\begin{array}{c}\pi_{\mathrm{n}} \text { (na } \\
\text { inatividade) }\end{array}$ & $\begin{array}{c}\pi_{\mathrm{u}} /\left(\pi_{\mathrm{u}}+\pi_{\mathrm{e}}\right) \\
(\%)\end{array}$ \\
\hline JOVENS & 0,615 & 0,052 & 0,333 & 7,8 \\
ADULTOS & 0,533 & 0,055 & 0,412 & 9,4 \\
\hline \hline
\end{tabular}

Fonte: Construído pela autora com base na PME

Com as probabilidades do adulto, o jovem aumentaria sensivelmente seu tempo no emprego (de 46,1\% para 61,5\%) e diminuiria o tempo no desemprego (de 7,2\% para $5,2 \%$ ) e na inatividade (de $46,7 \%$ para $33,3 \%$ ); assim como a taxa de desemprego diminuiu quase pela metade (de 13,5\% para 7,8\%). O adulto, com as probabilidades do jovem, diminuiria seu tempo no emprego (de $68,1 \%$ para 53,3\%) e aumentaria o tempo no desemprego (de 3,7\% para 5,5\%) e na inatividade (de $28,2 \%$ para $41,2 \%$ ); a taxa de desemprego quase dobra de valor (de 5,2\% para 9,4\%). Por enquanto, observa-se uma importância significativa da probabilidade de transição do emprego para a determinação da alta taxa de desemprego do jovem e da relativa baixa taxa do adulto. 
Da mesma maneira como foi feito na tabela acima, na Tabela 5 para a região metropolitana de São Paulo, substitui-se a segunda linha da matriz de cada categoria pela da outra. No Anexo A, na Tabela 3.4 encontram-se os resultados para as outras cinco regiões e na Tabela 3.9 para os outros anos na região de São Paulo. Obtêm-se como resultados, o comportamento da taxa de desemprego do jovem caso suas probabilidades de transição do desemprego para os três estados fossem como as do adulto, e o comportamento da do adulto com as probabilidades de desemprego do jovem:

TABELA 5

Fração de tempo no mercado de trabalho e taxa de desemprego de jovens e adultos, substituindo a segunda linha das matrizes, São Paulo, 2001

\begin{tabular}{ccccc}
\hline \hline & & & FRAÇÃO DE TEMPO & TAXA DE \\
CATEGORIAS & $\begin{array}{c}\pi_{\mathrm{e}}(\mathrm{no} \\
\text { emprego })\end{array}$ & $\begin{array}{c}\pi_{\mathrm{u}} \text { (no } \\
\text { desemprego })\end{array}$ & $\begin{array}{c}\pi_{\mathrm{n}} \text { (na } \\
\text { inatividade) }\end{array}$ & $\begin{array}{c}\pi_{\mathrm{u}} /\left(\pi_{\mathrm{u}}+\pi_{\mathrm{e}}\right) \\
(\%)\end{array}$ \\
\hline JOVENS & 0,486 & 0,066 & 0,448 & 12,0 \\
ADULTOS & 0,664 & 0,041 & 0,295 & 5,8 \\
\hline \hline
\end{tabular}

Fonte: Construído pela autora com base na PME

Observa-se que essa substituição das probabilidades de transição do desemprego de uma categoria pela da outra não gera uma diferença muito significativa nos resultados, nem para jovens nem para adultos. A taxa de desemprego do jovem cai (de 13,5\% para 12\%), mas não tanto quanto na substituição anterior, e a do adulto sobe (de 5,2\% para 5,8\%), mas também em magnitude reduzida. Por esses resultados, não se pode afirmar que a transição do desemprego é tão importante na determinação da magnitude da taxa de desemprego.

Novamente, na Tabela 6 para a região metropolitana de São Paulo, substitui-se a terceira linha da matriz de cada categoria pela da outra. No Anexo A, na Tabela 3.5 
encontram-se os resultados para as outras cinco regiões e na Tabela 3.10 para os outros anos na região de São Paulo. Os resultados mostrarão os comportamentos de jovens e adultos, e suas respectivas taxas de desemprego, caso suas probabilidades de transição da inatividade para os três estados fossem como as da outra categoria:

TABELA 6

Fração de tempo no mercado de trabalho e taxa de desemprego de jovens e adultos, substituindo a terceira linha das matrizes, São Paulo, 2001

\begin{tabular}{ccccc}
\hline & \multicolumn{3}{c}{ FRAÇÃO DE TEMPO } & $\begin{array}{c}\text { TAXA DE } \\
\text { DESEMPREGO }\end{array}$ \\
\hline CATEGORIAS & $\begin{array}{c}\pi_{\mathrm{e}}(\mathrm{no} \\
\text { emprego })\end{array}$ & $\begin{array}{c}\pi_{\mathrm{u}}(\mathrm{no} \\
\text { desemprego })\end{array}$ & $\begin{array}{c}\pi_{\mathrm{n}}(\mathrm{na} \\
\text { inatividade })\end{array}$ & $\begin{array}{c}\pi_{\mathrm{u}} /\left(\pi_{\mathrm{u}}+\pi_{\mathrm{e}}\right) \\
(\%)\end{array}$ \\
\hline JOVENS & 0,514 & 0,059 & 0,427 & 10,3 \\
ADULTOS & 0,639 & 0,047 & 0,314 & 6,9 \\
\hline \hline
\end{tabular}

Fonte: Construído pela autora com base na PME

De acordo com a tabela acima, é possível notar uma pequena redução na taxa de desemprego do jovem (de 13,5\% para 10,3\%), e um aumento na taxa do adulto (de 5,2\% par 6,9\%). Essa melhora da taxa de desemprego do jovem vem de pequenas variações nas frações de tempo gasto nos estados de mercado de trabalho, com aumento no emprego, e diminuição no desemprego e na inatividade. O aumento na taxa do adulto também é devido a pequenas variações, com diminuição no tempo de emprego e aumento no tempo de desemprego e de inatividade. Apesar dessa substituição (inatividade) gerar uma diferença maior do que a anterior (desemprego), em relação aos resultados originais, ela ainda não é tão significante como a substituição das probabilidades de transição do emprego.

A partir dessas simulações, constata-se que a menor probabilidade de continuar empregado, a maior probabilidade de ficar desempregado ou sair da força de trabalho, em relação ao adulto, que o jovem apresenta uma vez empregado, são os principais 
determinantes da sua alta taxa de desemprego. Pode-se concluir que estando o jovem empregado, o comportamento da transição do emprego para os três estados do mercado de trabalho é o responsável por uma taxa de desemprego tão alta, uma vez que ao substituí-la pelo comportamento dos adultos a taxa de desemprego dos jovens diminuiu sensivelmente; e, tendo a transição do emprego comportando-se como a do jovem, o adulto apresenta uma alta taxa de desemprego. Portanto, mais uma vez, conclui-se que o comportamento da transição do emprego para os três estados do mercado de trabalho é fator determinante da taxa de desemprego para todas as categorias. Esse resultado sugere, assim como no capítulo anterior, que as questões da rotatividade e da participação dos jovens que já tiveram empregos anteriores têm grande influência na elevada taxa de desemprego juvenil brasileira. 


\section{CAPÍTULO 4 - CONCLUSÃO}

Entender e saber identificar a dinâmica do desemprego juvenil é muito importante, pois conhecendo sua estrutura e determinantes é possível identificar o perfil dos trabalhadores desempregados e desenhar políticas de geração de emprego que tenham um enfoque mais adequado para integrá-los ao mercado de trabalho. E, como já foi mencionado, os índices de desemprego juvenil são muito altos (e superiores aos de trabalhadores mais velhos) em todo o mundo, o que leva essa questão a ser muito debatida nos trabalhos internacionais sobre mercado de trabalho, com exceção do Brasil, onde o tema apresenta poucos estudos, especialmente empíricos.

O emprego e o desemprego dos jovens são questões que vêm sendo objeto de preocupação crescente por parte dos governos e da sociedade, e a contribuição deste trabalho, foi mostrar empiricamente a concentração do desemprego dos jovens no Brasil, analisando seus determinantes e sua dinâmica, e identificando os motivos que levam o desemprego juvenil a ser tão superior ao desemprego de adultos.

Como nessa faixa etária concentra-se a maior parte das pessoas que procuram incorporar-se ao mercado de trabalho pela primeira vez, um dos argumentos para explicar o elevado desemprego é que o jovem tem dificuldade em conseguir o primeiro emprego. Mas, no segundo capítulo deste trabalho, mostrou-se que a duração do desemprego de jovens e de trabalhadores mais velhos é muito semelhante. A diferença entre esses dois grupos é a taxa de entrada no desemprego, muito maior para jovens. Efetuando a decomposição da taxa de entrada no desemprego, constatou-se que a parcela de jovens que está entrando na força de trabalho e procurando o primeiro emprego não é tão significante como a grande maioria que está entrando no desemprego por perder o emprego. No terceiro capítulo, ao testar as probabilidades de transição do mercado de trabalho, verificou-se que, seja jovem ou adulto, o fator determinante da alta ou baixa taxa de desemprego é a transição do emprego. 
Com isso, então, pode-se responder a questão proposta na introdução desse estudo: será mesmo a dificuldade em obter o primeiro emprego que faz com que os jovens apresentem uma taxa de desemprego tão elevada, ou será a alta rotatividade no mercado de trabalho juvenil? Constatou-se que o jovem entra e sai de um emprego em um curto período de tempo. Assim, em relação a adultos e idosos, a duração no emprego é que é baixa, e não a duração no desemprego que é alta. A dificuldade está, pois, em permanecer no emprego por um período de tempo mais longo, e não em encontrar o emprego, seja ele o primeiro ou não. Isso faz sentido, uma vez que o jovem está começando a trabalhar e é longo o tempo de busca de uma inserção estável no mercado de trabalho. Portanto, o jovem que já esteve empregado anteriormente responde em grande parte pela magnitude dessa taxa de desemprego, e não o que nunca trabalhou e está em busca do seu primeiro emprego.

Os resultados encontrados neste trabalho corroboram trabalhos anteriores quando mostram que os jovens apresentam uma alta rotatividade no mercado de trabalho, ou seja, trocam de emprego com mais freqüência, mas indicam, além disso, que essa rotatividade é o principal motivo por uma taxa de desemprego de jovens tão elevada e tão superior a de trabalhadores mais velhos. 

TABELA 2.1

Taxas de desemprego e entrada, duração média completa e incompleta do desemprego, segundo faixa etária, São Paulo, 1983-2002

\begin{tabular}{|c|c|c|c|c|c|c|c|c|c|c|c|c|}
\hline \multirow[b]{2}{*}{ Ano } & \multicolumn{4}{|c|}{ JOVEM } & \multicolumn{4}{|c|}{ ADULTO } & \multicolumn{4}{|c|}{ IDOSO } \\
\hline & $\begin{array}{c}T D \\
(U / N)^{1}\end{array}$ & $\begin{array}{c}T E \\
(S / N)^{2}\end{array}$ & $\begin{array}{l}D M C \\
(U / S)^{3}\end{array}$ & $D M I^{4}$ & $\begin{array}{c}T D \\
(U / N)\end{array}$ & $\begin{array}{c}T E \\
(S / N)\end{array}$ & $\begin{array}{l}D M C \\
(U / S)\end{array}$ & $\overline{D M I}$ & $\begin{array}{c}T D \\
(U / N)\end{array}$ & $\begin{array}{c}T E \\
(S / N)\end{array}$ & $\begin{array}{l}D M C \\
(U / S)\end{array}$ & $\overline{D M I}$ \\
\hline 1983 & 13,77 & 4,45 & 3,10 & 4,01 & 4,43 & 1,20 & 3,69 & 4,36 & 1,74 & 0,87 & 2,00 & 1,56 \\
\hline 1984 & 15,17 & 4,88 & 3,11 & 3,88 & 4,41 & 1,39 & 3,17 & 3,91 & 1,19 & 0,60 & 2,00 & 2,55 \\
\hline 1985 & 8,59 & 3,62 & 2,37 & 3,34 & 2,26 & 0,83 & 2,73 & 3,31 & 0,65 & 0,32 & 2,00 & 9,50 \\
\hline 1986 & 7,05 & 3,36 & 2,10 & 2,56 & 2,18 & 0,60 & 3,63 & 2,75 & 0,90 & 0,08 & 11,00 & 5,95 \\
\hline 1987 & 8,66 & 3,40 & 2,54 & 2,75 & 2,38 & 0,95 & 2,51 & 2,63 & 0,82 & 0,00 & 0,00 & 3,33 \\
\hline 1988 & 9,81 & 3,72 & 2,63 & 2,91 & 3,00 & 1,14 & 2,64 & 3,16 & 0,60 & 0,26 & 2,33 & 2,14 \\
\hline 1989 & 4,92 & 2,33 & 2,11 & 2,61 & 1,50 & 0,50 & 3,00 & 3,05 & 0,48 & 0,48 & 1,00 & 0,75 \\
\hline 1990 & 10,71 & 3,97 & 2,70 & 2,99 & 3,40 & 1,21 & 2,80 & 2,99 & 0,67 & 0,38 & 1,75 & 3,36 \\
\hline 1991 & 11,19 & 4,12 & 2,72 & 3,39 & 3,86 & 0,92 & 4,20 & 3,70 & 0,39 & 0,00 & 0,00 & 3,00 \\
\hline 1992 & 15,78 & 4,00 & 3,94 & 4,00 & 4,74 & 1,18 & 4,03 & 4,01 & 1,36 & 0,21 & 6,50 & 6,17 \\
\hline 1993 & 12,44 & 3,33 & 3,73 & 5,27 & 4,64 & 0,94 & 4,91 & 5,14 & 0,43 & 0,00 & 0,00 & 24,00 \\
\hline 1994 & 14,39 & 3,92 & 3,67 & 4,65 & 4,12 & 1,18 & 3,50 & 4,44 & 1,38 & 0,21 & 6,50 & 6,21 \\
\hline 1995 & 13,58 & 2,90 & 4,68 & 5,03 & 4,67 & 0,94 & 4,96 & 3,98 & 0,00 & 0,00 & 0,00 & 0,00 \\
\hline 1996 & 15,57 & 3,81 & 4,09 & 4,39 & 5,15 & 1,27 & 4,06 & 4,91 & 1,17 & 0,09 & 13,00 & 5,65 \\
\hline 1997 & 14,42 & 3,85 & 3,75 & 5,41 & 5,72 & 1,14 & 5,00 & 5,75 & 1,75 & 0,70 & 2,50 & 3,90 \\
\hline 1998 & 20,30 & 3,56 & 5,70 & 5,87 & 6,95 & 1,21 & 5,74 & 6,75 & 1,99 & 0,09 & 22,00 & 8,72 \\
\hline 1999 & 19,05 & 4,14 & 4,60 & 6,45 & 6,60 & 0,97 & 6,82 & 7,90 & 2,00 & 0,40 & 5,00 & 26,35 \\
\hline 2000 & 17,64 & 4,47 & 3,95 & 5,23 & 5,62 & 1,54 & 3,65 & 4,92 & 1,27 & 0,53 & 2,38 & 5,61 \\
\hline 2001 & 15,10 & 3,46 & 4,36 & 5,75 & 6,79 & 1,40 & 4,85 & 8,25 & 2,21 & 0,00 & 0,00 & 6,83 \\
\hline $2002 *$ & 19,65 & 3,30 & 5,96 & 5,61 & 7,09 & 1,36 & 5,20 & 6,30 & 2,02 & 0,00 & 0,00 & 7,18 \\
\hline
\end{tabular}

Fonte: Construído pela autora com base na PME

${ }^{1} \mathrm{TD}(\mathrm{U} / \mathrm{N})$ : taxa de desemprego, em porcentagem (indivíduos desempregados/indivíduos empregados)

${ }^{2} \mathrm{TE}(\mathrm{S} / \mathrm{N})$ : taxa de entrada no desemprego por mês, em porcentagem, (indivíduos que entraram no desemprego em um mês ou menos/indivíduos empregados)

${ }^{3} \mathrm{DMC}$ (U/S): duração média completa do desemprego de estado estacionário, em meses (indivíduos desempregados/indivíduos que entraram no desemprego em um mês ou menos)

${ }^{4}$ DMI: duração média incompleta do desemprego corrente, em meses, (razão entre a soma da duração do desemprego de cada indivíduo desempregado e o número total de desempregados)

* Para o ano de 2002, os dados se restringem apenas aos seis primeiros meses do ano (janeiro a junho) 
TABELA 2.2

Taxas de desemprego e entrada, duração média completa e incompleta do desemprego, segundo faixa etária, Belo Horizonte, 1983-2002

\begin{tabular}{|c|c|c|c|c|c|c|c|c|c|c|c|c|}
\hline \multirow[b]{2}{*}{ Ano } & \multicolumn{4}{|c|}{ JOVEM } & \multicolumn{4}{|c|}{ ADULTO } & \multicolumn{4}{|c|}{ IDOSO } \\
\hline & $\begin{array}{c}T D \\
(U / N)^{1}\end{array}$ & $\begin{array}{c}T E \\
(S / N)^{2}\end{array}$ & $\begin{array}{c}D M C \\
(U / S)^{3}\end{array}$ & $D M I^{4}$ & $\begin{array}{c}T D \\
(U / N)\end{array}$ & $\begin{array}{c}T E \\
(S / N)\end{array}$ & $\begin{array}{l}D M C \\
(U / S)\end{array}$ & $D M I$ & $\begin{array}{c}T D \\
(U / N)\end{array}$ & $\begin{array}{c}T E \\
(S / N)\end{array}$ & $\begin{array}{l}D M C \\
(U / S)\end{array}$ & $D M I$ \\
\hline 1983 & 16,88 & 7,32 & 2,31 & 3,23 & 5,43 & 2,28 & 2,38 & 3,23 & 1,42 & 0,47 & 3,00 & 5,00 \\
\hline 1984 & 18,65 & 8,21 & 2,27 & 2,94 & 5,40 & 2,09 & 2,58 & 3,22 & 2,00 & 0,94 & 2,13 & 3,32 \\
\hline 1985 & 9,34 & 5,14 & 1,82 & 2,30 & 2,07 & 0,91 & 2,27 & 3,04 & 0,47 & 0,47 & 1,00 & 0,75 \\
\hline 1986 & 7,72 & 4,10 & 1,88 & 2,13 & 2,15 & 1,14 & 1,88 & 2,33 & 0,64 & 0,11 & 6,00 & 2,33 \\
\hline 1987 & 6,96 & 3,19 & 2,18 & 2,28 & 2,10 & 1,09 & 1,93 & 1,89 & 0,40 & 0,00 & 0,00 & 4,00 \\
\hline 1988 & 8,90 & 4,35 & 2,04 & 2,20 & 2,68 & 1,23 & 2,19 & 2,37 & 0,82 & 0,12 & 7,00 & 8,21 \\
\hline 1989 & 7,01 & 4,07 & 1,72 & 1,78 & 1,74 & 0,82 & 2,12 & 2,29 & 1,65 & 0,55 & 3,00 & 3,00 \\
\hline 1990 & 8,98 & 4,16 & 2,16 & 2,19 & 2,65 & 1,19 & 2,22 & 2,29 & 0,49 & 0,37 & 1,33 & 9,38 \\
\hline 1991 & 6,91 & 3,71 & 1,86 & 2,17 & 2,40 & 0,93 & 2,60 & 3,24 & 0,00 & 0,00 & 0,00 & 0,00 \\
\hline 1992 & 10,11 & 3,92 & 2,58 & 2,71 & 3,46 & 1,22 & 2,84 & 2,95 & 0,94 & 0,13 & 7,00 & 4,50 \\
\hline 1993 & 10,46 & 4,04 & 2,59 & 2,62 & 3,31 & 1,51 & 2,19 & 2,54 & 0,60 & 0,60 & 1,00 & 1,00 \\
\hline 1994 & 9,62 & 4,34 & 2,21 & 2,60 & 3,04 & 1,30 & 2,34 & 2,82 & 0,55 & 0,00 & 0,00 & 3,38 \\
\hline 1995 & 9,24 & 4,49 & 2,06 & 2,39 & 2,72 & 0,99 & 2,74 & 2,76 & 0,44 & 0,00 & 0,00 & 6,50 \\
\hline 1996 & 10,40 & 4,72 & 2,20 & 2,50 & 3,47 & 1,35 & 2,57 & 3,01 & 1,07 & 0,24 & 4,50 & 6,83 \\
\hline 1997 & 10,10 & 3,45 & 2,93 & 2,93 & 3,60 & 1,29 & 2,80 & 3,31 & 0,52 & 0,00 & 0,00 & 3,00 \\
\hline 1998 & 14,93 & 5,22 & 2,86 & 3,26 & 5,03 & 1,80 & 2,80 & 3,75 & 1,19 & 0,26 & 4,50 & 6,64 \\
\hline 1999 & 19,77 & 8,73 & 2,26 & 3,22 & 6,51 & 3,03 & 2,15 & 3,17 & 2,58 & 1,29 & 2,00 & 2,54 \\
\hline 2000 & 17,77 & 7,23 & 2,46 & 3,21 & 5,80 & 2,36 & 2,45 & 3,34 & 2,56 & 0,94 & 2,71 & 4,06 \\
\hline 2001 & 16,32 & 5,67 & 2,88 & 3,80 & 5,56 & 1,62 & 3,43 & 4,24 & 1,36 & 0,90 & 1,50 & 1,67 \\
\hline 2002 & 15,79 & 4,78 & 3,31 & 3,63 & 5,93 & 1,79 & 3,30 & 4,27 & 1,88 & 0,47 & 4,00 & 4,56 \\
\hline
\end{tabular}

Fonte: Construído pela autora com base na PME

${ }^{1} \mathrm{TD}(\mathrm{U} / \mathrm{N})$ : taxa de desemprego, em porcentagem (indivíduos desempregados/indivíduos empregados)

${ }^{2} \mathrm{TE}(\mathrm{S} / \mathrm{N})$ : taxa de entrada no desemprego por mês, em porcentagem, (indivíduos que entraram no desemprego em um mês ou menos/indivíduos empregados)

${ }^{3} \mathrm{DMC}$ (U/S): duração média completa do desemprego de estado estacionário, em meses (indivíduos desempregados/indivíduos que entraram no desemprego em um mês ou menos)

${ }^{4}$ DMI: duração média incompleta do desemprego corrente, em meses, (razão entre a soma da duração do desemprego de cada indivíduo desempregado e o número total de desempregados)

* Para o ano de 2002, os dados se restringem apenas aos seis primeiros meses do ano (janeiro a junho) 
TABELA 2.3

Taxas de desemprego e entrada, duração média completa e incompleta do desemprego, segundo faixa etária, Rio de Janeiro, 1983-2002

\begin{tabular}{|c|c|c|c|c|c|c|c|c|c|c|c|c|}
\hline \multirow[b]{2}{*}{ Ano } & \multicolumn{4}{|c|}{ JOVEM } & \multicolumn{4}{|c|}{ ADULTO } & \multicolumn{4}{|c|}{ IDOSO } \\
\hline & $\begin{array}{c}T D \\
(U / N)^{1}\end{array}$ & $\begin{array}{c}T E \\
(S / N)^{2}\end{array}$ & $\begin{array}{l}D M C \\
(U / S)^{3}\end{array}$ & $D M I^{4}$ & $\begin{array}{c}T D \\
(U / N)\end{array}$ & $\begin{array}{c}T E \\
(S / N)\end{array}$ & $\begin{array}{l}D M C \\
(U / S)\end{array}$ & $D M I$ & $\begin{array}{c}T D \\
(U / N)\end{array}$ & $\begin{array}{c}T E \\
(S / N)\end{array}$ & $\begin{array}{l}D M C \\
(U / S)\end{array}$ & $D M I$ \\
\hline 1983 & 12,85 & 4,28 & 3,00 & 3,77 & 3,54 & 1,01 & 3,51 & 4,90 & 0,32 & 0,32 & 1,00 & 1,00 \\
\hline 1984 & 17,72 & 5,33 & 3,33 & 4,07 & 4,37 & 1,40 & 3,13 & 4,13 & 1,46 & 0,58 & 2,50 & 4,74 \\
\hline 1985 & 8,67 & 2,55 & 3,40 & 3,56 & 2,55 & 1,01 & 2,53 & 3,89 & 0,00 & 0,00 & 0,00 & 0,00 \\
\hline 1986 & 8,90 & 2,95 & 3,02 & 3,85 & 2,31 & 0,75 & 3,06 & 4,23 & 0,21 & 0,14 & 1,50 & 3,33 \\
\hline 1987 & 6,52 & 1,88 & 3,48 & 3,99 & 1,98 & 0,58 & 3,42 & 3,89 & 0,50 & 0,25 & 2,00 & 2,00 \\
\hline 1988 & 7,46 & 2,56 & 2,91 & 3,22 & 2,39 & 0,80 & 2,99 & 3,34 & 0,48 & 0,00 & 0,00 & 3,33 \\
\hline 1989 & 6,61 & 2,57 & 2,57 & 3,01 & 1,68 & 0,73 & 2,29 & 3,79 & 0,00 & 0,00 & 0,00 & 0,00 \\
\hline 1990 & 8,32 & 2,95 & 2,82 & 3,00 & 2,96 & 0,91 & 3,25 & 3,67 & 0,18 & 0,00 & 0,00 & 2,00 \\
\hline 1991 & 9,58 & 3,42 & 2,80 & 2,93 & 2,78 & 0,96 & 2,91 & 3,53 & 0,37 & 0,37 & 1,00 & 1,00 \\
\hline 1992 & 10,31 & 2,77 & 3,72 & 4,07 & 3,28 & 0,80 & 4,13 & 4,94 & 1,04 & 0,19 & 5,50 & 4,82 \\
\hline 1993 & 12,16 & 1,73 & 7,05 & 4,93 & 3,67 & 0,66 & 5,56 & 6,42 & 0,66 & 0,00 & 0,00 & 7,00 \\
\hline 1994 & 10,03 & 3,07 & 3,27 & 4,36 & 3,79 & 0,83 & 4,57 & 5,73 & 0,88 & 0,09 & 10,00 & 11,03 \\
\hline 1995 & 12,07 & 3,17 & 3,81 & 3,85 & 3,06 & 0,66 & 4,67 & 4,64 & 0,00 & 0,00 & 0,00 & 0,00 \\
\hline 1996 & 9,63 & 2,66 & 3,62 & 3,76 & 3,19 & 0,93 & 3,43 & 5,00 & 0,88 & 0,35 & 2,50 & 16,20 \\
\hline 1997 & 11,85 & 2,68 & 4,43 & 4,89 & 3,99 & 0,81 & 4,92 & 6,08 & 1,25 & 0,00 & 0,00 & 5,50 \\
\hline 1998 & 15,32 & 3,08 & 4,98 & 5,10 & 5,22 & 0,82 & 6,35 & 6,47 & 1,59 & 0,08 & 19,00 & 7,26 \\
\hline 1999 & 14,47 & 2,25 & 6,43 & 6,04 & 4,60 & 0,52 & 8,77 & 6,16 & 3,91 & 0,71 & 5,50 & 9,91 \\
\hline 2000 & 12,39 & 2,65 & 4,67 & 5,08 & 4,30 & 0,85 & 5,08 & 6,53 & 1,61 & 0,20 & 8,00 & 10,43 \\
\hline 2001 & 14,91 & 3,03 & 4,93 & 5,65 & 5,40 & 0,80 & 6,78 & 6,85 & 2,61 & 0,00 & 0,00 & 3,36 \\
\hline 2002 & 16,49 & 3,65 & 4,51 & 4,95 & 5,05 & 1,20 & 4,20 & 6,22 & 1,07 & 0,24 & 4,50 & 3,86 \\
\hline
\end{tabular}

Fonte: Construído pela autora com base na PME

${ }^{1} \mathrm{TD}(\mathrm{U} / \mathrm{N})$ : taxa de desemprego, em porcentagem (indivíduos desempregados/indivíduos empregados)

${ }^{2} \mathrm{TE}(\mathrm{S} / \mathrm{N})$ : taxa de entrada no desemprego por mês, em porcentagem, (indivíduos que entraram no desemprego em um mês ou menos/indivíduos empregados)

${ }^{3} \mathrm{DMC}$ (U/S): duração média completa do desemprego de estado estacionário, em meses (indivíduos desempregados/indivíduos que entraram no desemprego em um mês ou menos)

${ }^{4}$ DMI: duração média incompleta do desemprego corrente, em meses, (razão entre a soma da duração do desemprego de cada indivíduo desempregado e o número total de desempregados)

* Para o ano de 2002, os dados se restringem apenas aos seis primeiros meses do ano (janeiro a junho) 
TABELA 2.4

Taxas de desemprego e entrada, duração média completa e incompleta do desemprego, segundo faixa etária, Porto Alegre, 1983-2002

\begin{tabular}{|c|c|c|c|c|c|c|c|c|c|c|c|c|}
\hline \multirow[b]{2}{*}{ Ano } & \multicolumn{4}{|c|}{ JOVEM } & \multicolumn{4}{|c|}{ ADULTO } & \multicolumn{4}{|c|}{ IDOSO } \\
\hline & $\begin{array}{c}T D \\
(U / N)^{1}\end{array}$ & $\begin{array}{c}T E \\
(S / N)^{2}\end{array}$ & $\begin{array}{c}D M C \\
(U / S)^{3} \\
\end{array}$ & $D M I^{4}$ & $\begin{array}{c}T D \\
(U / N)\end{array}$ & $\begin{array}{c}T E \\
(S / N)\end{array}$ & $\begin{array}{l}D M C \\
(U / S)\end{array}$ & $D M I$ & $\begin{array}{c}T D \\
(U / N)\end{array}$ & $\begin{array}{c}T E \\
(S / N)\end{array}$ & $\begin{array}{l}D M C \\
(U / S)\end{array}$ & $D M I$ \\
\hline 1983 & 12,60 & 4,85 & 2,60 & 3,29 & 4,20 & 1,44 & 2,91 & 2,90 & 0,56 & 0,00 & 0,00 & 2,00 \\
\hline 1984 & 16,39 & 6,63 & 2,47 & 2,94 & 4,73 & 2,00 & 2,37 & 3,13 & 1,85 & 0,62 & 3,00 & 2,87 \\
\hline 1985 & 9,31 & 4,33 & 2,15 & 2,60 & 2,85 & 1,17 & 2,44 & 2,93 & 0,50 & 0,00 & 0,00 & 4,00 \\
\hline 1986 & 9,24 & 4,09 & 2,26 & 2,69 & 2,45 & 1,12 & 2,18 & 2,88 & 0,86 & 0,37 & 2,33 & 3,50 \\
\hline 1987 & 7,71 & 2,92 & 2,64 & 2,60 & 2,26 & 0,98 & 2,30 & 2,51 & 0,00 & 0,00 & 0,00 & 0,00 \\
\hline 1988 & 8,29 & 4,00 & 2,07 & 2,42 & 2,47 & 1,07 & 2,30 & 2,79 & 0,79 & 0,26 & 3,00 & 4,92 \\
\hline 1989 & 5,00 & 2,35 & 2,13 & 2,70 & 1,00 & 0,50 & 2,00 & 2,31 & 0,00 & 0,00 & 0,00 & 0,00 \\
\hline 1990 & 8,51 & 4,06 & 2,10 & 2,39 & 2,80 & 1,20 & 2,33 & 2,49 & 0,76 & 0,13 & 6,00 & 2,42 \\
\hline 1991 & 8,68 & 2,89 & 3,00 & 2,86 & 3,23 & 0,92 & 3,52 & 3,21 & 0,63 & 0,00 & 0,00 & 5,00 \\
\hline 1992 & 13,47 & 5,03 & 2,68 & 3,34 & 4,66 & 1,34 & 3,49 & 3,70 & 1,04 & 0,00 & 0,00 & 3,63 \\
\hline 1993 & 9,74 & 3,59 & 2,71 & 3,18 & 2,58 & 0,61 & 4,22 & 4,38 & 0,00 & 0,00 & 0,00 & 0,00 \\
\hline 1994 & 8,91 & 3,24 & 2,75 & 3,53 & 3,42 & 0,94 & 3,64 & 3,88 & 1,10 & 0,37 & 3,00 & 5,50 \\
\hline 1995 & 10,64 & 4,05 & 2,63 & 3,92 & 4,68 & 1,34 & 3,48 & 4,24 & 0,63 & 0,00 & 0,00 & 24,00 \\
\hline 1996 & 14,99 & 4,20 & 3,57 & 4,25 & 5,01 & 1,39 & 3,61 & 4,80 & 1,17 & 0,44 & 2,67 & 4,41 \\
\hline 1997 & 11,37 & 3,01 & 3,78 & 4,75 & 4,12 & 1,09 & 3,79 & 4,68 & 0,56 & 0,00 & 0,00 & 10,00 \\
\hline 1998 & 17,48 & 4,62 & 3,79 & 4,97 & 6,13 & 1,54 & 3,98 & 5,22 & 2,49 & 0,69 & 3,60 & 6,10 \\
\hline 1999 & 18,11 & 3,90 & 4,64 & 6,01 & 5,70 & 1,31 & 4,35 & 7,65 & 3,17 & 1,06 & 3,00 & 6,50 \\
\hline 2000 & 16,82 & 4,50 & 3,73 & 5,14 & 5,58 & 1,50 & 3,72 & 5,93 & 1,93 & 0,49 & 3,93 & 11,30 \\
\hline 2001 & 14,02 & 2,73 & 5,14 & 6,00 & 4,89 & 0,78 & 6,27 & 7,26 & 1,05 & 0,00 & 0,00 & 13,00 \\
\hline 2002 & 14,72 & 3,25 & 4,53 & 6,38 & 5,15 & 0,93 & 5,55 & 7,96 & 1,75 & 0,29 & 6,00 & 5,46 \\
\hline
\end{tabular}

Fonte: Construído pela autora com base na PME

${ }^{1} \mathrm{TD}(\mathrm{U} / \mathrm{N})$ : taxa de desemprego, em porcentagem (indivíduos desempregados/indivíduos empregados)

${ }^{2} \mathrm{TE}(\mathrm{S} / \mathrm{N})$ : taxa de entrada no desemprego por mês, em porcentagem, (indivíduos que entraram no desemprego em um mês ou menos/indivíduos empregados)

${ }^{3} \mathrm{DMC}$ (U/S): duração média completa do desemprego de estado estacionário, em meses (indivíduos desempregados/indivíduos que entraram no desemprego em um mês ou menos)

${ }^{4}$ DMI: duração média incompleta do desemprego corrente, em meses, (razão entre a soma da duração do desemprego de cada indivíduo desempregado e o número total de desempregados)

* Para o ano de 2002, os dados se restringem apenas aos seis primeiros meses do ano (janeiro a junho) 
TABELA 2.5

Taxas de desemprego e entrada, duração média completa e incompleta do desemprego, segundo faixa etária, Recife, 1983-2002

\begin{tabular}{|c|c|c|c|c|c|c|c|c|c|c|c|c|}
\hline \multirow[b]{2}{*}{ Ano } & \multicolumn{4}{|c|}{ JOVEM } & \multicolumn{4}{|c|}{ ADULTO } & \multicolumn{4}{|c|}{ IDOSO } \\
\hline & $\begin{array}{c}T D \\
(U / N)^{1}\end{array}$ & $\begin{array}{c}T E \\
(S / N)^{2}\end{array}$ & $\begin{array}{l}D M C \\
(U / S)^{3}\end{array}$ & $D M I^{4}$ & $\begin{array}{c}T D \\
(U / N)\end{array}$ & $\begin{array}{c}T E \\
(S / N) \\
\end{array}$ & $\begin{array}{l}D M C \\
(U / S)\end{array}$ & $D M I$ & $\begin{array}{c}T D \\
(U / N)\end{array}$ & $\begin{array}{c}T E \\
(S / N)\end{array}$ & $\begin{array}{l}D M C \\
(U / S) \\
\end{array}$ & $D M I$ \\
\hline 1983 & 15,33 & 4,96 & 3,09 & 4,48 & 5,08 & 1,45 & 3,50 & 4,26 & 0,00 & 0,00 & 0,00 & 0,00 \\
\hline 1984 & 19,31 & 5,45 & 3,54 & 5,33 & 6,55 & 1,78 & 3,68 & 5,64 & 1,36 & 0,52 & 2,60 & 2,46 \\
\hline 1985 & 12,66 & 3,21 & 3,94 & 5,43 & 2,91 & 0,76 & 3,83 & 5,23 & 0,43 & 0,00 & 0,00 & 6,25 \\
\hline 1986 & 8,59 & 2,32 & 3,70 & 4,67 & 2,92 & 0,81 & 3,61 & 5,44 & 1,06 & 0,59 & 1,80 & 2,00 \\
\hline 1987 & 10,92 & 2,74 & 3,98 & 4,21 & 3,52 & 0,89 & 3,97 & 4,74 & 1,15 & 0,38 & 3,00 & 5,00 \\
\hline 1988 & 12,85 & 3,44 & 3,73 & 3,99 & 3,94 & 1,17 & 3,38 & 4,28 & 0,12 & 0,00 & 0,00 & 4,00 \\
\hline 1989 & 8,02 & 2,53 & 3,17 & 4,44 & 2,61 & 0,73 & 3,55 & 4,02 & 0,00 & 0,00 & 0,00 & 0,00 \\
\hline 1990 & 12,37 & 3,37 & 3,67 & 4,01 & 4,20 & 1,15 & 3,64 & 3,85 & 0,29 & 0,15 & 2,00 & 6,50 \\
\hline 1991 & 12,20 & 4,48 & 2,72 & 3,53 & 3,72 & 1,01 & 3,70 & 4,77 & 1,81 & 0,60 & 3,00 & 5,33 \\
\hline 1992 & 18,94 & 5,01 & 3,78 & 4,52 & 6,89 & 1,72 & 4,01 & 5,05 & 1,96 & 0,52 & 3,75 & 4,42 \\
\hline 1993 & 17,21 & 5,26 & 3,27 & 4,94 & 6,69 & 1,71 & 3,92 & 6,27 & 1,27 & 0,00 & 0,00 & 6,75 \\
\hline 1994 & 13,60 & 4,35 & 3,13 & 4,60 & 5,68 & 1,62 & 3,52 & 4,85 & 0,40 & 0,40 & 1,00 & 0,88 \\
\hline 1995 & 9,17 & 2,48 & 3,70 & 4,73 & 3,96 & 0,88 & 4,52 & 5,14 & 0,70 & 0,00 & 0,00 & 1,50 \\
\hline 1996 & 11,82 & 3,24 & 3,65 & 9,19 & 4,96 & 1,38 & 3,61 & 4,61 & 0,76 & 0,57 & 1,33 & 6,75 \\
\hline 1997 & 11,60 & 4,58 & 2,53 & 3,59 & 5,20 & 2,13 & 2,44 & 4,10 & 1,17 & 1,17 & 1,00 & 0,50 \\
\hline 1998 & 18,14 & 7,06 & 2,57 & 4,02 & 7,43 & 2,66 & 2,80 & 4,12 & 1,08 & 0,31 & 3,50 & 4,18 \\
\hline 1999 & 16,09 & 3,20 & 5,04 & 5,72 & 6,41 & 1,37 & 4,67 & 6,06 & 0,00 & 0,00 & 0,00 & 0,00 \\
\hline 2000 & 16,18 & 4,34 & 3,73 & 5,34 & 6,80 & 1,81 & 3,76 & 5,48 & 1,59 & 0,35 & 4,50 & 5,73 \\
\hline 2001 & 17,89 & 4,06 & 4,41 & 5,45 & 7,40 & 1,37 & 5,38 & 5,84 & 1,97 & 1,32 & 1,50 & 4,17 \\
\hline 2002 & 14,29 & 2,64 & 5,40 & 5,51 & 5,34 & 1,05 & 5,08 & 5,99 & 0,74 & 0,00 & 0,00 & 4,00 \\
\hline
\end{tabular}

Fonte: Construído pela autora com base na PME

${ }^{1} \mathrm{TD}(\mathrm{U} / \mathrm{N})$ : taxa de desemprego, em porcentagem (indivíduos desempregados/indivíduos empregados)

${ }^{2} \mathrm{TE}(\mathrm{S} / \mathrm{N})$ : taxa de entrada no desemprego por mês, em porcentagem, (indivíduos que entraram no desemprego em um mês ou menos/indivíduos empregados)

${ }^{3} \mathrm{DMC}$ (U/S): duração média completa do desemprego de estado estacionário, em meses (indivíduos desempregados/indivíduos que entraram no desemprego em um mês ou menos)

${ }^{4}$ DMI: duração média incompleta do desemprego corrente, em meses, (razão entre a soma da duração do desemprego de cada indivíduo desempregado e o número total de desempregados)

* Para o ano de 2002, os dados se restringem apenas aos seis primeiros meses do ano (janeiro a junho) 
TABELA 2.6

Taxas de desemprego e entrada, duração média completa e incompleta do desemprego, segundo faixa etária, Salvador, 1983-2002

\begin{tabular}{|c|c|c|c|c|c|c|c|c|c|c|c|c|}
\hline \multirow[b]{2}{*}{ Ano } & \multicolumn{4}{|c|}{ JOVEM } & \multicolumn{4}{|c|}{ ADULTO } & \multicolumn{4}{|c|}{ IDOSO } \\
\hline & $\begin{array}{c}T D \\
(U / N)^{1}\end{array}$ & $\begin{array}{c}T E \\
(S / N)^{2}\end{array}$ & $\begin{array}{l}D M C \\
(U / S)^{3}\end{array}$ & $D M I^{4}$ & $\begin{array}{c}T D \\
(U / N)\end{array}$ & $\begin{array}{c}T E \\
(S / N)\end{array}$ & $\begin{array}{l}D M C \\
(U / S)\end{array}$ & $D M I$ & $\begin{array}{c}T D \\
(U / N)\end{array}$ & $\begin{array}{c}T E \\
(S / N)\end{array}$ & $\begin{array}{l}D M C \\
(U / S)\end{array}$ & $D M I$ \\
\hline 1983 & 10,63 & 3,42 & 3,11 & 4,13 & 4,05 & 1,45 & 2,80 & 3,24 & 0,64 & 0,00 & 0,00 & 5,00 \\
\hline 1984 & 16,66 & 3,82 & 4,36 & 4,90 & 5,39 & 1,40 & 3,86 & 4,93 & 0,31 & 0,16 & 2,00 & 1,38 \\
\hline 1985 & 9,34 & 1,95 & 4,79 & 5,12 & 3,13 & 0,88 & 3,57 & 5,59 & 1,30 & 0,65 & 2,00 & 3,25 \\
\hline 1986 & 9,19 & 2,35 & 3,90 & 5,28 & 3,43 & 0,92 & 3,75 & 6,05 & 0,88 & 0,29 & 3,00 & 9,08 \\
\hline 1987 & 9,29 & 2,05 & 4,54 & 5,20 & 2,64 & 0,70 & 3,79 & 4,78 & 0,55 & 0,00 & 0,00 & 3,00 \\
\hline 1988 & 9,42 & 2,13 & 4,43 & 4,72 & 3,84 & 0,83 & 4,63 & 5,09 & 0,50 & 0,50 & 1,00 & 1,00 \\
\hline 1989 & 8,68 & 2,54 & 3,41 & 4,14 & 2,51 & 0,62 & 4,05 & 4,08 & 0,00 & 0,00 & 0,00 & 0,00 \\
\hline 1990 & 11,52 & 3,21 & 3,59 & 4,30 & 4,29 & 1,17 & 3,68 & 4,77 & 0,86 & 0,00 & 0,00 & 3,85 \\
\hline 1991 & 7,58 & 2,11 & 3,58 & 4,76 & 4,47 & 0,96 & 4,68 & 4,92 & 0,00 & 0,00 & 0,00 & 0,00 \\
\hline 1992 & 13,35 & 2,39 & 5,60 & 5,23 & 5,94 & 1,19 & 5,00 & 5,17 & 1,25 & 0,00 & 0,00 & 8,00 \\
\hline 1993 & 9,58 & 2,02 & 4,75 & 5,28 & 5,89 & 1,81 & 3,25 & 4,90 & 2,92 & 0,73 & 4,00 & 4,06 \\
\hline 1994 & 13,62 & 3,32 & 4,10 & 5,16 & 6,13 & 1,52 & 4,04 & 5,33 & 1,68 & 0,42 & 4,00 & 4,88 \\
\hline 1995 & 11,85 & 3,15 & 3,76 & 4,24 & 5,79 & 1,25 & 4,63 & 4,98 & 2,33 & 1,55 & 1,50 & 2,50 \\
\hline 1996 & 13,78 & 2,88 & 4,78 & 5,34 & 5,88 & 1,28 & 4,58 & 5,81 & 1,49 & 0,25 & 6,00 & 13,63 \\
\hline 1997 & 13,89 & 3,32 & 4,19 & 5,40 & 6,73 & 1,81 & 3,72 & 5,00 & 2,94 & 0,98 & 3,00 & 4,75 \\
\hline 1998 & 18,59 & 4,61 & 4,03 & 5,13 & 8,12 & 1,71 & 4,76 & 6,38 & 2,65 & 0,66 & 4,00 & 3,40 \\
\hline 1999 & 5,73 & 1,04 & 5,50 & 4,98 & 8,42 & 1,35 & 6,23 & 7,78 & 2,13 & 1,06 & 2,00 & 4,63 \\
\hline 2000 & 4,55 & 1,08 & 4,21 & 4,78 & 8,12 & 1,99 & 4,07 & 5,28 & 2,82 & 0,76 & 3,71 & 7,01 \\
\hline 2001 & 16,59 & 3,58 & 4,63 & 4,85 & 6,20 & 1,29 & 4,82 & 4,82 & 0,88 & 0,00 & 0,00 & 2,00 \\
\hline 2002 & 18,27 & 4,60 & 3,97 & 5,28 & 6,20 & 1,30 & 4,77 & 5,96 & 1,31 & 0,44 & 3,00 & 4,33 \\
\hline
\end{tabular}

Fonte: Construído pela autora com base na PME

${ }^{1} \mathrm{TD}(\mathrm{U} / \mathrm{N})$ : taxa de desemprego, em porcentagem (indivíduos desempregados/indivíduos empregados)

${ }^{2} \mathrm{TE}(\mathrm{S} / \mathrm{N})$ : taxa de entrada no desemprego por mês, em porcentagem, (indivíduos que entraram no desemprego em um mês ou menos/indivíduos empregados)

${ }^{3} \mathrm{DMC}$ (U/S): duração média completa do desemprego de estado estacionário, em meses (indivíduos desempregados/indivíduos que entraram no desemprego em um mês ou menos)

${ }^{4}$ DMI: duração média incompleta do desemprego corrente, em meses, (razão entre a soma da duração do desemprego de cada indivíduo desempregado e o número total de desempregados)

* Para o ano de 2002, os dados se restringem apenas aos seis primeiros meses do ano (janeiro a junho) 
TABELA 2.7

Taxa de entrada no desemprego de jovens que procuram pelo primeiro emprego e que já trabalharam anteriormente, São Paulo, 1983-2002

\begin{tabular}{|c|c|c|c|}
\hline Ano & $\begin{array}{c}\text { Taxa de entrada no } \\
\text { desemprego do jovem por mês } \\
(\%)(S / N)^{*}\end{array}$ & $\begin{array}{c}\text { Tx. entrada - jovem } \\
\text { procurando primeiro } \\
\text { emprego }(\%)(S p / N)\end{array}$ & $\begin{array}{c}\text { Tx. entrada - jovem já } \\
\text { trabalhou anteriormente } \\
(\%)(S n p / N)\end{array}$ \\
\hline 1983 & 4,45 & 0,63 & 3,82 \\
\hline 1984 & 4,88 & 0,72 & 4,16 \\
\hline 1985 & 3,62 & 0,62 & 3,01 \\
\hline 1986 & 3,36 & 0,59 & 2,78 \\
\hline 1987 & 3,40 & 0,40 & 3,00 \\
\hline 1988 & 3,72 & 0,37 & 3,36 \\
\hline 1989 & 2,33 & 0,20 & 2,13 \\
\hline 1990 & 3,97 & 0,51 & 3,47 \\
\hline 1991 & 4,12 & 0,56 & 3,56 \\
\hline 1992 & 4,00 & 0,52 & 3,48 \\
\hline 1993 & 3,33 & 0,44 & 2,89 \\
\hline 1994 & 3,92 & 0,49 & 3,43 \\
\hline 1995 & 2,90 & 0,33 & 2,57 \\
\hline 1996 & 3,81 & 0,58 & 3,23 \\
\hline 1997 & 3,85 & 0,51 & 3,33 \\
\hline 1998 & 3,56 & 0,46 & 3,10 \\
\hline 1999 & 4,14 & 0,53 & 3,61 \\
\hline 2000 & 4,47 & 0,60 & 3,87 \\
\hline 2001 & 3,46 & 0,48 & 2,98 \\
\hline 2002 & 3,30 & 0,44 & 2,86 \\
\hline
\end{tabular}

Fonte: Construído pela autora com base na PME

* $S / N=S p / N+S n p / N$ 
TABELA 2.8

Taxa de entrada no desemprego de jovens que procuram pelo primeiro emprego e que já trabalharam anteriormente, Belo Horizonte, 1983-2002

\begin{tabular}{lccc}
\hline Ano & $\begin{array}{c}\text { Taxa de entrada no } \\
\text { desemprego do jovem por mês } \\
(\%)(S / N)^{*}\end{array}$ & $\begin{array}{c}\text { Tx. entrada-jovem } \\
\text { procurando primeiro } \\
\text { emprego }(\%)(S p / N)\end{array}$ & $\begin{array}{c}\text { Tx. entrada-jovem já } \\
\text { trabalhou anteriormente } \\
(\%)(S n p / N)\end{array}$ \\
\hline 1983 & 7,32 & 1,17 & 6,15 \\
1984 & 8,21 & 1,99 & 6,21 \\
1985 & 5,14 & 1,09 & 4,05 \\
1986 & 4,10 & 0,89 & 3,21 \\
1987 & 3,19 & 0,46 & 2,73 \\
1988 & 4,35 & 0,69 & 3,66 \\
1989 & 4,07 & 0,68 & 3,39 \\
1990 & 4,16 & 0,45 & 3,71 \\
1991 & 3,71 & 0,75 & 2,95 \\
1992 & 3,92 & 0,48 & 3,44 \\
1993 & 4,04 & 0,26 & 3,77 \\
1994 & 4,34 & 0,63 & 3,72 \\
1995 & 4,49 & 0,44 & 4,06 \\
1996 & 4,72 & 0,69 & 4,03 \\
1997 & 3,45 & 0,25 & 3,20 \\
1998 & 5,22 & 0,82 & 4,39 \\
1999 & 8,73 & 2,17 & 6,57 \\
2000 & 7,23 & 1,48 & 5,75 \\
2001 & 5,67 & 0,71 & 3,85 \\
2002 & 4,78 & & \\
\hline \hline
\end{tabular}

Fonte: Construído pela autora com base na PME

* $S / N=S p / N+S n p / N$ 
TABELA 2.9

Taxa de entrada no desemprego de jovens que procuram pelo primeiro emprego e que já trabalharam anteriormente, Rio de Janeiro, 1983-2002

\begin{tabular}{|c|c|c|c|}
\hline Ano & $\begin{array}{c}\text { Taxa de entrada no } \\
\text { desemprego do jovem por mês } \\
(\%)(S / N)^{*}\end{array}$ & $\begin{array}{l}\text { Tx. entrada - jovem } \\
\text { procurando primeiro } \\
\text { emprego }(\%)(S p / N)\end{array}$ & $\begin{array}{c}\text { Tx. entrada - jovem já } \\
\text { trabalhou anteriormente } \\
(\%)(S n p / N)\end{array}$ \\
\hline 1983 & 4,28 & 1,00 & 3,28 \\
\hline 1984 & 5,33 & 0,94 & 4,39 \\
\hline 1985 & 2,55 & 0,41 & 2,14 \\
\hline 1986 & 2,95 & 0,60 & 2,35 \\
\hline 1987 & 1,88 & 0,09 & 1,78 \\
\hline 1988 & 2,56 & 0,30 & 2,26 \\
\hline 1989 & 2,57 & 0,28 & 2,29 \\
\hline 1990 & 2,95 & 0,41 & 2,53 \\
\hline 1991 & 3,42 & 0,33 & 3,08 \\
\hline 1992 & 2,77 & 0,47 & 2,30 \\
\hline 1993 & 1,73 & 0,25 & 1,48 \\
\hline 1994 & 3,07 & 0,35 & 2,71 \\
\hline 1995 & 3,17 & 0,26 & 2,91 \\
\hline 1996 & 2,66 & 0,43 & 2,23 \\
\hline 1997 & 2,68 & 0,76 & 1,91 \\
\hline 1998 & 3,08 & 0,33 & 2,75 \\
\hline 1999 & 2,25 & 0,54 & 1,71 \\
\hline 2000 & 2,65 & 0,45 & 2,21 \\
\hline 2001 & 3,03 & 0,78 & 2,24 \\
\hline 2002 & 3,65 & 0,81 & 2,85 \\
\hline
\end{tabular}

Fonte: Construído pela autora com base na PME

* $S / N=S p / N+S n p / N$ 
TABELA 2.10

Taxa de entrada no desemprego de jovens que procuram pelo primeiro emprego e que já trabalharam anteriormente, Porto Alegre, 1983-2002

\begin{tabular}{|c|c|c|c|}
\hline Ano & $\begin{array}{c}\text { Taxa de entrada no } \\
\text { desemprego do jovem por mês } \\
(\%)(S / N)^{*}\end{array}$ & $\begin{array}{l}\text { Tx. entrada - jovem } \\
\text { procurando primeiro } \\
\text { emprego }(\%)(\mathrm{Sp} / \mathrm{N})\end{array}$ & $\begin{array}{c}\text { Tx. entrada - jovem já } \\
\text { trabalhou anteriormente } \\
(\%)(S n p / N)\end{array}$ \\
\hline 1983 & 4,85 & 0,78 & 4,07 \\
\hline 1984 & 6,63 & 1,19 & 5,43 \\
\hline 1985 & 4,33 & 0,66 & 3,67 \\
\hline 1986 & 4,09 & 0,84 & 3,25 \\
\hline 1987 & 2,92 & 0,22 & 2,70 \\
\hline 1988 & 4,00 & 0,46 & 3,55 \\
\hline 1989 & 2,35 & 0,15 & 2,20 \\
\hline 1990 & 4,06 & 0,46 & 3,60 \\
\hline 1991 & 2,89 & 0,19 & 2,70 \\
\hline 1992 & 5,03 & 0,80 & 4,23 \\
\hline 1993 & 3,59 & 0,51 & 3,08 \\
\hline 1994 & 3,24 & 0,52 & 2,72 \\
\hline 1995 & 4,05 & 0,53 & 3,52 \\
\hline 1996 & 4,20 & 0,66 & 3,54 \\
\hline 1997 & 3,01 & 0,24 & 2,76 \\
\hline 1998 & 4,62 & 0,85 & 3,76 \\
\hline 1999 & 3,90 & 0,65 & 3,25 \\
\hline 2000 & 4,50 & 0,82 & 3,68 \\
\hline 2001 & 2,73 & 0,47 & 2,26 \\
\hline 2002 & 3,25 & 0,79 & 2,46 \\
\hline
\end{tabular}

Fonte: Construído pela autora com base na PME

* $S / N=S p / N+S n p / N$ 
TABELA 2.11

Taxa de entrada no desemprego de jovens que procuram pelo primeiro emprego e que já trabalharam anteriormente, Recife, 1983-2002

\begin{tabular}{|c|c|c|c|}
\hline Ano & $\begin{array}{c}\text { Taxa de entrada no } \\
\text { desemprego do jovem por mês } \\
(\%)(S / N)^{*}\end{array}$ & $\begin{array}{l}\text { Tx. entrada - jovem } \\
\text { procurando primeiro } \\
\text { emprego }(\%)(S p / N)\end{array}$ & $\begin{array}{c}\text { Tx. entrada - jovem já } \\
\text { trabalhou anteriormente } \\
(\%)(S n p / N)\end{array}$ \\
\hline 1983 & 4,96 & 0,83 & 4,13 \\
\hline 1984 & 5,45 & 1,20 & 4,25 \\
\hline 1985 & 3,21 & 1,25 & 1,97 \\
\hline 1986 & 2,32 & 0,53 & 1,80 \\
\hline 1987 & 2,74 & 0,56 & 2,18 \\
\hline 1988 & 3,44 & 0,68 & 2,76 \\
\hline 1989 & 2,53 & 0,35 & 2,18 \\
\hline 1990 & 3,37 & 0,65 & 2,72 \\
\hline 1991 & 4,48 & 0,54 & 3,95 \\
\hline 1992 & 5,01 & 1,19 & 3,81 \\
\hline 1993 & 5,26 & 1,05 & 4,21 \\
\hline 1994 & 4,35 & 0,86 & 3,48 \\
\hline 1995 & 2,48 & 0,43 & 2,05 \\
\hline 1996 & 3,24 & 0,68 & 2,56 \\
\hline 1997 & 4,58 & 0,81 & 3,76 \\
\hline 1998 & 7,06 & 2,10 & 4,96 \\
\hline 1999 & 3,20 & 0,83 & 2,37 \\
\hline 2000 & 4,34 & 0,83 & 3,51 \\
\hline 2001 & 4,06 & 0,89 & 3,17 \\
\hline 2002 & 2,64 & 0,50 & 2,14 \\
\hline
\end{tabular}

Fonte: Construído pela autora com base na PME

* $S / N=S p / N+S n p / N$ 
TABELA 2.12

Taxa de entrada no desemprego de jovens que procuram pelo primeiro emprego e que já trabalharam anteriormente, Salvador, 1983-2002

\begin{tabular}{|c|c|c|c|}
\hline Ano & $\begin{array}{c}\text { Taxa de entrada no } \\
\text { desemprego do jovem por mês } \\
(\%)(S / N)^{*}\end{array}$ & $\begin{array}{l}\text { Tx. entrada - jovem } \\
\text { procurando primeiro } \\
\text { emprego (\%) }(\mathrm{Sp} / \mathrm{N})\end{array}$ & $\begin{array}{c}\text { Tx. entrada - jovem já } \\
\text { trabalhou anteriormente } \\
\text { (\%) }(\text { Snp/N) }\end{array}$ \\
\hline 1983 & 3,42 & 0,66 & 2,77 \\
\hline 1984 & 3,82 & 0,91 & 2,91 \\
\hline 1985 & 1,95 & 0,56 & 1,39 \\
\hline 1986 & 2,35 & 0,57 & 1,79 \\
\hline 1987 & 2,05 & 0,15 & 1,90 \\
\hline 1988 & 2,13 & 0,19 & 1,94 \\
\hline 1989 & 2,54 & 0,09 & 2,46 \\
\hline 1990 & 3,21 & 0,35 & 2,85 \\
\hline 1991 & 2,11 & 0,26 & 1,85 \\
\hline 1992 & 2,39 & 0,37 & 2,02 \\
\hline 1993 & 2,02 & 0,50 & 1,51 \\
\hline 1994 & 3,32 & 0,37 & 2,95 \\
\hline 1995 & 3,15 & 0,28 & 2,87 \\
\hline 1996 & 2,88 & 0,19 & 2,70 \\
\hline 1997 & 3,32 & 0,41 & 2,90 \\
\hline 1998 & 4,61 & 0,83 & 3,78 \\
\hline 1999 & 1,04 & 0,26 & 0,78 \\
\hline 2000 & 1,08 & 0,19 & 0,89 \\
\hline 2001 & 3,58 & 1,07 & 2,51 \\
\hline 2002 & 4,60 & 1,58 & 3,02 \\
\hline
\end{tabular}

Fonte: Construído pela autora com base na PME

* $S / N=S p / N+S n p / N$ 
TABELA 3.1

Probabilidades de transição de jovens e adultos, nas cinco regiões metropolitanas brasileiras, 2001

\begin{tabular}{|c|c|c|c|c|c|c|c|c|c|c|}
\hline \multirow{3}{*}{ TRANSIÇÕES } & \multicolumn{10}{|c|}{ CATEGORIAS, POR REGIÃO } \\
\hline & \multicolumn{2}{|c|}{ Belo Horizonte } & \multicolumn{2}{|c|}{ Rio de Janeiro } & \multicolumn{2}{|c|}{ Porto Alegre } & \multicolumn{2}{|c|}{ Recife } & \multicolumn{2}{|c|}{ Salvador } \\
\hline & Jovem & Adulto & Jovem & Adulto & Jovem & Adulto & Jovem & Adulto & Jovem & Adulto \\
\hline$P_{e e}^{1}$ & 0,839 & 0,928 & 0,885 & 0,943 & 0,884 & 0,945 & 0,817 & 0,908 & 0,760 & 0,887 \\
\hline$P_{e u}^{2}$ & 0,033 & 0,017 & 0,018 & 0,010 & 0,025 & 0,011 & 0,028 & 0,018 & 0,041 & 0,030 \\
\hline$P_{e n}{ }^{3}$ & 0,128 & 0,055 & 0,097 & 0,047 & 0,091 & 0,044 & 0,155 & 0,074 & 0,199 & 0,083 \\
\hline$P_{u e^{4}}$ & 0,238 & 0,311 & 0,219 & 0,260 & 0,203 & 0,307 & 0,187 & 0,318 & 0,218 & 0,326 \\
\hline$P_{u u}^{5}$ & 0,363 & 0,378 & 0,475 & 0,467 & 0,426 & 0,465 & 0,349 & 0,318 & 0,256 & 0,311 \\
\hline$P_{u n}^{6}$ & 0,399 & 0,311 & 0,306 & 0,273 & 0,371 & 0,228 & 0,464 & 0,364 & 0,526 & 0,363 \\
\hline$P_{n e}^{7}$ & 0,093 & 0,118 & 0,049 & 0,080 & 0,063 & 0,095 & 0,075 & 0,116 & 0,077 & 0,150 \\
\hline$P_{n u}^{8}$ & 0,054 & 0,034 & 0,017 & 0,015 & 0,034 & 0,022 & 0,038 & 0,043 & 0,041 & 0,061 \\
\hline$P_{n n}^{9}$ & 0,853 & 0,848 & 0,934 & 0,905 & 0,903 & 0,883 & 0,887 & 0,841 & 0,882 & 0,789 \\
\hline
\end{tabular}

Fonte: Construído pela autora com base na PME

${ }^{1} \mathrm{P}_{\mathrm{ee}}$ : probabilidade de um indivíduo empregado no período $t$, continuar empregado em $t+1$

${ }^{2} \mathrm{P}_{\mathrm{eu}}$ : probabilidade de um indivíduo empregado em $t$, ficar desempregado em $t+1$

${ }^{3} \mathrm{P}_{\text {en }}$ : probabilidade de um indivíduo empregado em $t$, sair da força de trabalho em $t+1$

${ }^{4} \mathrm{P}_{\mathrm{ue}}$ : probabilidade de um indivíduo desempregado em $t$, conseguir um emprego em $t+1$

${ }^{5} \mathrm{P}_{\mathrm{uu}}$ : probabilidade de um indivíduo desempregado em $t$, continuar desempregado em $t+1$

${ }^{6} \mathrm{P}_{\text {un }}$ : probabilidade de um indivíduo desempregado em $t$, sair da força de trabalho em $t+1$

${ }^{7} \mathrm{P}_{\mathrm{ne}}$ : probabilidade de um indivíduo inativo em $t$, entrar na força de trabalho como empregado em $t+1$

${ }^{8} \mathrm{P}_{\mathrm{nu}}$ : probabilidade de um indivíduo inativo em $t$, entrar na força de trabalho como desempregado em $t+1$

${ }^{9} \mathrm{P}_{\mathrm{nn}}$ : probabilidade de um indivíduo inativo em $t$, continuar inativo em $t+1$ 

TABELA 3.2

Fração de tempo gasto em cada estado do mercado de trabalho e taxa de desemprego, de jovens e adultos, nas cinco regiões metropolitanas, 2001

\begin{tabular}{|c|c|c|c|c|c|}
\hline & \multicolumn{3}{|c|}{ FRAÇÃO DE TEMPO } & \multicolumn{2}{|c|}{$\begin{array}{c}\text { TAXA DE } \\
\text { DESEMPREGO }\end{array}$} \\
\hline $\begin{array}{l}\text { CATEGORIAS, } \\
\text { POR REGIÃO }\end{array}$ & $\begin{array}{c}\pi_{e}(\text { no } \\
\text { emprego) }\end{array}$ & $\begin{array}{c}\pi_{u}(\text { no } \\
\text { desemprego) }\end{array}$ & $\begin{array}{c}\pi_{n}(\mathrm{na} \\
\text { inatividade) } \\
\end{array}$ & $\begin{array}{c}\pi_{u} /\left(\pi_{u}+\pi_{e}\right) \\
(\%)\end{array}$ & $\begin{array}{c}U /(U+E) \\
(\%)\end{array}$ \\
\hline \multicolumn{6}{|l|}{ Belo Horizonte } \\
\hline Jovem & 0,404 & 0,066 & 0,530 & 14,0 & 14,0 \\
\hline Adulto & 0,656 & 0,035 & 0,309 & 5,1 & 5,3 \\
\hline \multicolumn{6}{|l|}{ Rio de Janeiro } \\
\hline Jovem & 0,332 & 0,032 & 0,636 & 8,8 & 10,5 \\
\hline Adulto & 0,612 & 0,022 & 0,366 & 3,5 & 3,5 \\
\hline \multicolumn{6}{|l|}{ Porto Alegre } \\
\hline Jovem & 0,391 & 0,050 & 0,559 & 11,3 & 11,5 \\
\hline Adulto & 0,671 & 0,026 & 0,303 & 3,7 & 4,0 \\
\hline \multicolumn{6}{|l|}{ Recife } \\
\hline Jovem & 0,313 & 0,051 & 0,637 & 14,0 & 14,6 \\
\hline Adulto & 0,595 & 0,039 & 0,366 & 6,2 & 6,3 \\
\hline \multicolumn{6}{|l|}{ Salvador } \\
\hline Jovem & 0,266 & 0,052 & 0,682 & 16,4 & 16,3 \\
\hline Adulto & 0,608 & 0,056 & 0,336 & 8,4 & 7,7 \\
\hline
\end{tabular}

Fonte: Construído pela autora com base na PME 
TABELA 3.3

Fração de tempo no mercado de trabalho e taxa de desemprego, de jovens e adultos, substituindo a primeira linha das matrizes, nas cinco regiões metropolitanas, 2001

\begin{tabular}{|c|c|c|c|c|}
\hline & \multicolumn{3}{|c|}{ FRAÇÃO DE TEMPO } & $\begin{array}{c}\text { TAXA DE } \\
\text { DESEMPREGO }\end{array}$ \\
\hline $\begin{array}{l}\text { CATEGORIAS, } \\
\text { POR REGIÃO }\end{array}$ & $\pi_{e}$ (no emprego) & $\begin{array}{c}\pi_{u}(\text { no } \\
\text { desemprego })\end{array}$ & $\begin{array}{c}\pi_{n}(\mathrm{na} \\
\text { inatividade) } \\
\end{array}$ & $\begin{array}{c}\pi_{u} /\left(\pi_{u}+\pi_{e}\right) \\
(\%)\end{array}$ \\
\hline \multicolumn{5}{|l|}{ Belo Horizonte } \\
\hline Jovem & 0,604 & 0,046 & 0,350 & 7,1 \\
\hline Adulto & 0,458 & 0,051 & 0,491 & 10,0 \\
\hline \multicolumn{5}{|l|}{ Rio de Janeiro } \\
\hline Jovem & 0,502 & 0,025 & 0,473 & 4,7 \\
\hline Adulto & 0,438 & 0,030 & 0,532 & 6,4 \\
\hline \multicolumn{5}{|l|}{ Porto Alegre } \\
\hline Jovem & 0,575 & 0,034 & 0,391 & 5,6 \\
\hline Adulto & 0,493 & 0,042 & 0,465 & 7,9 \\
\hline \multicolumn{5}{|l|}{ Recife } \\
\hline Jovem & 0,477 & 0,041 & 0,482 & 7,9 \\
\hline Adulto & 0,422 & 0,051 & 0,527 & 10,8 \\
\hline \multicolumn{5}{|l|}{ Salvador } \\
\hline Jovem & 0,439 & 0,046 & 0,515 & 9,5 \\
\hline Adulto & 0,416 & 0,070 & 0,514 & 14,4 \\
\hline
\end{tabular}

Fonte: Construído pela autora com base na PME 
TABELA 3.4

Fração de tempo no mercado de trabalho e taxa de desemprego, de jovens e adultos, substituindo a segunda linha das matrizes, nas cinco regiões metropolitanas, 2001

\begin{tabular}{|c|c|c|c|c|}
\hline & \multicolumn{3}{|c|}{ FRAÇÃO DE TEMPO } & \multirow{2}{*}{$\begin{array}{c}\text { TAXA DE } \\
\text { DESEMPREGO } \\
\pi_{u} /\left(\pi_{u}+\pi_{e}\right) \\
(\%) \\
\end{array}$} \\
\hline $\begin{array}{l}\text { CATEGORIAS, } \\
\text { POR REGIÃO }\end{array}$ & $\pi_{e}($ no emprego) & $\begin{array}{c}\pi_{u}(\text { no } \\
\text { desemprego) }\end{array}$ & $\begin{array}{c}\pi_{n}(\mathrm{na} \\
\text { inatividade) } \\
\end{array}$ & \\
\hline \multicolumn{5}{|l|}{ Belo Horizonte } \\
\hline Jovem & 0,423 & 0,067 & 0,510 & 13,7 \\
\hline Adulto & 0,643 & 0,034 & 0,323 & 5,0 \\
\hline \multicolumn{5}{|l|}{ Rio de Janeiro } \\
\hline Jovem & 0,339 & 0,032 & 0,629 & 8,6 \\
\hline Adulto & 0,607 & 0,022 & 0,371 & 3,5 \\
\hline \multicolumn{5}{|l|}{ Porto Alegre } \\
\hline Jovem & 0,424 & 0,053 & 0,523 & 11,1 \\
\hline Adulto & 0,651 & 0,025 & 0,324 & 3,7 \\
\hline \multicolumn{5}{|l|}{ Recife } \\
\hline Jovem & 0,336 & 0,048 & 0,616 & 12,5 \\
\hline Adulto & 0,572 & 0,041 & 0,387 & 6,7 \\
\hline \multicolumn{5}{|l|}{ Salvador } \\
\hline Jovem & 0,287 & 0,056 & 0,657 & 16,3 \\
\hline Adulto & 0,584 & 0,053 & 0,363 & 8,3 \\
\hline
\end{tabular}

Fonte: Construído pela autora com base na PME 
TABELA 3.5

Fração de tempo no mercado de trabalho e taxa de desemprego, de jovens e adultos, substituindo a terceira linha das matrizes, nas cinco regiões metropolitanas, 2001

\begin{tabular}{|c|c|c|c|c|}
\hline & \multicolumn{3}{|c|}{ FRAÇÃO DE TEMPO } & \multirow{2}{*}{$\begin{array}{c}\text { TAXA DE } \\
\text { DESEMPREGO } \\
\pi_{u} /\left(\pi_{u}+\pi_{e}\right) \\
(\%)\end{array}$} \\
\hline $\begin{array}{l}\text { CATEGORIAS, } \\
\text { POR REGIÃO }\end{array}$ & $\pi_{e}$ (no emprego) & $\begin{array}{c}\pi_{u}(\text { no } \\
\text { desemprego) }\end{array}$ & $\begin{array}{c}\pi_{n}(\mathrm{na} \\
\text { inatividade) } \\
\end{array}$ & \\
\hline \multicolumn{5}{|l|}{ Belo Horizonte } \\
\hline Jovem & 0,444 & 0,050 & 0,506 & 10,1 \\
\hline Adulto & 0,624 & 0,046 & 0,330 & 6,9 \\
\hline \multicolumn{5}{|l|}{ Rio de Janeiro } \\
\hline Jovem & 0,432 & 0,030 & 0,538 & 6,5 \\
\hline Adulto & 0,511 & 0,024 & 0,465 & 4,5 \\
\hline \multicolumn{5}{|l|}{ Porto Alegre } \\
\hline Jovem & 0,470 & 0,039 & 0,491 & 7,7 \\
\hline Adulto & 0,607 & 0,035 & 0,358 & 5,5 \\
\hline \multicolumn{5}{|l|}{ Recife } \\
\hline Jovem & 0,401 & 0,053 & 0,546 & 11,7 \\
\hline Adulto & 0,505 & 0,039 & 0,456 & 7,2 \\
\hline \multicolumn{5}{|l|}{ Salvador } \\
\hline Jovem & 0,396 & 0,066 & 0,538 & 14,3 \\
\hline Adulto & 0,470 & 0,049 & 0,481 & 9,4 \\
\hline
\end{tabular}

Fonte: Construído pela autora com base na PME 
TABELA 3.6

Probabilidades de transição de jovens e adultos, São Paulo, 1986, 1991 e 1996

\begin{tabular}{|c|c|c|c|c|c|c|}
\hline \multirow{3}{*}{ TRANSIÇÕES } & \multicolumn{6}{|c|}{ CATEGORIAS, POR ANO } \\
\hline & \multicolumn{2}{|c|}{1986} & \multicolumn{2}{|c|}{1991} & \multicolumn{2}{|c|}{1996} \\
\hline & Jovem & Adulto & Jovem & Adulto & Jovem & Adulto \\
\hline$P_{e e}{ }^{1}$ & 0,926 & 0,955 & 0,897 & 0,944 & 0,879 & 0,941 \\
\hline$P_{e u}{ }^{2}$ & 0,023 & 0,008 & 0,033 & 0,015 & 0,033 & 0,015 \\
\hline$P_{e n}{ }^{3}$ & 0,051 & 0,037 & 0,070 & 0,041 & 0,088 & 0,044 \\
\hline$P_{u e}^{4}$ & 0,360 & 0,57 & 0,287 & 0,423 & 0,256 & 0,307 \\
\hline$P_{u u}{ }^{5}$ & 0,337 & 0,305 & 0,393 & 0,421 & 0,431 & 0,441 \\
\hline$P_{\text {un }}{ }^{6}$ & 0,303 & 0,188 & 0,320 & 0,156 & 0,313 & 0,252 \\
\hline$P_{n e}{ }^{7}$ & 0,110 & 0,077 & 0,091 & 0,094 & 0,088 & 0,095 \\
\hline$P_{n u}^{8}$ & 0,040 & 0,013 & 0,060 & 0,020 & 0,044 & 0,022 \\
\hline$P_{n n}^{9}$ & 0,850 & 0,910 & 0,849 & 0,886 & 0,868 & 0,883 \\
\hline
\end{tabular}

Fonte: Construído pela autora com base na PME

${ }^{1} \mathrm{P}_{\text {ee }}$ : probabilidade de um indivíduo empregado no período $t$, continuar empregado em $t+1$

${ }^{2} \mathrm{P}_{\text {eu }}$ : probabilidade de um indivíduo empregado em $t$, ficar desempregado em $t+1$

${ }^{3} \mathrm{P}_{\mathrm{en}}$ : probabilidade de um indivíduo empregado em $t$, sair da força de trabalho em $t+1$

${ }^{4} \mathrm{P}_{\mathrm{ue}}$ : probabilidade de um indivíduo desempregado em $t$, conseguir um emprego em $t+1$

${ }^{5} \mathrm{P}_{\mathrm{uu}}$ : probabilidade de um indivíduo desempregado em $t$, continuar desempregado em $t+1$

${ }^{6} \mathrm{P}_{\text {un }}$ : probabilidade de um indivíduo desempregado em $t$, sair da força de trabalho em $t+1$

${ }^{7} \mathrm{P}_{\text {ne }}$ : probabilidade de um indivíduo inativo em $t$, entrar na força de trabalho como empregado em $t+1$

${ }^{8} \mathrm{P}_{\mathrm{nu}}$ : probabilidade de um indivíduo inativo em $t$, entrar na força de trabalho como desempregado em $t+1$

${ }^{9} \mathrm{P}_{\mathrm{nn}}$ : probabilidade de um indivíduo inativo em $t$, continuar inativo em $t+1$ 
TABELA 3.7

Fração de tempo gasto em cada estado do mercado de trabalho e taxa de desemprego, de jovens e adultos, São Paulo, 1986, 1991 e 1996

\begin{tabular}{|c|c|c|c|c|c|}
\hline \multirow[b]{2}{*}{$\begin{array}{l}\text { CATEGORIAS, } \\
\text { POR ANO }\end{array}$} & \multicolumn{3}{|c|}{ FRAÇÃO DE TEMPO } & \multicolumn{2}{|c|}{$\begin{array}{c}\text { TAXA DE } \\
\text { DESEMPREGO }\end{array}$} \\
\hline & $\begin{array}{c}\pi_{e}(\text { no } \\
\text { emprego) }\end{array}$ & $\begin{array}{c}\pi_{u}(\text { no } \\
\text { desemprego) }\end{array}$ & $\begin{array}{c}\pi_{n}(\text { na } \\
\text { inatividade) }\end{array}$ & $\begin{array}{l}\pi_{u} /\left(\pi_{u}+\pi_{e}\right) \\
\quad(\%)\end{array}$ & $\begin{array}{c}U /(U+E) \\
(\%)\end{array}$ \\
\hline \multicolumn{6}{|l|}{1986} \\
\hline Jovem & 0,654 & 0,041 & 0,305 & 5,9 & 6,5 \\
\hline Adulto & 0,679 & 0,014 & 0,307 & 2,0 & 2,0 \\
\hline \multicolumn{6}{|l|}{1991} \\
\hline Jovem & 0,538 & 0,068 & 0,394 & 11,2 & 10,9 \\
\hline Adulto & 0,687 & 0,028 & 0,285 & 3,9 & 3,9 \\
\hline \multicolumn{6}{|l|}{1996} \\
\hline Jovem & 0,472 & 0,063 & 0,465 & 11,8 & 12,0 \\
\hline Adulto & 0,658 & 0,030 & 0,312 & 4,4 & 4,5 \\
\hline
\end{tabular}

Fonte: Construído pela autora com base na PME 
TABELA 3.8

Fração de tempo no mercado de trabalho e taxa de desemprego, de jovens e adultos, substituindo a primeira linha das matrizes, São Paulo, 1986, 1991 e 1996

\begin{tabular}{|c|c|c|c|c|}
\hline & \multicolumn{3}{|c|}{ FRAÇÃO DE TEMPO } & \multirow{2}{*}{$\begin{array}{c}\text { TAXA DE } \\
\text { DESEMPREGO } \\
\pi_{u} /\left(\pi_{u}+\pi_{e}\right) \\
(\%)\end{array}$} \\
\hline $\begin{array}{c}\text { CATEGORIAS, } \\
\text { POR ANO }\end{array}$ & $\pi_{e}($ no emprego) & $\begin{array}{c}\pi_{u}(\text { no } \\
\text { desemprego })\end{array}$ & $\begin{array}{c}\pi_{n}(n a \\
\text { inatividade) }\end{array}$ & \\
\hline \multicolumn{5}{|l|}{1986} \\
\hline Jovem & 0,747 & 0,023 & 0,230 & 3,0 \\
\hline Adulto & 0,586 & 0,027 & 0,387 & 4,4 \\
\hline \multicolumn{5}{|l|}{1991} \\
\hline Jovem & 0,678 & 0,044 & 0,278 & 6,1 \\
\hline Adulto & 0,553 & 0,045 & 0,402 & 7,5 \\
\hline \multicolumn{5}{|l|}{1996} \\
\hline Jovem & 0,646 & 0,041 & 0,313 & 6,0 \\
\hline Adulto & 0,486 & 0,47 & 0,467 & 8,8 \\
\hline
\end{tabular}

Fonte: Construído pela autora com base na PME 
TABELA 3.9

Fração de tempo no mercado de trabalho e taxa de desemprego, de jovens e adultos, substituindo a segunda linha das matrizes, São Paulo, 1986, 1991 e 1996

\begin{tabular}{|c|c|c|c|c|}
\hline & \multicolumn{3}{|c|}{ FRAÇÃO DE TEMPO } & \multirow{2}{*}{$\begin{array}{c}\text { TAXA DE } \\
\text { DESEMPREGO } \\
\pi_{u} /\left(\pi_{u}+\pi_{e}\right) \\
(\%)\end{array}$} \\
\hline $\begin{array}{c}\text { CATEGORIAS, } \\
\text { POR ANO }\end{array}$ & $\pi_{e}$ (no emprego) & $\begin{array}{c}\pi_{u}(\text { no } \\
\text { desemprego) }\end{array}$ & $\begin{array}{c}\pi_{n}(\mathrm{na} \\
\text { inatividade) }\end{array}$ & \\
\hline \multicolumn{5}{|l|}{1986} \\
\hline Jovem & 0,681 & 0,039 & 0,280 & 5,4 \\
\hline Adulto & 0,665 & 0,014 & 0,321 & 2,1 \\
\hline \multicolumn{5}{|l|}{1991} \\
\hline Jovem & 0,587 & 0,069 & 0,344 & 10,5 \\
\hline Adulto & 0,661 & 0,027 & 0,312 & 3,9 \\
\hline \multicolumn{5}{|l|}{1996} \\
\hline Jovem & 0,488 & 0,064 & 0,448 & 11,6 \\
\hline Adulto & 0,648 & 0,029 & 0,323 & 4,3 \\
\hline
\end{tabular}

Fonte: Construído pela autora com base na PME 
TABELA 3.10

Fração de tempo no mercado de trabalho e taxa de desemprego, de jovens e adultos, substituindo a terceira linha das matrizes, São Paulo, 1986, 1991 e 1996

\begin{tabular}{|c|c|c|c|c|}
\hline & \multicolumn{3}{|c|}{ FRAÇÃO DE TEMPO } & \multirow{2}{*}{$\begin{array}{c}\text { TAXA DE } \\
\text { DESEMPREGO } \\
\pi_{u} /\left(\pi_{u}+\pi_{e}\right) \\
(\%)\end{array}$} \\
\hline $\begin{array}{c}\text { CATEGORIAS, } \\
\text { POR ANO }\end{array}$ & $\pi_{e}$ (no emprego) & $\begin{array}{c}\pi_{u}(\text { no } \\
\text { desemprego) }\end{array}$ & $\begin{array}{c}\pi_{n}(n a \\
\text { inatividade) }\end{array}$ & \\
\hline \multicolumn{5}{|l|}{1986} \\
\hline Jovem & 0,562 & 0,027 & 0,411 & 4,6 \\
\hline Adulto & 0,764 & 0,021 & 0,215 & 2,7 \\
\hline \multicolumn{5}{|l|}{1991} \\
\hline Jovem & 0,519 & 0,043 & 0,438 & 7,7 \\
\hline Adulto & 0,717 & 0,043 & 0,240 & 5,7 \\
\hline \multicolumn{5}{|l|}{1996} \\
\hline Jovem & 0,474 & 0,046 & 0,480 & 8,8 \\
\hline Adulto & 0,660 & 0,041 & 0,299 & 5,8 \\
\hline
\end{tabular}

Fonte: Construído pela autora com base na PME 


\section{ANEXO B}

Gráfico 2.1 - Taxa de desemprego segundo faixa etária - Belo Horizonte

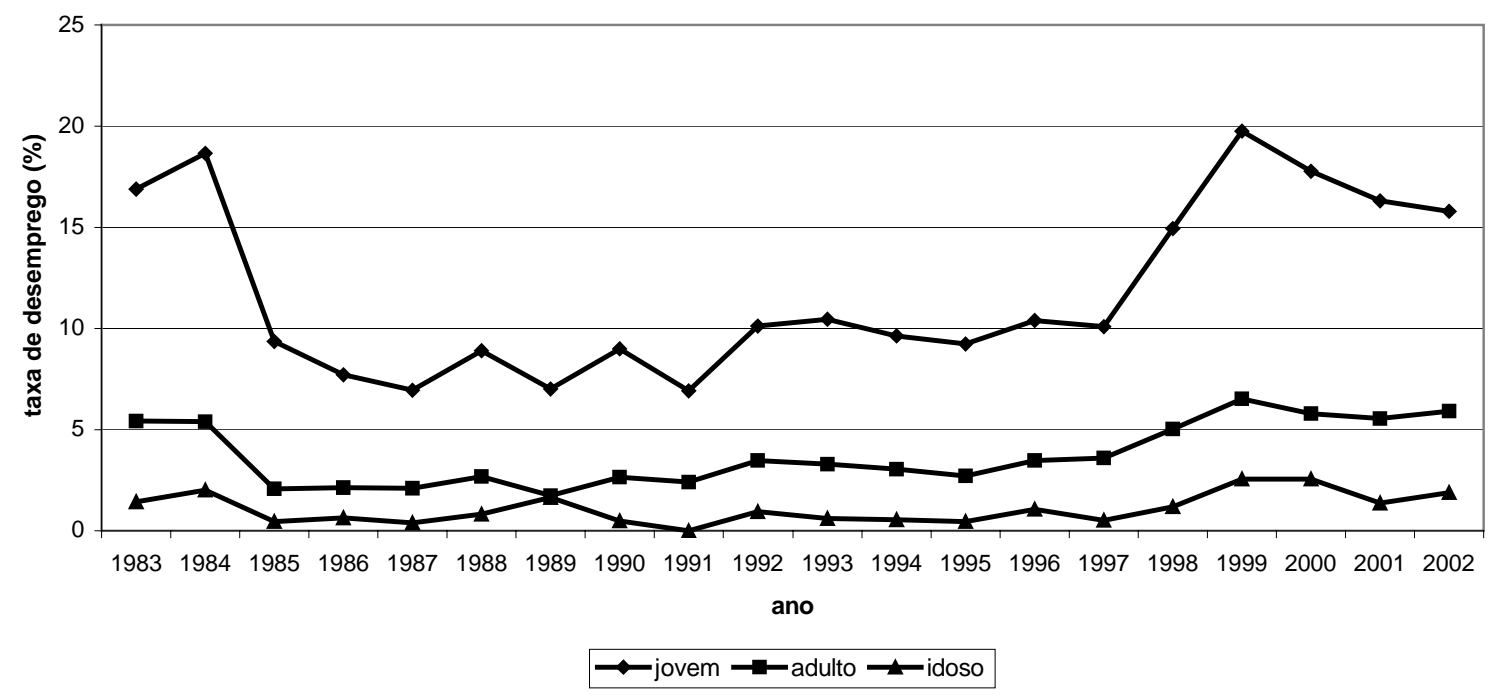

Fonte: Construído pela autora com base na PME

Gráfico 2.2 - Taxa de desemprego segundo faixa etária - Rio de Janeiro

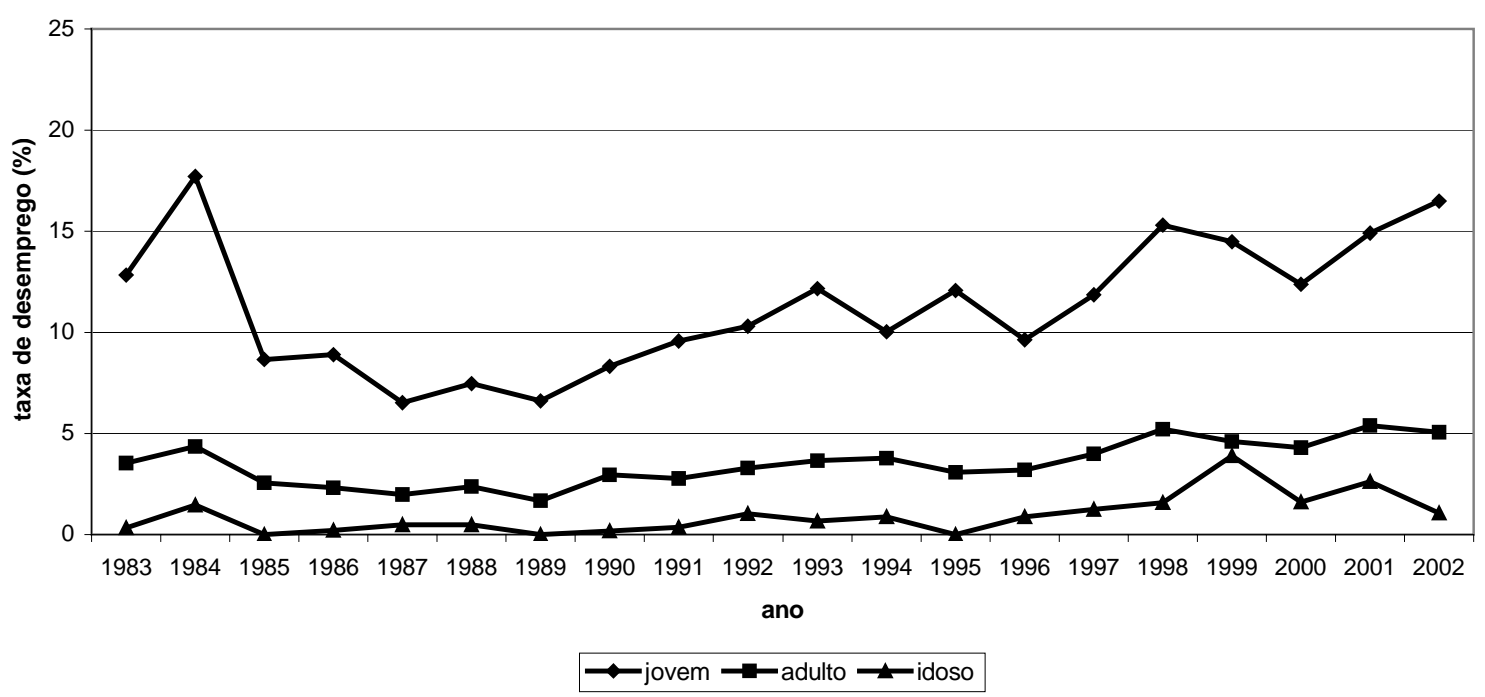

Fonte: Construído pela autora com base na PME 
Gráfico 2.3 - Taxa de desemprego segundo faixa etária - Porto Alegre

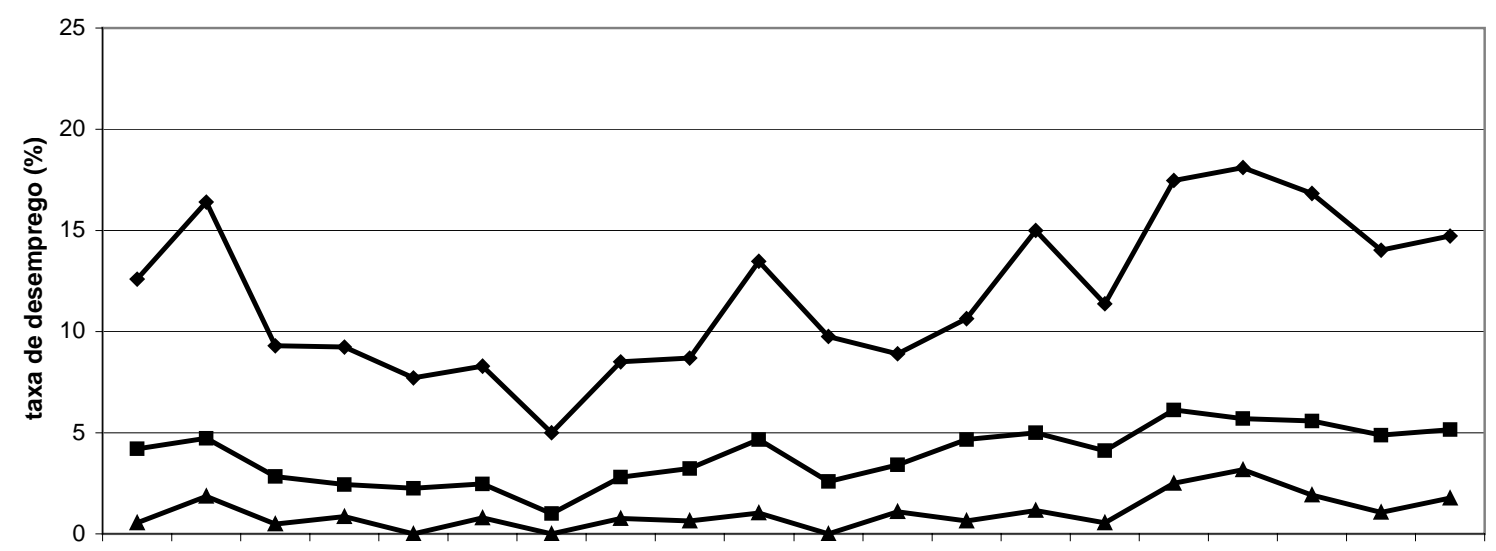

$\begin{array}{llllllllllllllllllll}1983 & 1984 & 1985 & 1986 & 1987 & 1988 & 1989 & 1990 & 1991 & 1992 & 1993 & 1994 & 1995 & 1996 & 1997 & 1998 & 1999 & 2000 & 2001 & 2002\end{array}$ ano

$\rightarrow$-jovem $\rightarrow$-adulto $\rightarrow$-idoso

Fonte: Construído pela autora com base na PME

Gráfico 2.4 - Taxa de desemprego segundo faixa etária - Recife

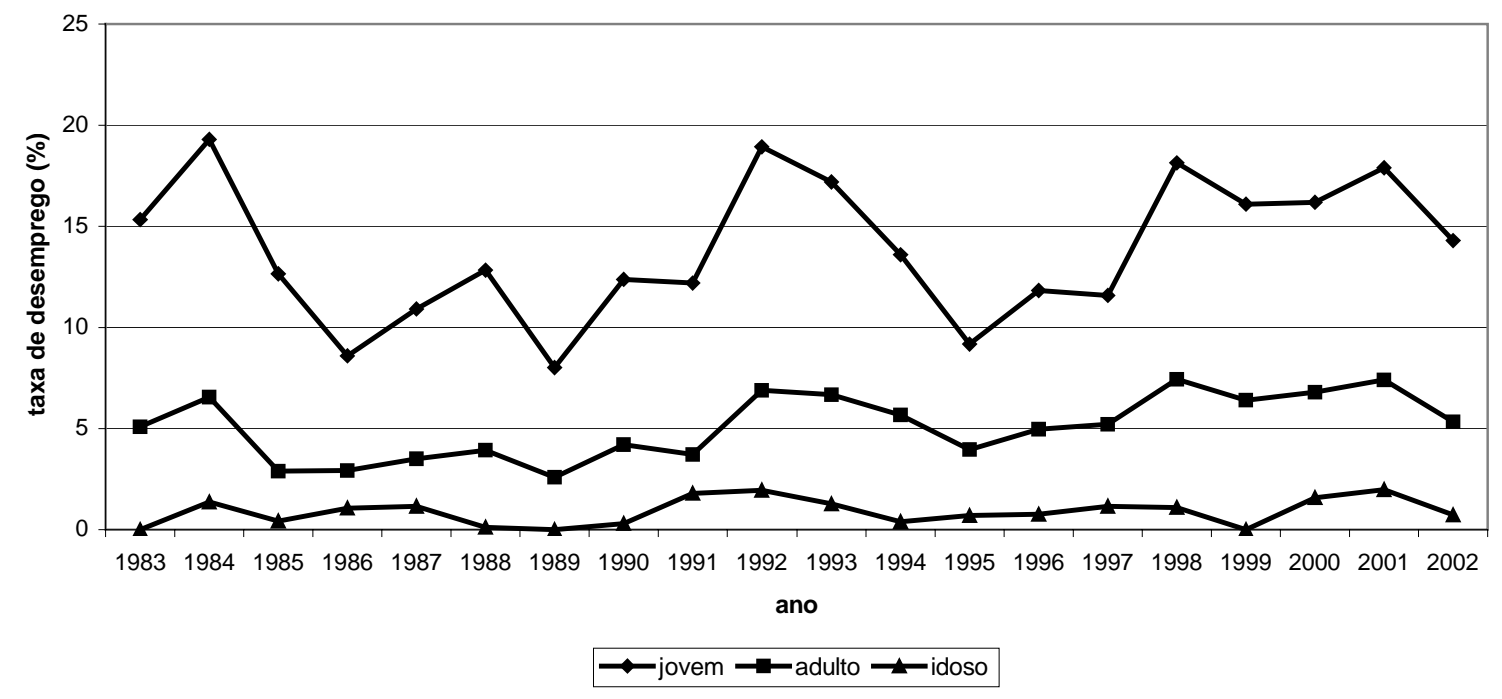

Fonte: Construído pela autora com base na PME 
Gráfico 2.5 - Taxa de desemprego segundo faixa etária - Salvador

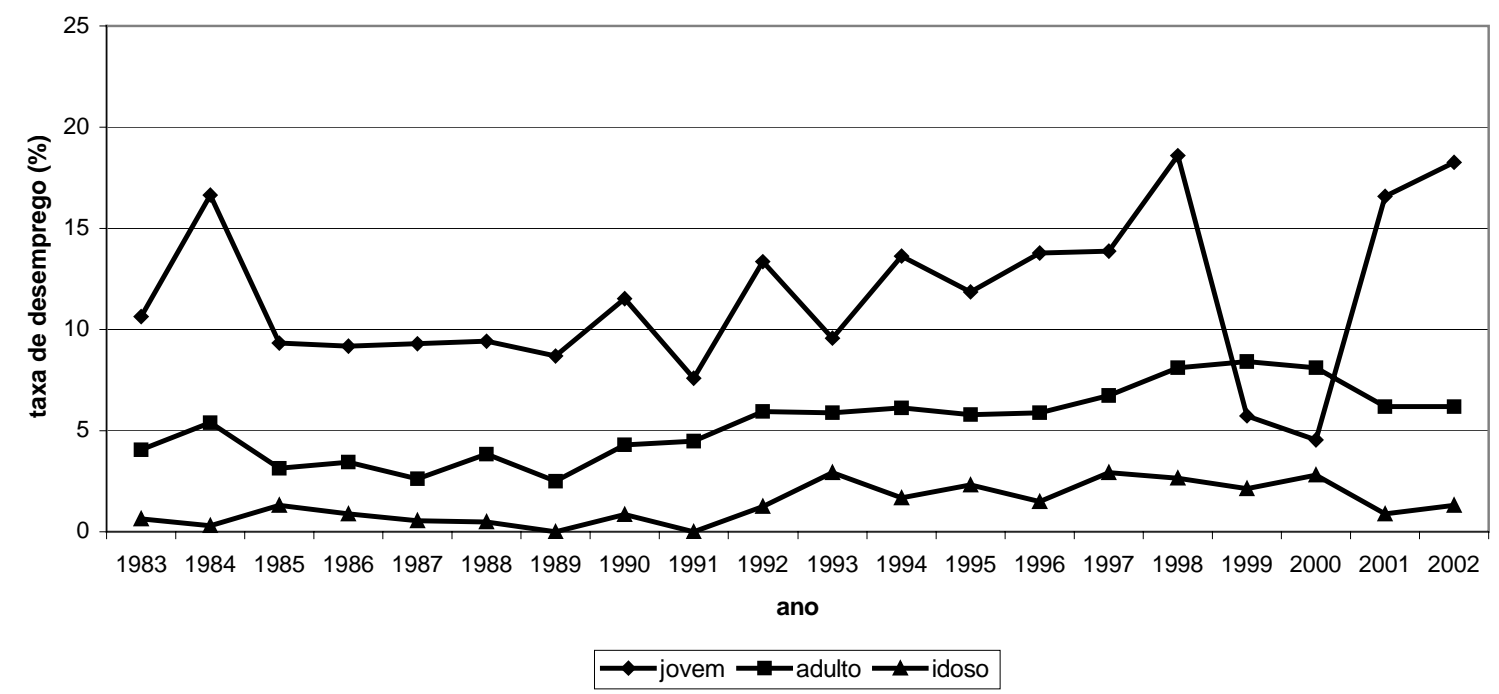

Fonte: Construído pela autora com base na PME

Gráfico 2.6 - Taxa de entrada e duração média no desemprego - jovem/MG

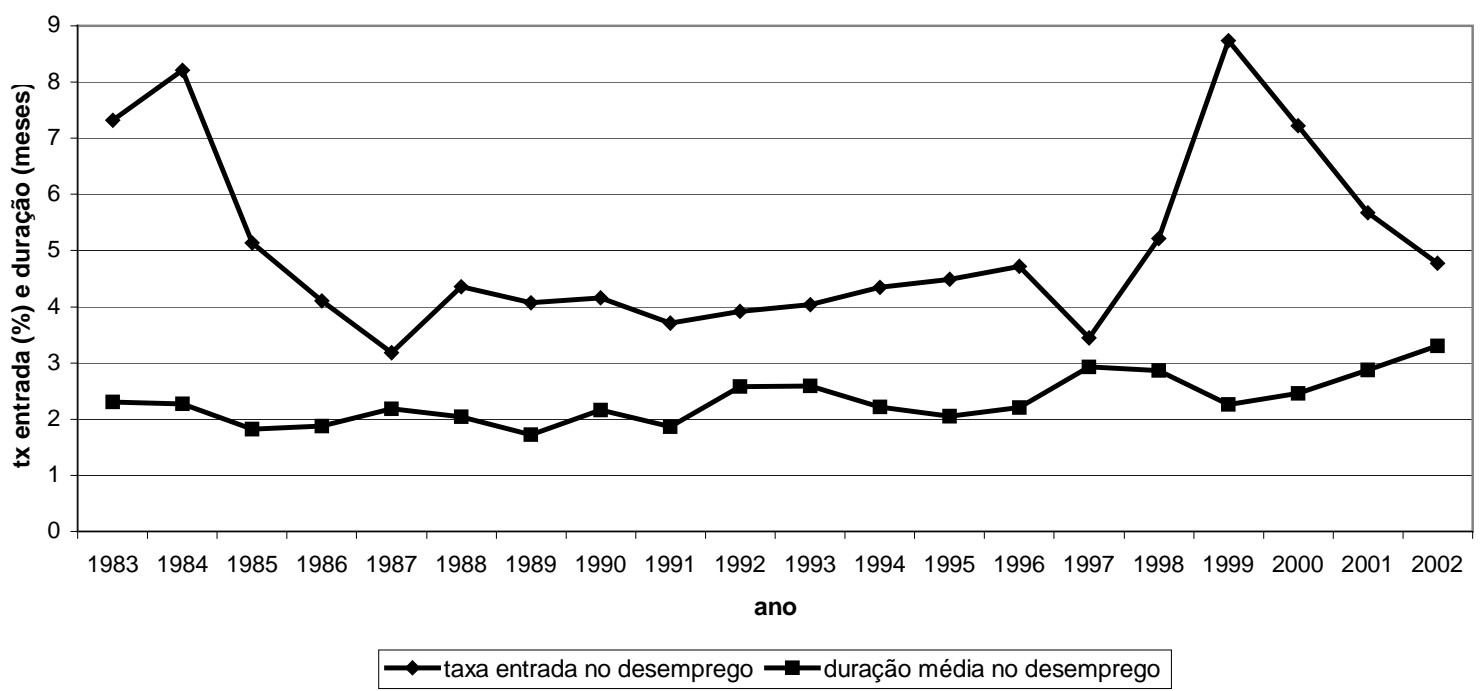

Fonte: Construído pela autora com base na PME 
Gráfico 2.7 - Taxa de entrada e duração média no desemprego - adulto/MG

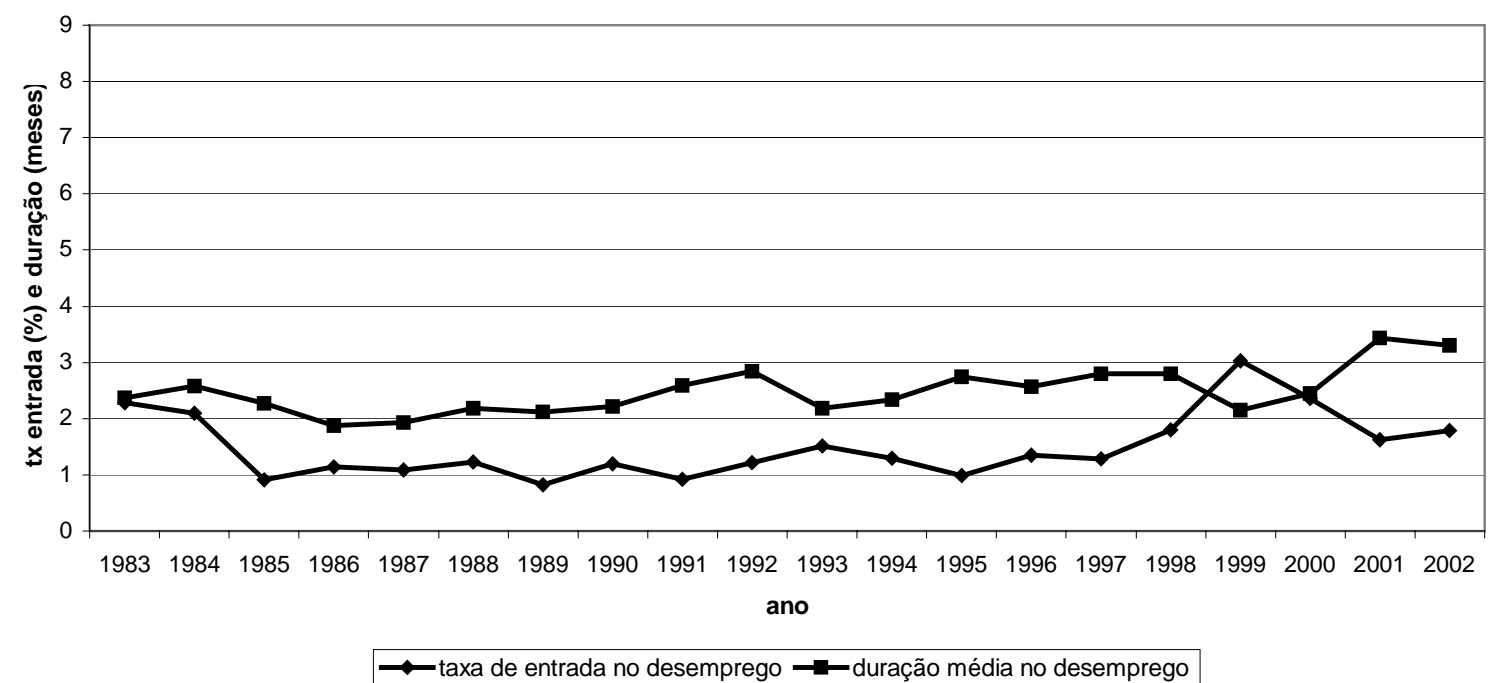

Fonte: Construído pela autora com base na PME

Gráfico 2.8 - Taxa de entrada e duração média no desemprego - idoso/MG

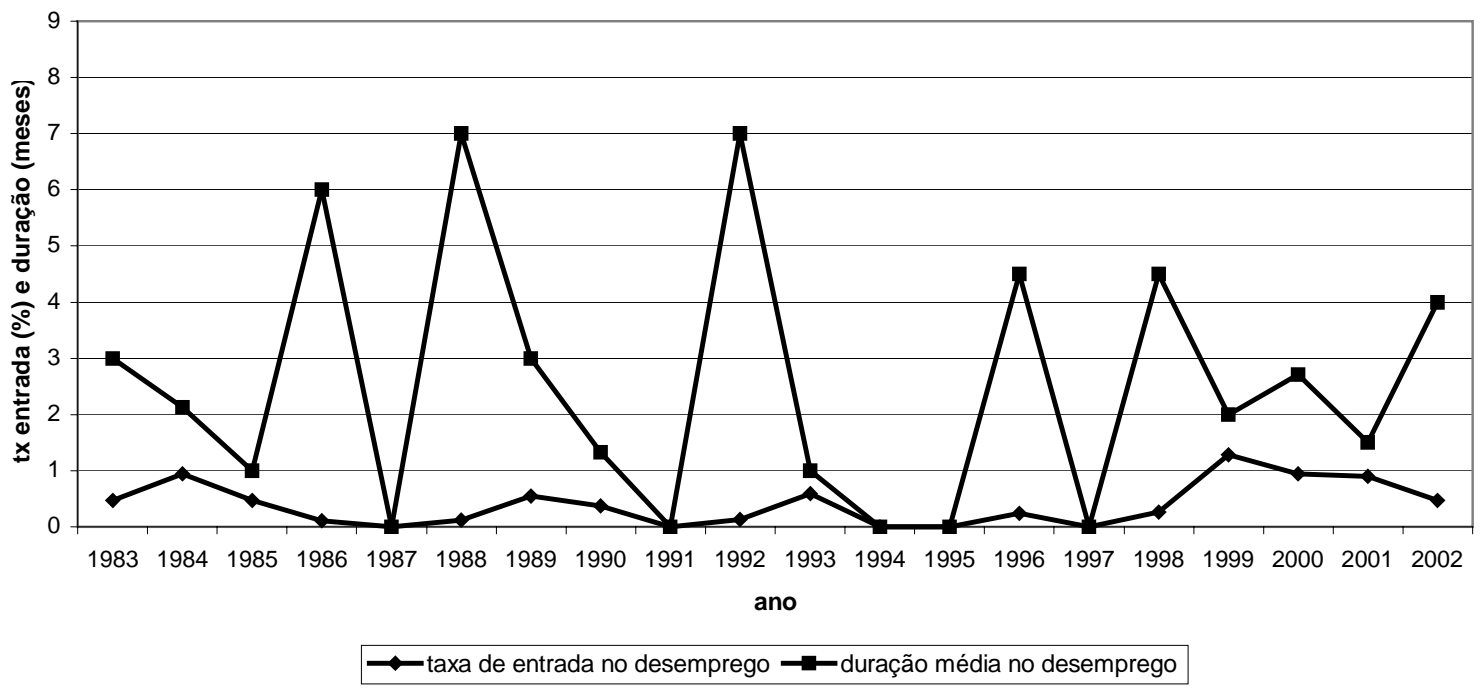

Fonte: Construído pela autora com base na PME 
Gráfico 2.9 - Taxa de entrada e duração média no desemprego - jovem/RJ

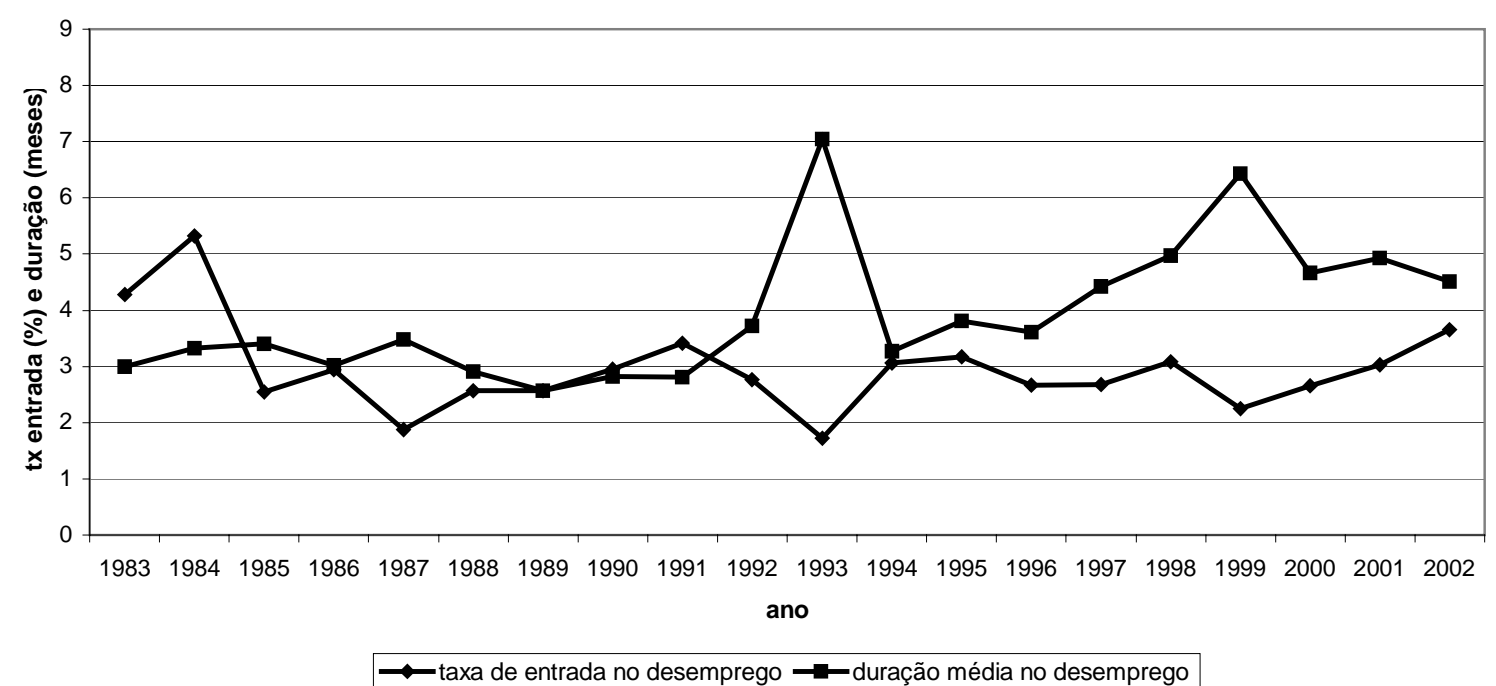

Fonte: Construído pela autora com base na PME

Gráfico 2.10 - Taxa de entrada e duração média no desemprego - adulto/RJ

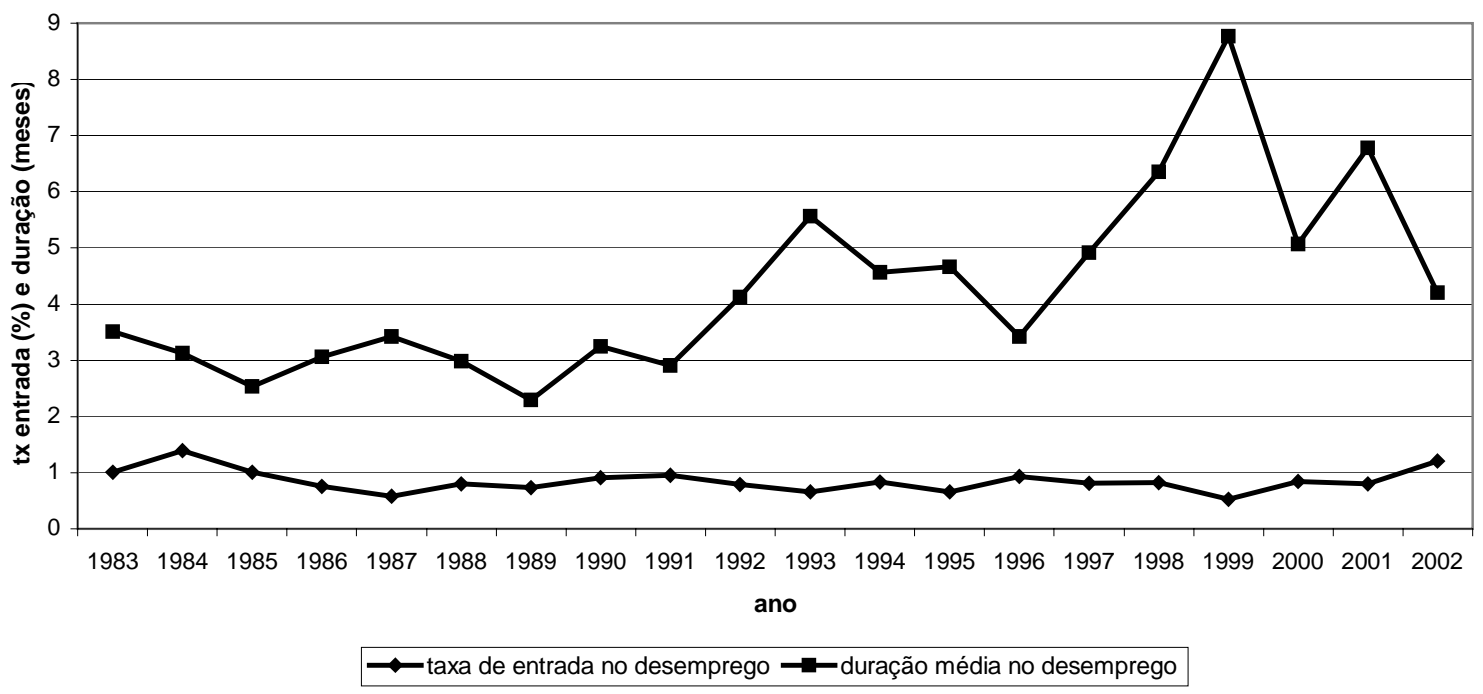

Fonte: Construído pela autora com base na PME 
Gráfico 2.11 - Taxa de entrada e duração média no desemprego - idoso/RJ

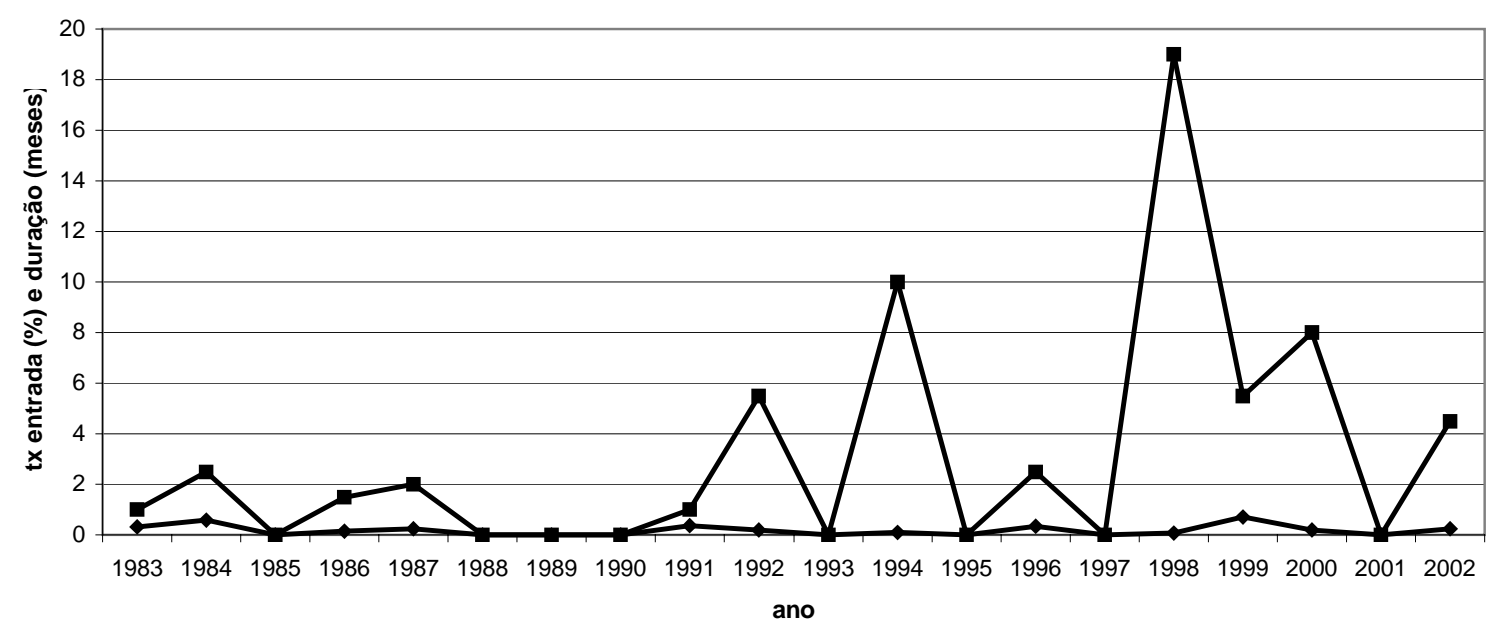

$\rightarrow$ taxa de entrada no desemprego $\rightarrow$ - duração média no desemprego

Fonte: Construído pela autora com base na PME

Gráfico 2.12 - Taxa de entrada e duração média no desemprego - jovem/RS

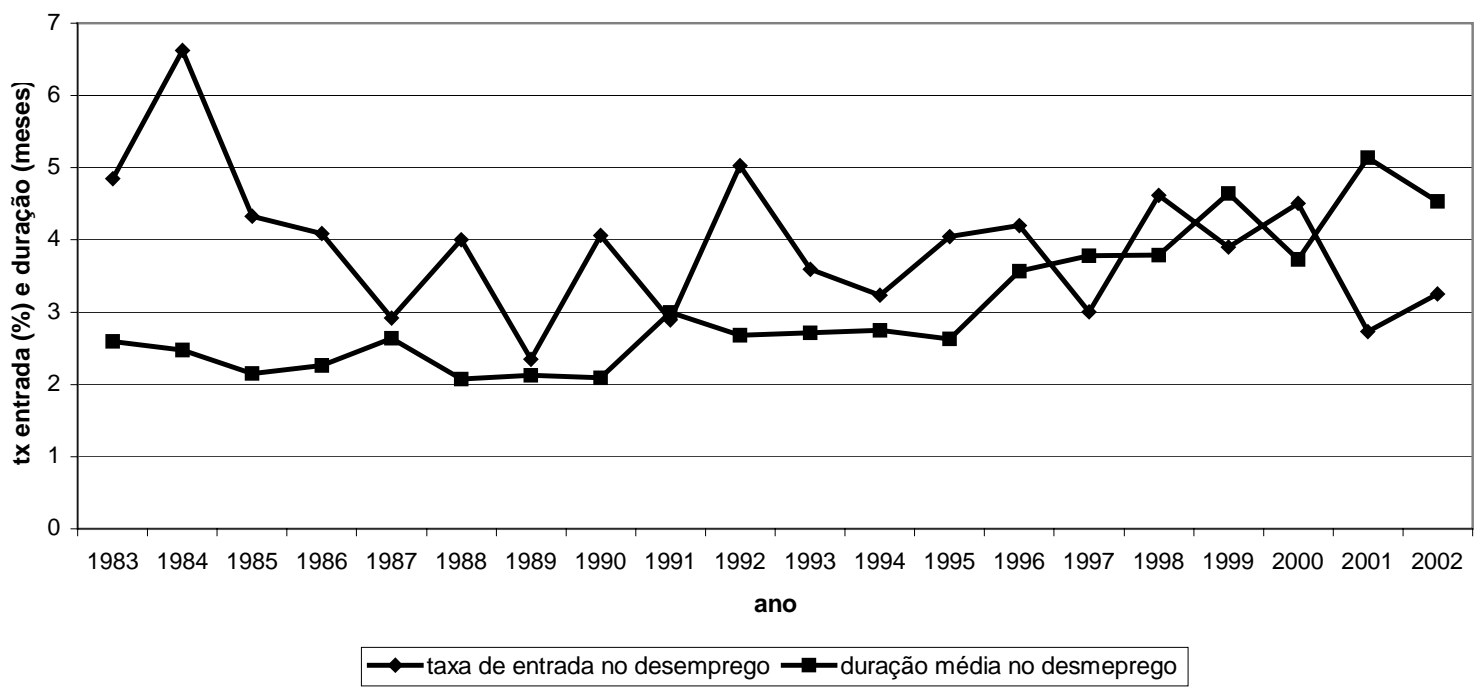

Fonte: Construído pela autora com base na PME 
Gráfico 2.13 - Taxa de entrada e duração média no desemprego - adulto/RS

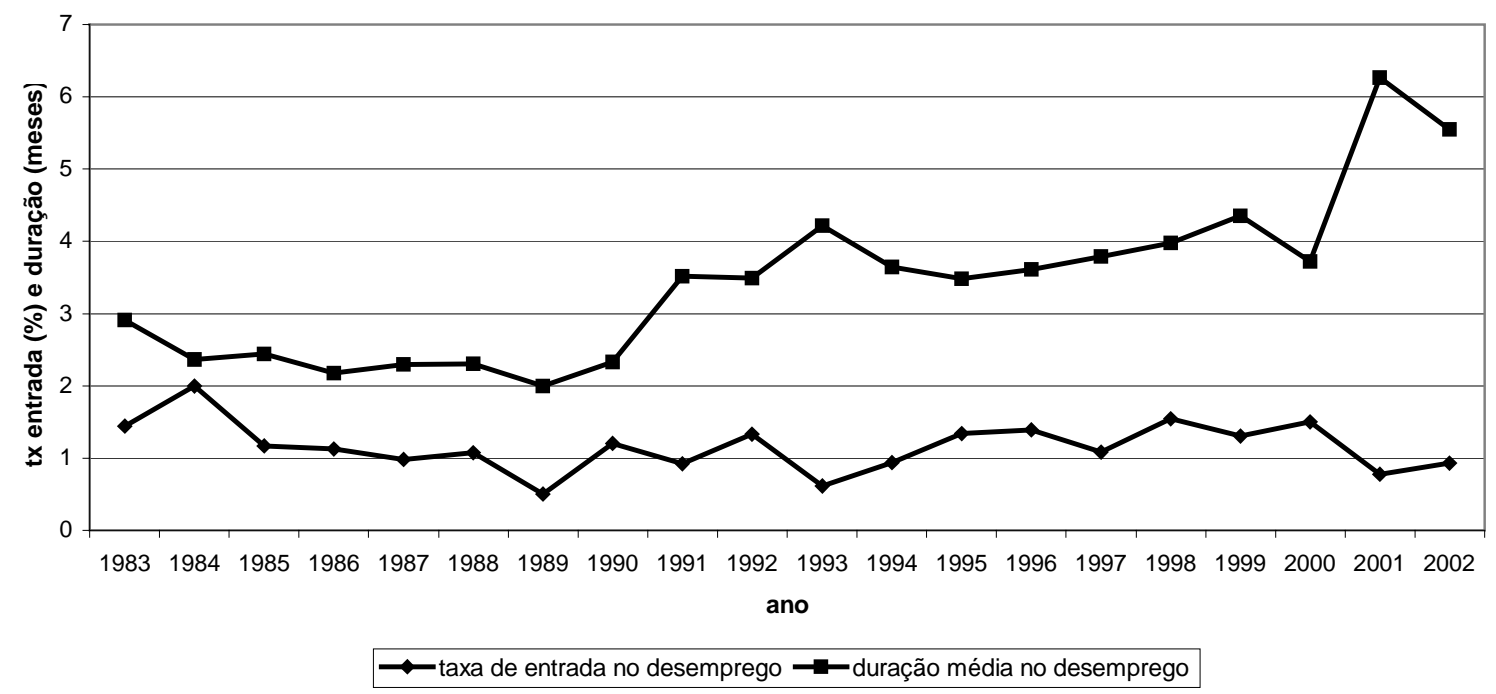

Fonte: Construído pela autora com base na PME

Gráfico 2.14 - Taxa de entrada e duração média no desemprego - idoso/RS

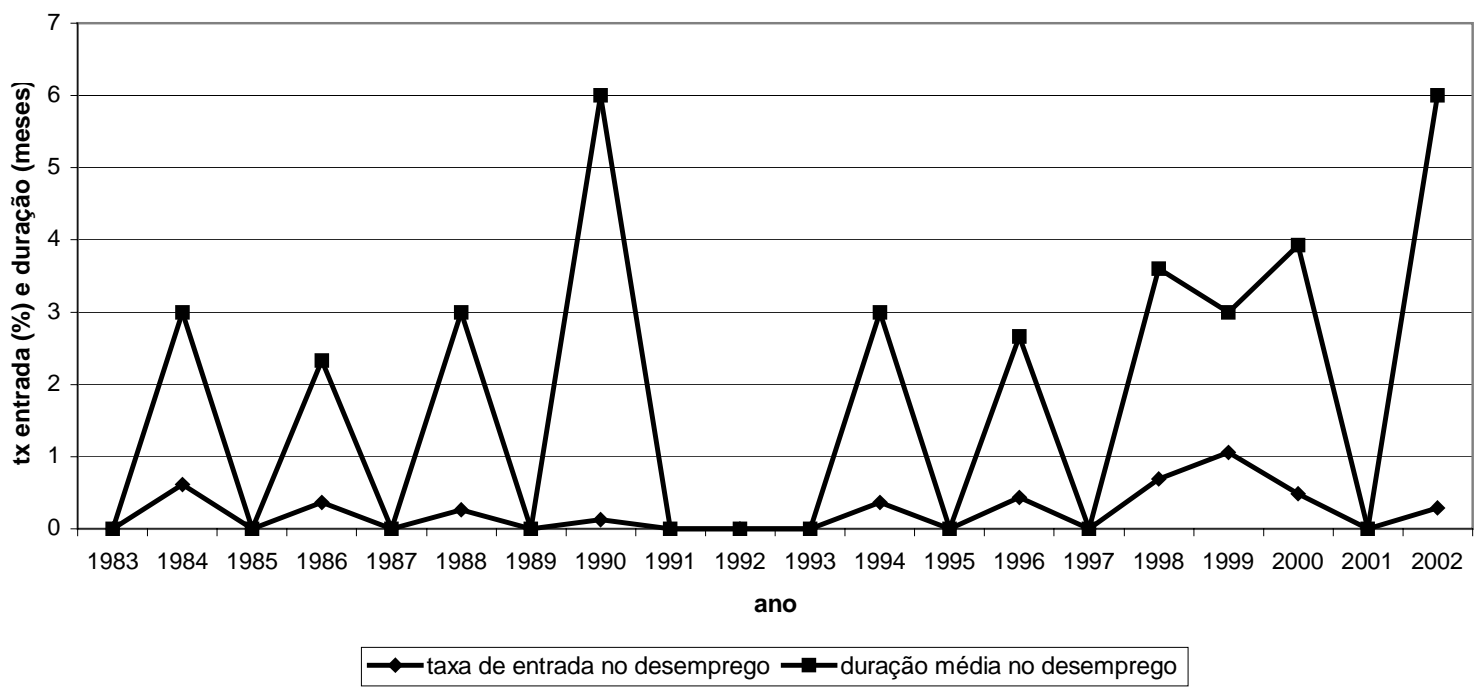

Fonte: Construído pela autora com base na PME 


\section{Gráfico 2.15 - Taxa de entrada e duração média no desemprego - jovem/PE}

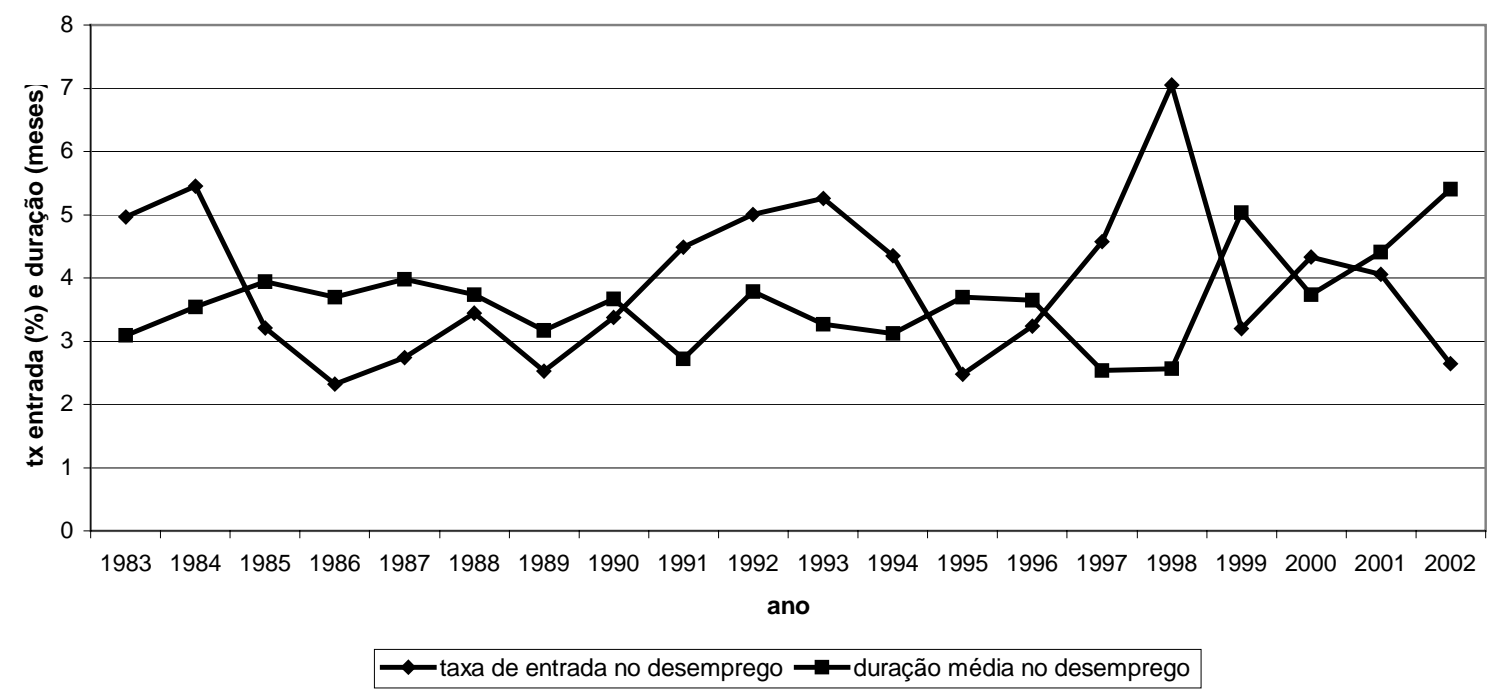

Fonte: Construído pela autora com base na PME

Gráfico 2.16 - Taxa de entrada e duração média no desemprego - adulto/PE

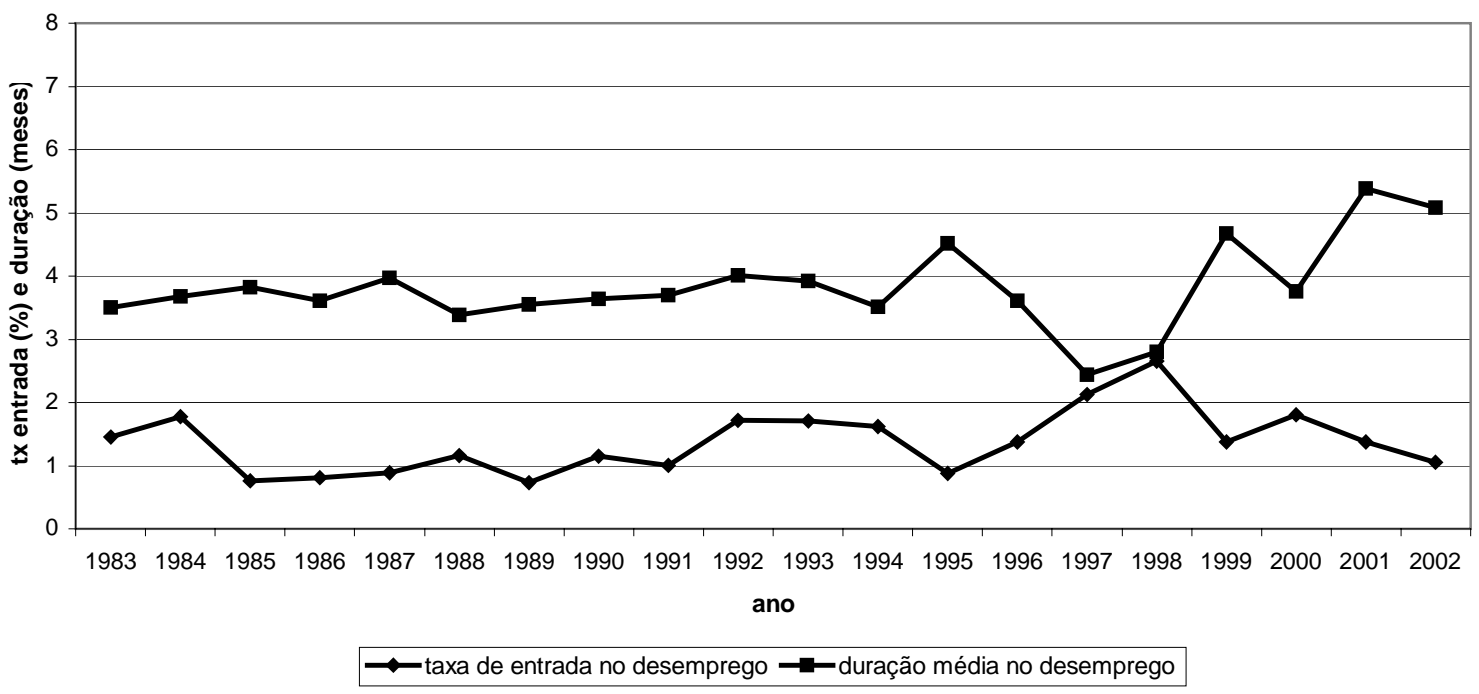

Fonte: Construído pela autora com base na PME 
Gráfico 2.17 - Taxa de entrada e duração média no desemprego - idoso/PE

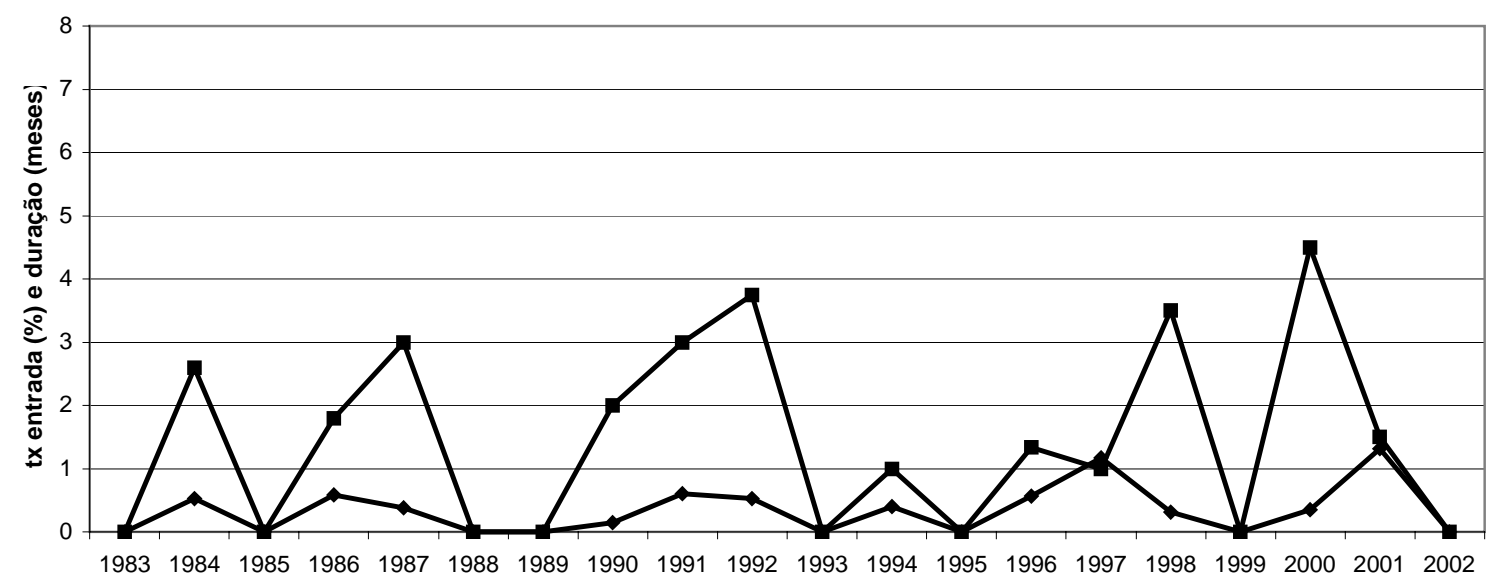

ano

$\longrightarrow$ taxa de entrada no desemprego $\rightarrow$ duração média no desemprego

Fonte: Construído pela autora com base na PME

Gráfico 2.18 - Taxa de entrada e duração média no desemprego - jovem/BA

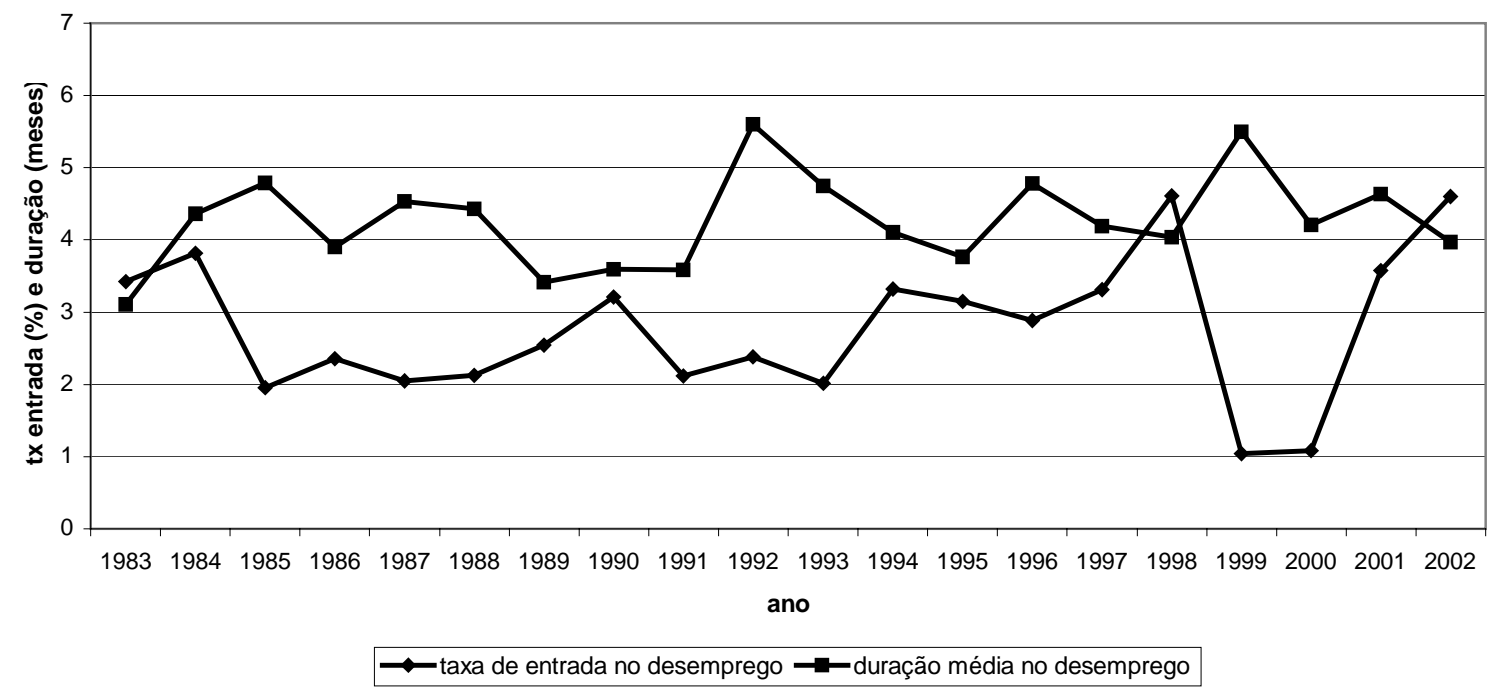

Fonte: Construído pela autora com base na PME 
Gráfico 2.19 - Taxa de entrada e duração média no desemprego - adulto/BA

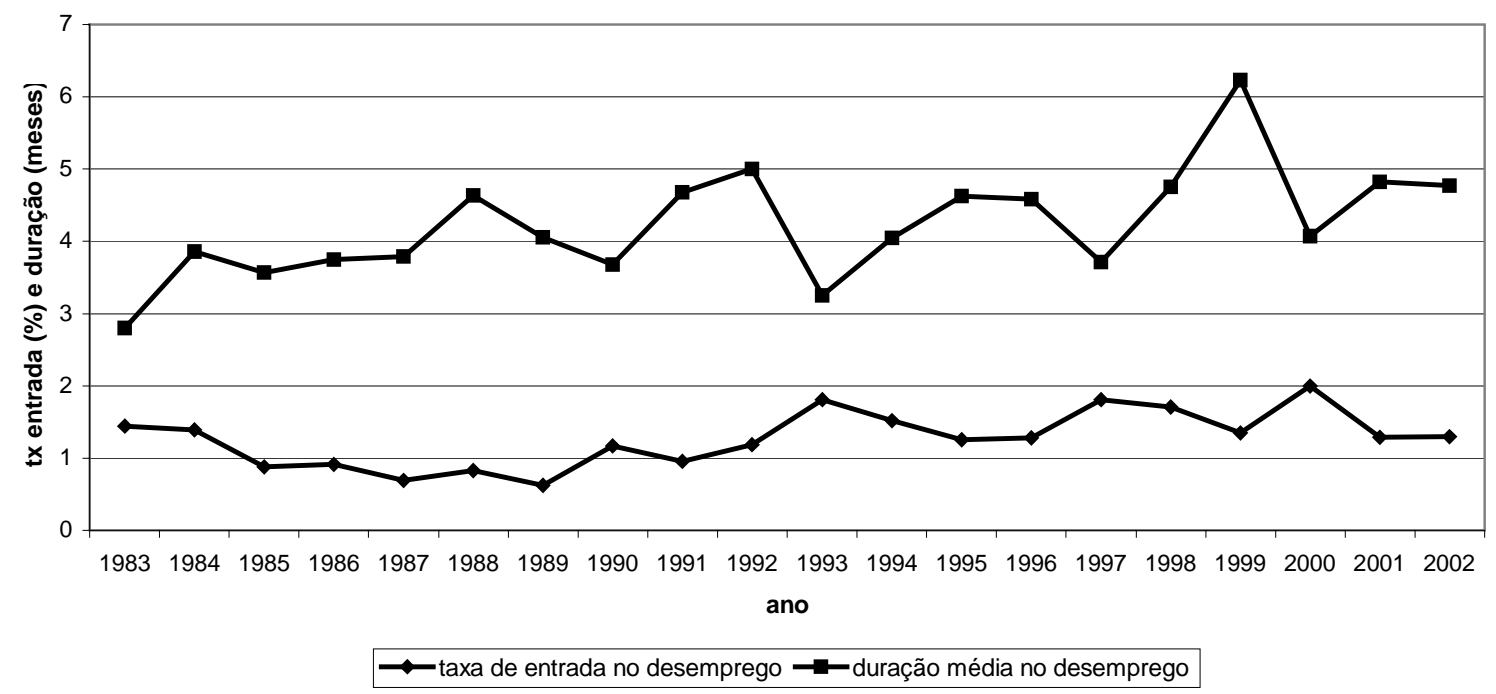

Fonte: Construído pela autora com base na PME

Gráfico 2.20 - Taxa de entrada e duração média no desemprego - idoso/BA

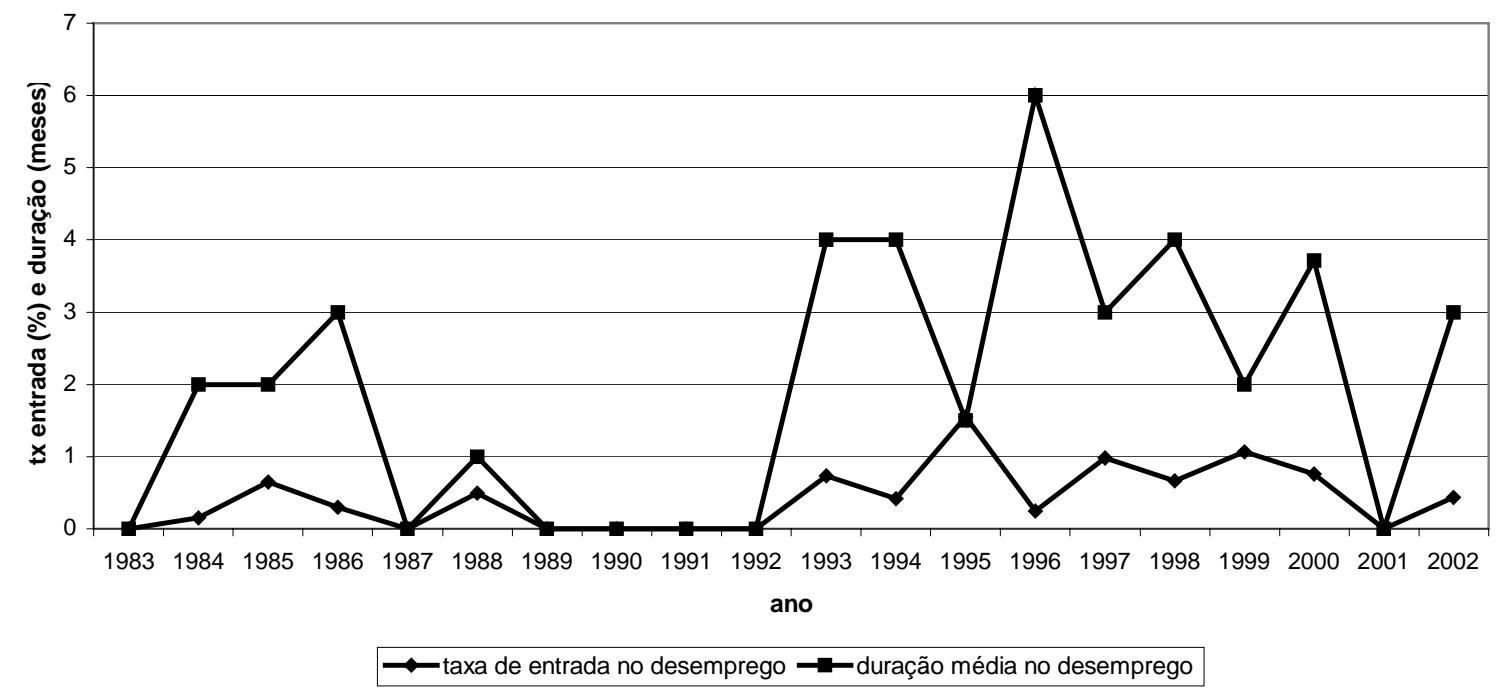

Fonte: Construído pela autora com base na PME 
Gráfico 2.21 - Taxa de entrada no desemprego de jovens segundo procura por emprego - MG

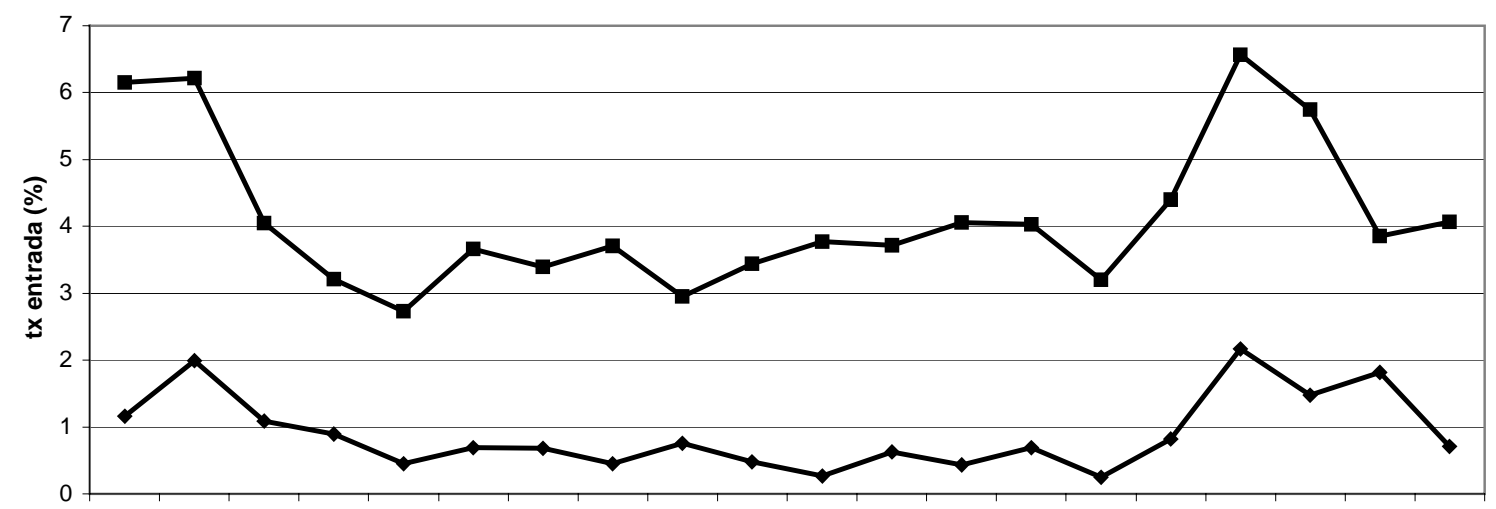

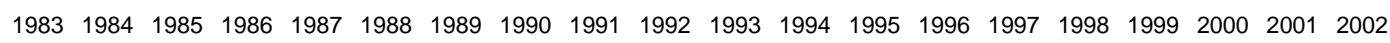
ano

$\rightarrow$ primeiro emprego $\rightarrow$ não primeiro emprego

Fonte: Construído pela autora com base na PME

Gráfico 2.22 - Taxa de entrada no desemprego de jovens segundo procura por emprego - RJ

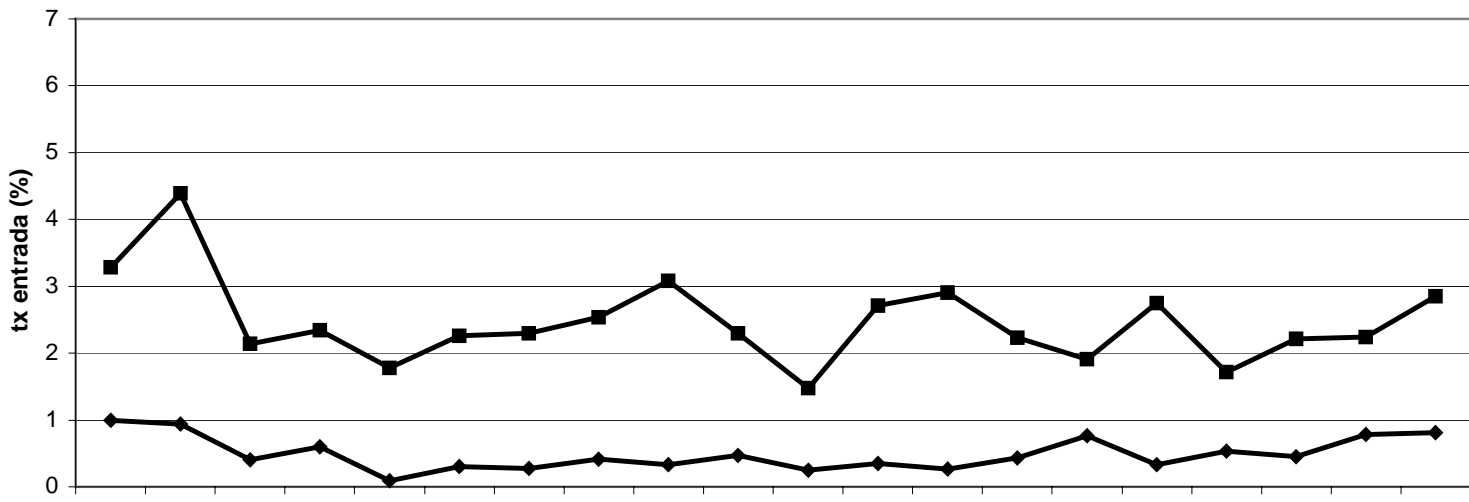

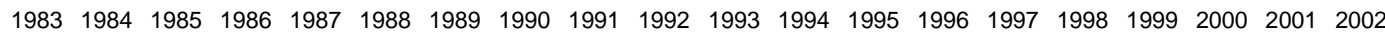
ano

$\rightarrow$ primeiro emprego $\rightarrow$ não primeiro emprego

Fonte: Construído pela autora com base na PME 
Gráfico 2.23 - Taxa de entrada no desemprego de jovens segundo procura por emprego - RS

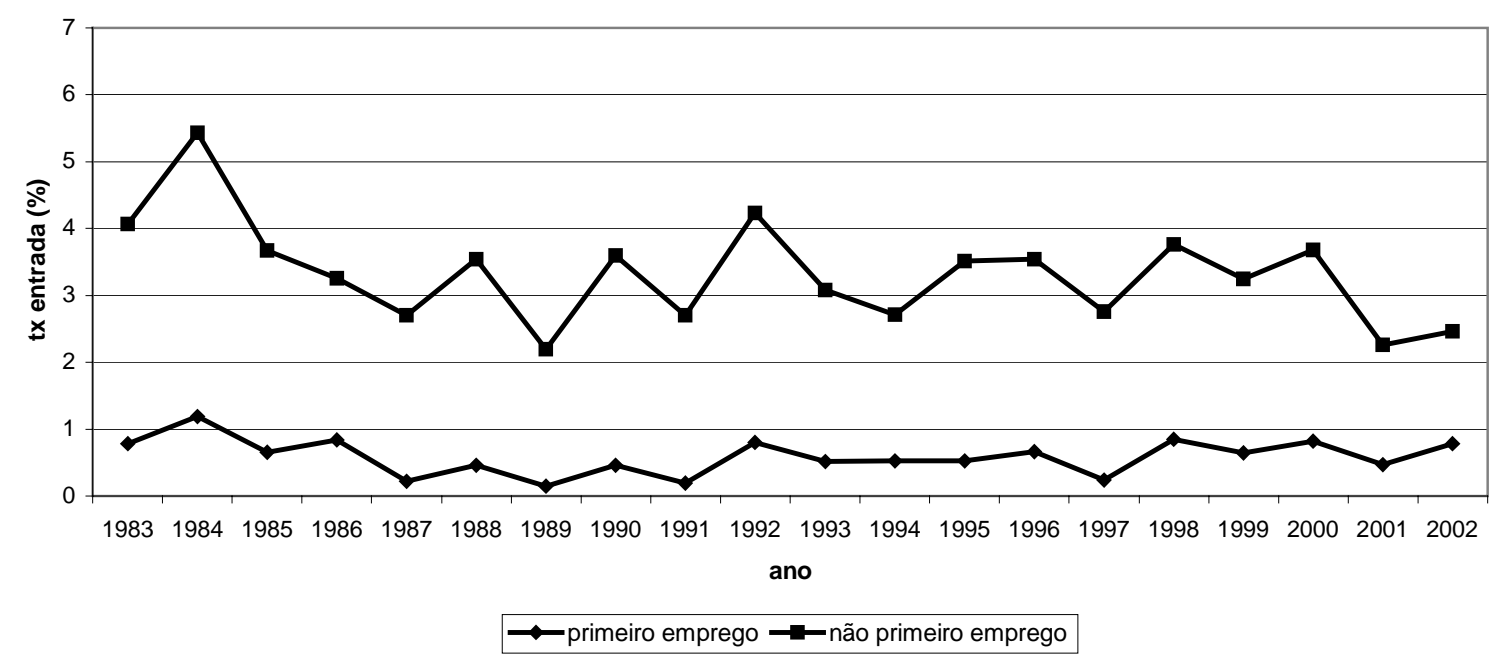

Fonte: Construído pela autora com base na PME

Gráfico 2.24 - Taxa de entrada no desemprego de jovens segundo procura por emprego - PE

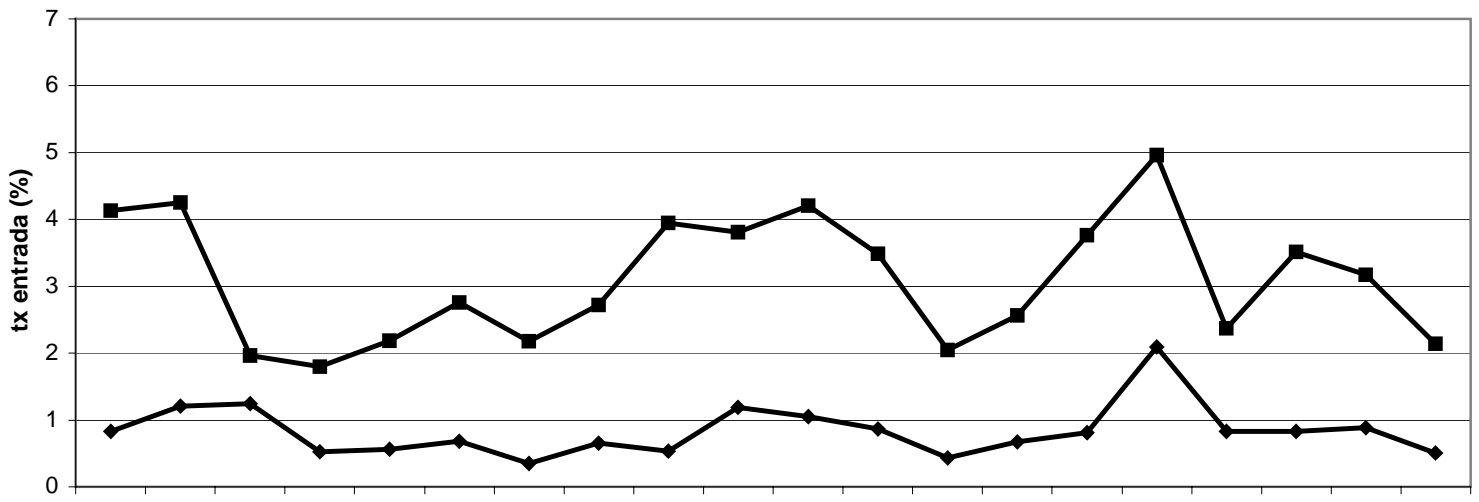

$\begin{array}{llllllllllllllllllll}1983 & 1984 & 1985 & 1986 & 1987 & 1988 & 1989 & 1990 & 1991 & 1992 & 1993 & 1994 & 1995 & 1996 & 1997 & 1998 & 1999 & 2000 & 2001 & 2002\end{array}$ ano

$\rightarrow$ primeiro emprego $\rightarrow$ não primeiro emprego

Fonte: Construído pela autora com base na PME 
Gráfico 2.25 - Taxa de entrada no desemprego de jovens segundo procura por emprego - BA

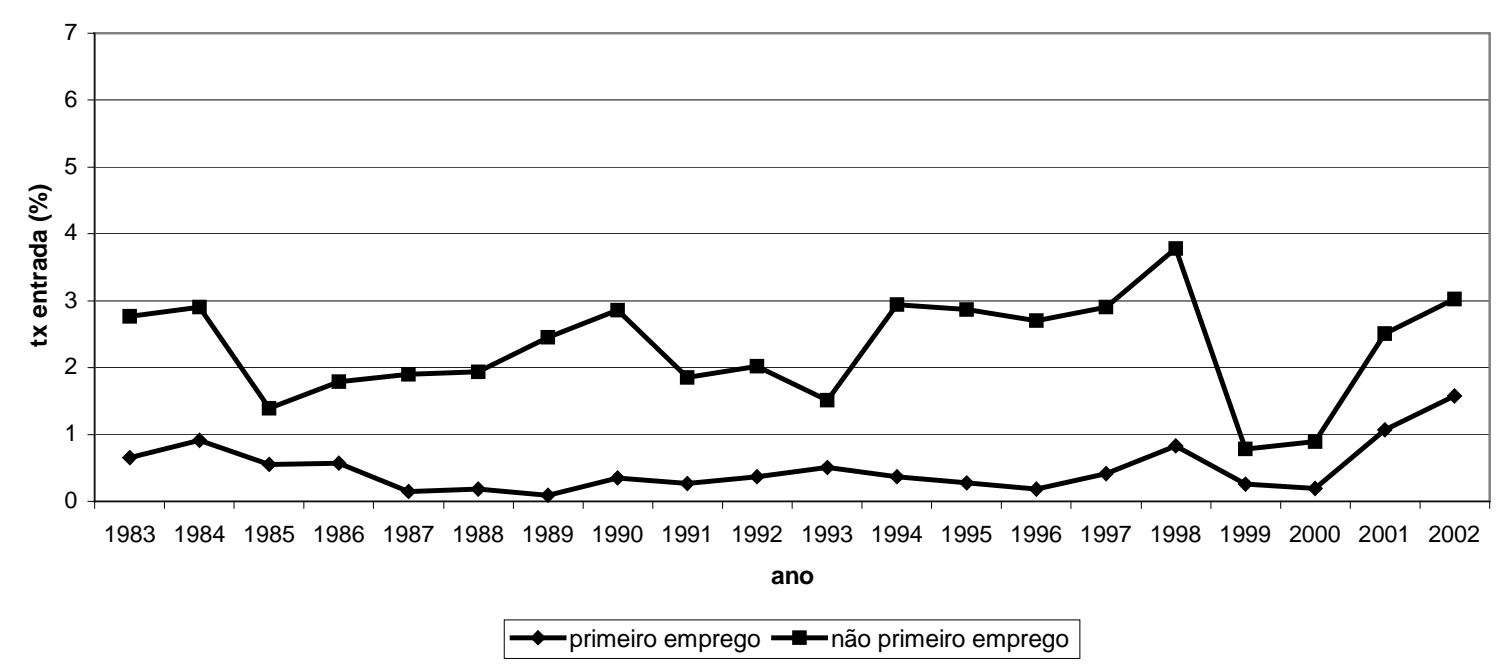

Fonte: Construído pela autora com base na PME 


\section{REFERÊNCIAS BIBLIOGRÁFICAS}

AVELINO, R. R. G. (2001). “Os Determinantes da Duração do Desemprego em São Paulo”, Textos para Discussão, n. 11/2001, IPE/USP, São Paulo.

BARROS, R. P., CAMARGO, J. M. \& MENDONÇA, R. (1997). “A Estrutura do Desemprego no Brasil”, Rio de Janeiro, IPEA, Texto para Discussão, n. 478.

BIVAR, W. S. B. (1993). "Aspectos da estrutura do desemprego no Brasil: composição por sexo e duração", Rio de Janeiro: BNDES. $17^{0}$ Prêmio BNDES de Economia. Tese (M) PUC-RJ.

BLANCHFLOWER, David G. \& FREEMAN, Richard B. (2000). "The Declining Economic Status of Young Workers in OECD Countries", in David G. Blanchflower and Richard Freeman, eds. Youth Employment and Joblessness in Advanced Countries, NBER and University of Chicago Press.

BORUS, Michael E., MOTT, Frank L. \& NESTEL, Gilbert. "Counting Youth: a comparison of youth labor force statistics in the current population surveys”, from Conference Report on Youth Unemployment: Its Measurement and Meaning, p.1534.

BURGESS, J., MITCHELL, W., O’BRIEN, D. \& WATTS, M. (1998). “Unemployment: Promisses, Policies and Progress", Labor and Industry, dezembro, vol. 9, i. 2, p. $103(1)$.

CENTERFOR/OIT (1997). "El empleo y la capacitación para el empleo de jóvenes en América Latina”, Montevideu, OJI/OIT. 
CHAHAD, José Paulo Zeetano \& FERNANDES, Reynaldo (2002). “Unemployment insurance and transitions in the labor market: An evaluation of the Brazilian program”, Brazilian Review of Econometrics, Rio de Janeiro, vol. 22, n. 2, p. 239274.

CLARK, Kim B. \& SUMMERS, Lawrence H. (1982). “The Dynamics of Youth Unemployment”, in Richard Freeman and David Wise, eds. The Youth Labor Market Problem: Its Nature, Causes and Consequences, p. 199-235, Chicago: University of Chicago Press.

CLARK, Kim B. \& SUMMERS, Lawrence H. (1990). “Unemployment insurance and labor market transitions”, in L. H. Summers, Understanding Unemployment, The MIT Press, Cambridge, Massachusetts.

CORSEUIL, C. H. L. (1994). “Desemprego: aspectos teóricos e o caso brasileiro”, Rio de Janeiro: IPEA, abril (Série Seminários, 4/94).

CORSEUIL, C. H. L., GONZAGA, G. \& ISSLER, J. V. (1996). “Desemprego regional no Brasil: uma abordagem empírica”, Rio de Janeiro: IPEA, julho (Série Seminários, 09/96).

CORSEUIL, C. H. L., SANTOS, D. D. \& FOGUEL, M. N. (2001). “Decisões críticas em idades críticas: a escolha dos jovens entre estudo e trabalho no Brasil e em outros países da América Latina”, Revista Economia Aplicada, vol. 5, n. 4.

FERNANDES, R. \& PICCHETTI, P. (1999). “Uma Análise da Estrutura do Desemprego e da Inatividade no Brasil Metropolitano”, Pesquisa e Planejamento Econômico, vol. 29, n. 1.

FISHER, A. (2001). “The kids are all right”, Fortune, 30/abr., vol. 143, i. 9, p. 28. 
FLAIM, Paul (1979). “The effect of demographic change on the nation's unemployment rate”, Monthly Labor Review, 102, p. 13-23.

FLAIM, Paul (1990). "Population Changes, the Baby Boom and the Unemployment Rate”, Monthly Labor Review, 113, p. 3-10.

FOUGÈRE, D., KRAMARZ, F. \& MAGNAC, T. (2000). “Youth employment policies in France”, European Economic Review, vol. 44, i. 4-6, mai., p. 928-942.

FREEMAN, Richard B. (1979). “Why is there a youth labor market problem?”, NBER Working Paper, 365.

IBGE. Pesquisa Mensal de Emprego.

KORENMAN, Sanders \& NEUMARK, David (1997). "Cohort crowding and youth labor markets: a cross-national analysis”, NBER Working Paper, 6031, maio.

LASSIBILLE, G., GÓMEZ, L. N., RAMOS, I. A. \& SÁNCHEZ, C. O. (2001). "Youth transition from school to work in Spain”, Economic of Education Review, vol. 20, i. 2, ab., p. 139-149.

LAYARD, R., NICKELL, S. \& JACKMAN, R. (1991). “Unemployment: Macroeconomic Performance and the Labour Market”, Oxford University Press.

LEIGHTON, Linda \& MINCER, Jacob (1979). "Labor Turnover and Youth Unemployment”, NBER Working Paper, 378, agosto.

LEWIS, P. E. T. \& KOSHY, P. (1999). “Youth employment, unemployment and school participation”, Australian Journal of Education, vol. 43, i. 1, abr., p. 42. 
MADEIRA, Felícia Reicher \& RODRIGUES, Eliana Monteiro (1998). "Recado dos Jovens: Mais Qualificação”, in Jovens Acontecendo na Trilha das Políticas Públicas, Brasília: Comissão Nacional de População e Desenvolvimento (CNPD), vol. 1, p. 427-496.

MENEZES-FILHO, N. \& PICCHETTI, P. (2000). “Os Determinantes da Duração do Desemprego em São Paulo”, Pesquisa e Planejamento Econômico, vol. 30, n. 1.

OECD (1980). "Youth unemployment: the causes and consequences”, (OECD: Paris).

O’HIGGINS, N. (2001). “Youth unemployment and employment policy: a global perspective”, in International Labour Review, vol. 140, i. 1, p.132.

PICCHETTI, P., ORELlANO, V. \& CHAHAD, J. P. Z. (2002). “Um modelo de decisões relacionadas à rotatividade de mão-de-obra no Brasil”, in J. P. Z. Chahad e N. A. Menezes-Filho, Mercado de Trabalho no Brasil: salário, emprego e desemprego numa era de grandes mudanças, São Paulo: LTr, p. 247-276.

ROCHA, S. (1993). “Metropolização da pobreza: uma análise nucleoperiférica”, Perspectivas da Economia Brasileira. Rio de Janeiro: IPEA, vol. 2, p. 527-539.

SARRIERA, J. C., CÂMARA, S. G. \& BERLIM, C. S. (2000). "Elaboração, desenvolvimento e avaliação de um programa de inserção ocupacional para jovens desempregados”, Psicologia: Reflexão e Crítica, vol. 13, n.1, Porto Alegre, PUC-RS.

SCHMIDT, Christoph M. (1993). “Ageing and unemployment”, in Paul Johnson and Klaus F. Zimmermann, eds. Labor Markets in an Ageing Europe, Cambridge: Cambridge University Press. 
SHIMER, Robert (1999). “The Impact of Young Workers on the Aggregate Labor Market”, NBER Working Paper, 7306, agosto.

SILVA, N. D. V. (2001). "Jovens brasileiros: o conflito entre estudo e trabalho e a crise de desemprego", Piracicaba. 131 p. Tese (Doutorado) ESALQ/USP.

SORRENTINO, Constance (1993). "International Comparisons of Unemployment Indicators”, Monthly Labor Review,116, p. 3-24, março.

ZIMMERMANN, Klaus F. (1991). “Ageing and the labor market age structure, cohort size and unemployment”, Journal of Population Economics, 4, p. 177-200. 